\title{
Public versus Private Voice
}

Citation for published version (APA):

Isaakyan, S. (2018). Public versus Private Voice: The Role of Social Setting in Explaining Managerial Reactions to Employee Voice. [Doctoral Thesis, Maastricht University]. Datawyse / Universitaire Pers Maastricht. https://doi.org/10.26481/dis.20180601si

Document status and date:

Published: 01/01/2018

DOI:

10.26481/dis.20180601si

Document Version:

Publisher's PDF, also known as Version of record

\section{Please check the document version of this publication:}

- A submitted manuscript is the version of the article upon submission and before peer-review. There can be important differences between the submitted version and the official published version of record.

People interested in the research are advised to contact the author for the final version of the publication, or visit the DOI to the publisher's website.

- The final author version and the galley proof are versions of the publication after peer review.

- The final published version features the final layout of the paper including the volume, issue and page numbers.

Link to publication

\footnotetext{
General rights rights.

- You may freely distribute the URL identifying the publication in the public portal. please follow below link for the End User Agreement:

www.umlib.nl/taverne-license

Take down policy

If you believe that this document breaches copyright please contact us at:

repository@maastrichtuniversity.nl

providing details and we will investigate your claim.
}

Copyright and moral rights for the publications made accessible in the public portal are retained by the authors and/or other copyright owners and it is a condition of accessing publications that users recognise and abide by the legal requirements associated with these

- Users may download and print one copy of any publication from the public portal for the purpose of private study or research.

- You may not further distribute the material or use it for any profit-making activity or commercial gain

If the publication is distributed under the terms of Article $25 \mathrm{fa}$ of the Dutch Copyright Act, indicated by the "Taverne" license above, 


\title{
Public versus Private Voice:
}

\author{
The Role of Social Setting in Explaining \\ Managerial Reactions to Employee Voice
}


The research presented in this dissertation was conducted at the School of Business and Economics (SBE), Department of Organization \& Strategy, Maastricht University

(C) Sofya Isaakyan, Maastricht 2018

All rights reserved. No part of this publication may be reproduced, stored in a retrieval system, or transmitted in any form or by any means, electronic, mechanical, photocopying, recording or otherwise, without prior permission in writing from the author.

ISBN:

978-94-6295-959-0

Cover Design:

Ruzanna Navoyan

Publisher:

Datawyse, Universitaire Pers Maastricht

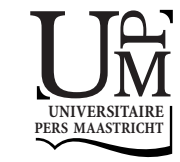




\title{
Public versus Private Voice:
}

\section{The Role of Social Setting in Explaining Managerial Reactions to Employee Voice}

\author{
DISSERTATION \\ To obtain the degree of Doctor at Maastricht University, \\ On the authority of the Rector Magnificus, \\ Prof. Dr. Rianne M. Letschert \\ In accordance with the decision of the Board of Deans, \\ To be defended in public \\ On June $1^{\text {st }}, 2018$, at $10 \mathrm{am}$
} By

Sofya Isaakyan 


\section{Supervisor:}

Prof. dr. Fred R.H. Zijlstra

\section{Co-supervisor:}

Dr. Hannes Guenter

\section{Assessment Committee:}

Prof. dr. Wim H. Gijselaers (Chairman)

Prof. dr. Steffen R. Giessner (Erasmus University Rotterdam, The Netherlands)

Prof. dr. Onne Janssen (University of Groningen, The Netherlands)

Dr. Bert Schreurs (Free University of Brussels, Belgium) 
"Sometimes you move publicly, sometimes privately. Sometimes quietly, sometimes at the top of your voice."

James Baker, American attorney and statesman 



\section{Acknowledgements}

We often hear the quote by Carl Lewis: "It's all about the journey, not the outcome." And so, while I am extremely happy and proud that at this moment you are holding the outcome of my four-year PhD journey, I have to agree with Carl, it is the journey that matters most. This journey was not an easy one. It definitely had its ups and downs. Luckily, I was not alone in the journey but always had people next to me who provided me with so much help and support. With that in mind, I would like to express my sincere gratitude to my supervisory team, colleagues, friends, and family.

First and foremost, I would like to thank my promoter Professor Fred Zijlstra and my supervisor Dr. Hannes Guenter. Fred, although I know that as a researcher I am not supposed to, I do believe in destiny. You were the first academic I met in the Netherlands when I started my Master in Work and Organisational Psychology. Could I have imagined that two years after my PhD had started you would become my promoter? This was a very unexpected but thoroughly fortunate turn of events. I am so glad that I had the chance to work with you again. I am really grateful for all the support and advice that you provided to me. I always truly enjoyed our meetings, your research insights, and your great sense of humour. Hannes, first of all, thank you for being the only supervisor who started my PhD journey with me and also ended it with me. Jokes aside, there are no words to express how grateful I am for all you have done for me in the past years. You have always been very supportive by encouraging and guiding me in every step of my development as a scholar. I was always impressed with your diligent research approach and your in-depth conceptual knowledge. Thank you for the huge amount of quality feedback that you gave me that has allowed me to both recognise my accomplishments as well as make improvements where necessary. I really appreciate the trust you had in me and in my decisions. You were always open and ready to listen and discuss my thoughts and concerns, you definitely let me speak up! Thank you for all the chats and jokes in between the hard work, they made my PhD journey much more enjoyable. And finally, I am especially grateful for all the support and encouragement you provided me when I entered the job market, at that time you believed in me more than I believed in myself.

I would further like to thank the members of the assessment committee - Professor Wim Gijselaers, Professor Steffen Giessner, Professor Onne Janssen, and Dr. Bert Schreurs. Wim, every time we talk you are always very encouraging. I really appreciate that you agreed to be the chair of my committee. Steffen, thank you for such a warm 
welcome to RSM and your continuous support. Onne, for me it is great pleasure to know you and I really hope that one day we will get the opportunity to work together. Bert, although you were never formally my supervisor, you always had your door open for me. I am very grateful for all the advice you gave me and inspiring talks we had.

I further wish to thank you, Subra. My research visit to the University of Maryland turned out to be one of the most rewarding and intense experiences I had during my PhD. Our discussions were always very encouraging and inspiring. You have a rare quality of making people around you curious and passionate about research. Since our first meeting you always demonstrated your commitment to this work by providing me with opportunities to develop and supporting me through that development. I am very grateful to you for all the doors that you have opened for me. Thank you for everything you did for me, I am so very lucky to have a mentor like you. I would also like to thank you for introducing me to Elad. Elad, every time I talk to you, I learn something new. You helped and supported me a great deal, I am very fortunate to know you. You are such a talented scholar and a good person, that I am sure that you have a very bright future ahead.

My paranymphs, Judith and Jasper: you became my friends for life. Judith, you are my partner in crime, my KGB, my biggest animal lover, my shoulder to cry on, and my backbone. I can make a long list of things for which I would like to thank you including building my IKEA furniture, buying me flowers just because you know how much I like them, or making me freeze to death and then dance for US officers on the Canadian border. But, most importantly, I want to thank you for being a wonderful friend whom I could always rely on and trust with all my heart. What I find the most amazing about you is that once you love someone, then you are ready to move mountains for that person. I am very happy to be in this special circle of people.

Jasper, I am truly happy to have a friend like you. Thank you for caring about me, thank you for listening to all my stories (some of which you heard several times before!), thank you for all the advice and support that you gave me, and thank you for all the great moments that we shared. Although you do not always admit it, you are a very warm person with a big heart. I am very happy and proud for all your success and I am sure that much more will come your way because you really deserve it. And I am also sure that you will handle any difficulties you may face, and that they will only make you stronger. Also, as a citizen of the Russian Federation, I would like to thank you on behalf of my country for taking care of Mr. Putin in your office for so many years.

I would also like to thank my dear O\&S PhDs. Caren, you are the one who suggested that I apply to the O\&S group when we accidentally met at a BBQ six years ago. Since then you were always there for me whenever I needed you. I am really grateful for that. And thank you for always cheering me up with your amazing sense of humour. I am happy to see that so many great things are happening in your beautiful family. Kathi, my schmetterling, it makes me smile every time that I think about our conference trips to the US. I think 
these trips were one of the highlights of my PhD, and this is all thanks to you. During these trips you taught me how to illegally bring a banana to the US or how to become a schnitzel on the beach. I really hope that we can repeat it one day. Thank you for always being so supportive. Anna, maybe we had only one conference trip together, but what a trip that was! Thank you for our talks and what I really appreciate about you is how considerate and helpful you are to the people around you. Dinah and Nina, I couldn't ask for better officemates! Thank you for all the girl-talks and laughter that we shared. Nina, I really admire how many talents you have and how many interesting things you do in your life. Thank you for always helping me to find peace when I really need it. It was great to share the office with you for so many years. Dinah, my beautiful, intelligent, independent woman, you became very close to me in such a short period of time. I have so many warm memories from our trip to Ireland and I am really looking forward for our next trips when we will again almost miss our flight because of crazy make up shopping in Duty-free. Nardo, although your passport is Dutch, you have a Latin soul. Thank you for bringing so much energy and such a positive vibe to our O\&S group. I feel that you have the right attitude to life and we can all learn from you. Matthias, thank you for being an awesome skateboarder (as promised :) ) and for being one of the most positive PhDs that I know. I am really glad that I met you even though it was only for my last PhD year. Harold, as a more experienced PhD fellow, you gave me so much valuable advice as I started out on my PhD. But, most importantly, I wanted to thank you for sharing with us your piece of wisdom that we need to find our own rhythm. Gabri, thank you for being the best PR manager I could ask for and for introducing me to the PhD crowd. And, of course, thank you for all the joy and laughter you brought to the O\&S group. Martijn, thank you for all the great moments that we shared and for all the good things that you did for me. Tom and Desiree, thank you for showing me around during the early stages of my PhD. Darja, I am glad that I shared an office with you at the beginning of my PhD. I really learned a lot from you. And it was of course always nice to have someone with whom I could talk and laugh in Russian. Thanks also to all my other PhD fellows-Bart, Baer, Colja, Emma, Kars, Kasia, Maitane, Michael, Nazareno, Nina K., Pilar, Roy, and Tim-for sharing all those lunches, drinks, chats, and many other great memories.

I would also like to thank the O\&S department as a whole as it was really great to be working alongside you all these years. I would like to mention a few people in particular. Wilko, thank you for being very understanding in multiple situations when I was struggling. I always enjoyed our corridor conversations and, of course, our discussions about Russian politics. Melvyn, thank you for the huge support you provided me during the application process. I really appreciate all the valuable advice you gave me. Shuhua, thank you very much for your guidance at the beginning of my PhD. Ad, thank you for our talks and for your love of Russian culture. And a special thank you for opening the door of your home and introducing me to your wonderful family. A special thank you to Anita and 
Adela for not only taking care of all the administrative tasks but also for creating the feeling of a big family in the O\&S group. Anita, you are one of the kindest and warmest people that I met in Maastricht. I really appreciate how much you supported me. Adela, you are so full of life and energy, I truly miss our shared moments of chatting and laughing together.

I would also like to thank my PhD fellows and colleagues outside the O\&S department. Lars, I am very grateful that on the second year of my PhD one of the smartest and most "modest" PhDs moved to our corridor. This resulted in never ending drawings of sheep, boats, and equations of "who visits whose office more often" on my whiteboard, as well as karaoke singing of t.A.T.u songs, dances in bicycle outfits, and constant use of chicken emoticons... I can continue this list, but, although these moments were great and made my PhD so much fun, I do want to thank you for proving to me that you can be the greatest support when I need it. Shuan jan, you are one of the closest people I have in Maastricht. Thank you for always being there for me, thank you for making me smile every time we meet, and, of course, for searching for my family treasures in Van. Ehsan jan, our Prince of Persia, our leader of the Alla Rescue Team, I am grateful that every weekend of my second PhD year I would accidentally bump into you somewhere around the Basilica area. Thank you for your friendship and for all the great moments that we shared, icecreams that we ate, and dances that we danced ("no touch!"). I really appreciate how much you take care of me. My dear Mueid and Gintare, you know how much I love you, right? To me, you are the best event organizers in Maastricht. It is amazing how many great memories I have from delicious lunches and dinners and crazy loud Mafia nights at your place. Gintare, I admire how much love and warmth you put into everything you do for the people around you. Mueid, you are my Maastricht brother, thank you so much for your endless love and support. Saba jan, there are so many great moments full of laughter and joy that we shared together and I really hope that very soon we will again "take off" and "be on the top of it". Kouma, you are such a special person, and when I say special I mean both a bit crazy as well as very dear to me. I am grateful that I met you, it is always very important to have someone who shares with you similar values and beliefs. Paula and Giacomo, my Maastricht friends who became my Rotterdam family, thank you for giving me a feeling of home when I moved to Rotterdam. I don't know what I would do without you. Ahmad jan, I am very happy to have you in Rotterdam, thank you for all your help. And, I thank you for introducing us to Ahmad's invisible hand. Diogo, every time we meet you are always full of life and energy. Thank you for bringing this life and energy to our PhD group. And a special thank you for introducing me to your amazing nephews, I am still completely in love with them! Vera, thank you for your cheerful personality and such a cool attitude to the PhD process and life in general. I always enjoyed our little talks and, of course, the 90's parties! Nasser jan, thank you for organizing the best Armenian- 
Iranian party with only one Armenian present :) Frank, thank you for all your encouragement, support, and simply for being such a cool professor and great person. Christoph, thank you for being an awesome co-paranymph and for your great daily contributions to my dissertation. Anant, thank you so much for your famous Punjabi workshops at my parties. I hope we will repeat it at my defence party! Fernanda, although not officially, you were definitely a part of our PhD group and my PhD life in particular. My friend, I am so grateful that completely unexpectedly for me, as well as for you, you came back to Maastricht. There are so many beautiful, as well as tough, moments we shared together. Thank you for always being there for me when I needed you. You have a big heart and I am sure that all the things you dream about will happen very soon!

I further would like to thank my dream M.O.R.T. team! Ninja and Franzi, I think it is a great gift when you can work with and get inspired by your friends! Ninja, I really appreciate all the advice you gave me and the boost of motivation from overseas. Franzi, I am so glad that we met in Oslo. Thank you for your continuous support and encouragement, and I hope that the tradition of Armenian names will continue in your family.

William, your friendship is one of the greatest gifts I got during my master's studies in Maastricht. I will be more elaborate in my words of gratitude when I write a book about you (you know when to expect that book :)), but for now I want to thank you for all the help and support you provided me before, during, and at the end of my PhD and your endless belief in me. Alexandra and Patrick, thank you for your warmth and for welcoming me into your beautiful family. Ruzanna, thank you so much for designing the cover of my dissertation book and bringing an Armenian flavour to it. I am really happy and proud of all your achievements and successes.

I would also really like to thank my new colleagues in Rotterdam for such a warm welcome and continuous support in my first year. It is really a great pleasure to be part of such a talented group.

A big thank you to my amazing friends in Moscow as well as in other parts of the world for their endless support and encouragement. A special thank you to Kristina not only for formatting my document in the middle of a party in Australia, but also for being the one with whom I started this whole idea of going abroad and being in my life every single day no matter how far we are from each other.

I would also really like to thank my dear relatives in Armenia for all their love, which I felt while being so many kilometres away. A special thank you to my sister Iren. Ир джан, никакими словами не описать насколько я тебе благодарна за то, сколько ты для меня сделала, сколько ты мне помогала и как ты меня поддерживала все эти годы. Сестренка моя, спасибо, что всегда рядом.

My biggest thanks go to my parents Harutyun and Vera and my brother Hovanes. Овуль джан, я помню, как мы впервые вместе приехали в Маастрихт, и как ты в течение трех дней делал все, чтобы подготовить меня к моей новой жизни вдалеке от 
дома. И я никогда не забуду, как сильно я не хотела тогда, чтобы ты уезжал. Спасибо тебе за все. я безумно горда, что у меня такой брат, и я очень счастлива, что совсем скоро у тебя наступает новый этап в жизни с нашей любимой Настей. Мои дорогие мама и папа, спасибо вам за вашу безграничную любовь и веру в нас. Все то, чего мы сегодня достигли, - это только благодаря вам и вашей любви. Папа, все мое детство ты мне говорил, чтобы я учила английский. Как видишь, ты был прав-он мне все-таки пригодился :) Я знаю, как тебе было сложно меня отпустить. Спасибо, что доверился мне. Мамочка, ты моя главная опора и поддержка. Спасибо тебе, что все эти годы каждый день ты даешь мне веру и силу двигаться вперед. 


\section{Table of Contents}

CHAPTER 1 AN INTRODUCTION AND LITERATURE REVIEW........................................ 15

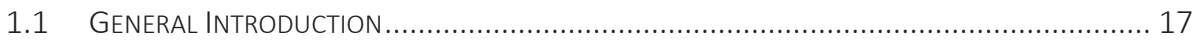

1.2 Employee Voice: From the Origins to the Current Conceptualization ................... 19

1.3 Challenging Nature of Voice and EfFicacy-Safety CALCulus................................ 20

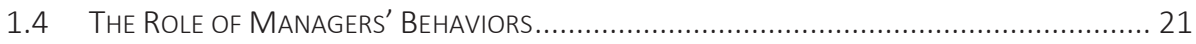

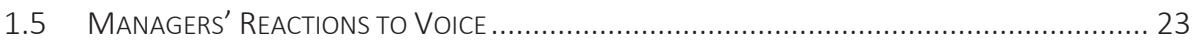

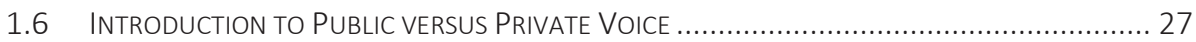

1.7 EXPloratory ReSEARCh INTO PubliC Versus Private VoicE........................................ 28

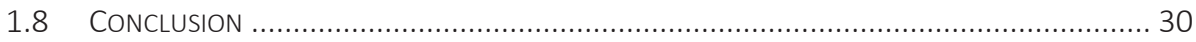

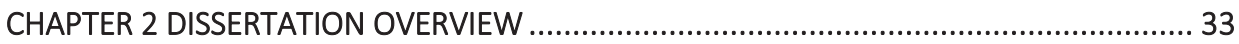

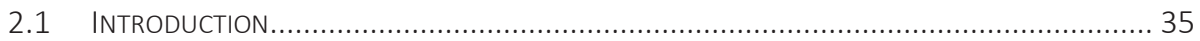

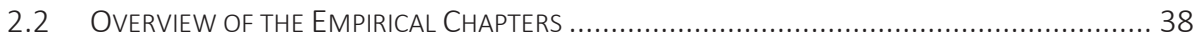

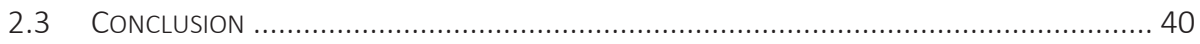

CHAPTER 3 KEEPING IT BETWEEN US: MANAGERIAL ENDORSEMENT OF PUBLIC VERSUS

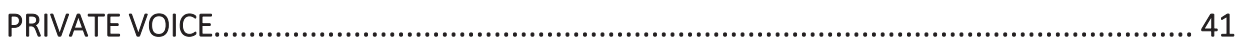

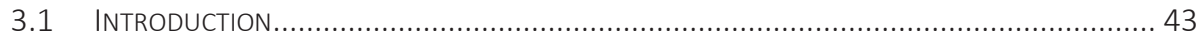

3.2 Theoretical BACKGROUND AND HyPotheSES DEVELOPMENT ..................................... 46

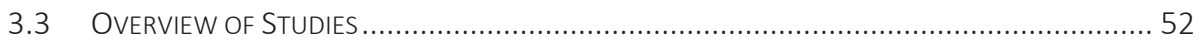

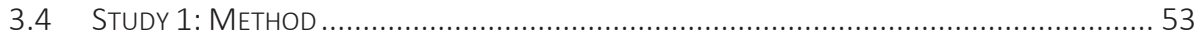

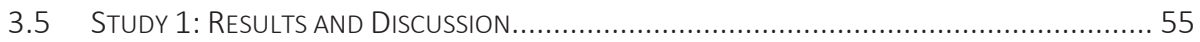

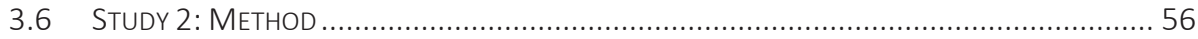

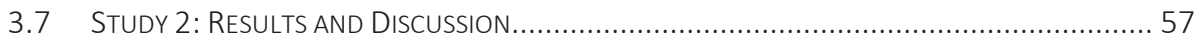

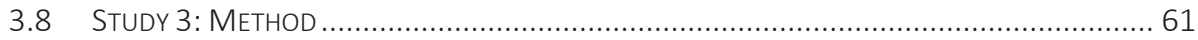

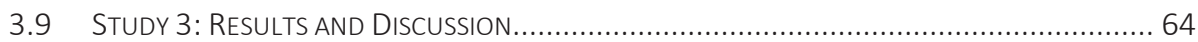

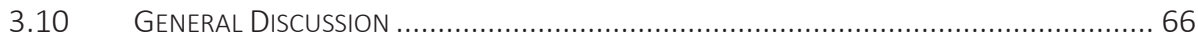


CHAPTER 4 WHEN DO EMPLOYEES SPEAK UP PUBLICLY: THE ROLE OF MANAGER SELFEFFICACY AND LEADER-MEMBER EXCHANGE......................................................... 73

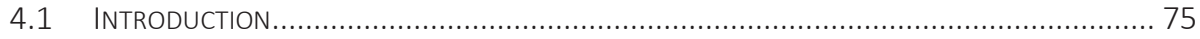

4.2 TheORETICAL BACKGROUND AND HYPOTHESES DEVELOPMENT ......................................... 77

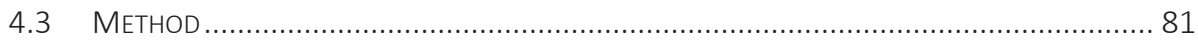

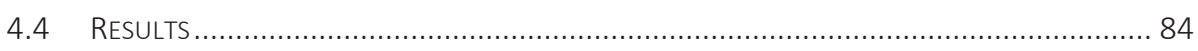

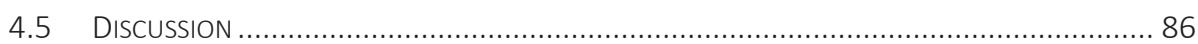

CHAPTER 5 EMPLOYEES' MISPLACED LOYALTY: PERCEIVED COSTS AND ACTUAL BENEFITS

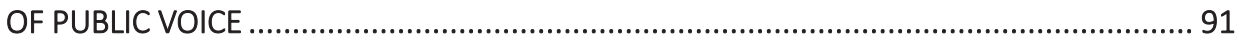

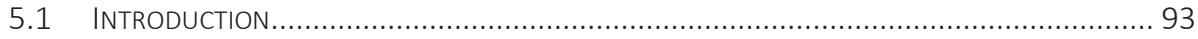

5.2 TheORETICAL BACKGROUND AND HYPotheSES DeVELOPMENT ........................................ 95

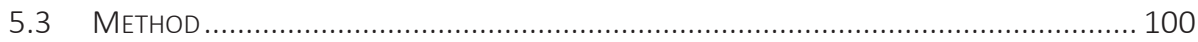

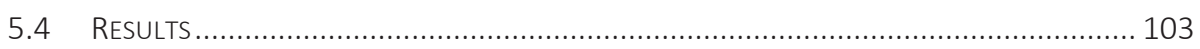

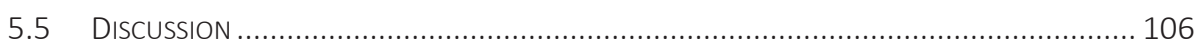

CHAPTER 6 GENERAL DISCUSSION AND CONCLUSIONS........................................... 111

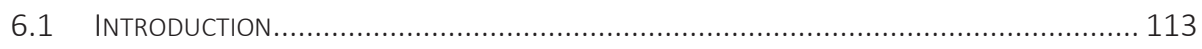

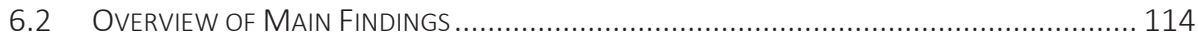

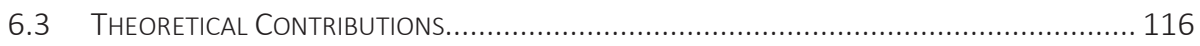

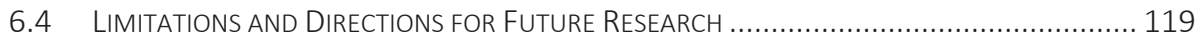

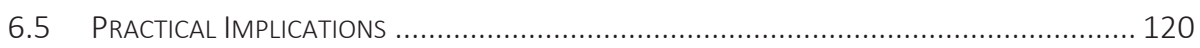

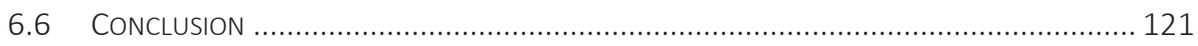

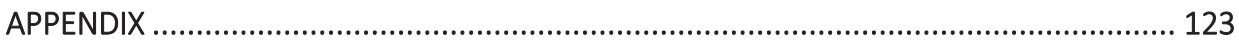

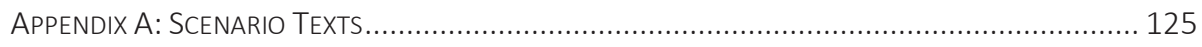

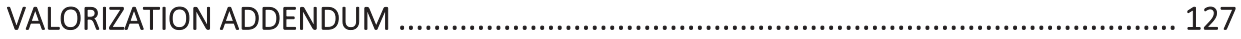

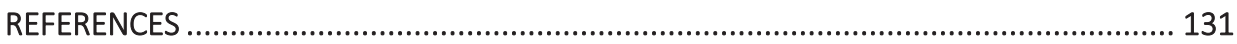

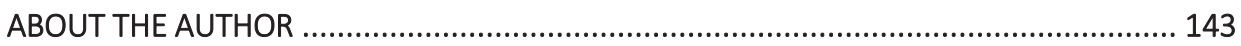


Chapter

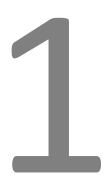

An Introduction and Literature Review 



\subsection{General Introduction}

Today's rapidly changing world holds tremendous challenges for organizations. Organizations need to be prepared to face and promptly respond to these challenges including intense competition, rising globalization, and innovation demands. Given the pace and complexity of today's business world, managers may overlook emerging trends and promising opportunities. One way managers can stay ahead of the curve is to encourage employees to engage in voice behavior - that is, openly communicate work-related ideas, opinions, or concerns (Morrison, 2014). Employees, due to their proximity to customers and daily work processes, frequently hold diverging viewpoints and unique knowledge that can provide managers with valuable insights required to adapt to the changing business landscape. Furthermore, given increased complexity in today's organizations, employees' input might be critical for identifying emerging issues and problems (Edmondson, 2003). Not surprisingly, extensive research indicates that voice improves managers' decision-making (Morrison \& Milliken, 2000), helps to avoid errors (Edmondson, 2003), and enhances innovation (Liu, Song, Li, \& Liao, 2017).

The importance of voice for effective organizational functioning stimulated research into factors that promote employees to express their ideas, opinions, or concerns (see Morrison, 2011, 2014). Next to factors such as employee attributes (e.g., Tangirala, Kamdar, Venkataramani, \& Parke, 2013) and voice climate (e.g., Morrison, WheelerSmith, \& Kamdar, 2011), managers' openness and responsiveness to voice has been shown to play an important role in affecting employee voice behaviour (e.g., Detert \& Burris, 2007). In fact, this research has indicated that, although voice is associated with various benefits, managers do not always welcome voice and may react in dysfunctional ways by disregarding or ignoring the provided input or denigrating the voicing employee (Morrison \& Milliken, 2000). Over the past years, there has been growing scholarly interest in exploring factors that affect managers' reactions to voice. Studies have shown that voice frequency (e.g., Seibert, Kraimer, \& Crant, 2001), the attributes of people involved (the voicing employee and the manager; e.g., Fast, Burris, \& Bartel, 2014; Sijbom, Janssen, \& Van Yperen, 2015a, 2015b), and the attributes of the voice message (e.g., Burris, 2012) affect managers' reactions to voice.

Yet, much less is known about the role of the social setting in which voice is enacted. As suggested by the guiding quotation to this dissertation, employees not only decide whether to voice, but also whether to make their "moves" privately or publicly. In particular, employees may express their ideas, opinions, or concerns in private (i.e., when no other people are present besides the voicing employee and the manager) or in public (i.e., in the presence of other people besides the voicing employee and the manager). The general notion within voice literature is that employees often believe that expressing their ideas, opinions, or concerns to their managers in the presence of other people might 
be inappropriate towards their managers and therefore risky (Detert \& Edmondson, 2011). However, no systematic research has been done to examine how managers' reactions differ when voice is expressed in public versus private settings.

At the same time, the broader social psychology literature suggests that the presence of other people may fundamentally affect an individual's behaviour (Breckler \& Greenwald, 1986; Triplett, 1898; Zajonc, 1965). Individuals, when in public, are more likely to be concerned about how they appear to other people and thus strive to behave in a way that allows them to preserve their desired social image (Goffman, 1959, 1967; Sproull, Subramani, Kiesler, Walker, \& Waters, 1996; Triplett, 1898; Uziel, 2007; Zajonc, 1965). Managers, due to their distinct role-which often puts them in the spotlight-are particularly concerned about how they appear in the eyes of their colleagues (e.g., Pfeffer, 1977). Thus, the social setting in which voice is enacted is likely to be an important factor that we need to consider to explain and predict how managers react to voice.

This dissertation introduces the concept of public versus private voice and aims to examine how the social setting in which voice occurs may shape managers' reactions to voice. To unveil and highlight the role of the social setting in which voice is enacted, this dissertation addresses the following research questions: 1) what is private and public voice; 2 ) how does managerial voice endorsement differ when voice is expressed in public as compared to private settings; 3 ) how does an employee's tendency to voice in public versus private settings affect his/her capacity to initiate change; 4) what are the factors that determine an employee's preference for public versus private voice.

By addressing these research questions, this dissertation makes two important theoretical contributions. First, it contributes to the growing literature on managerial reactions to voice. This literature has mostly focused on how voice frequency, attributes of the people involved, or of the voice message affect managerial reactions to voice (Burris, 2012; Fast et al., 2014; Seibert et al., 2001; Sijbom et al., 2015a, 2015b). I add to this literature by highlighting how and why the social setting (private vs. public) in which voice is enacted may affect managers' reactions to voice.

Second, this dissertation adds to the conversation on how employees' evaluation of potential risks associated with voice influences their voice behaviour. In particular, the general notion in the literature is that when employees perceive that voice is risky and may lead to negative implications, such as low performance appraisals, being denigrated, or harming personal relationships at the workplace (Detert \& Treviño, 2010; Grant, 2013; Milliken, Morrison, \& Hewlin, 2003), they are likely to withhold their input and remain silent. In this sense, scholars often consider voice behaviour as an "either-or" decision such that employees may either speak up or remain silent (see Morrison, 2014). This dissertation challenges this perspective and suggests that when employees perceive that voice may lead to negative personal repercussions, they do not necessarily withhold their input, but may adapt their voice tactics by expressing their ideas, opinions, or concerns 
in private settings. Consequently, this dissertation provides evidence that the perceived risks associated with voice do not only affect the frequency with which employees speak up, but also their choice about the setting in which to speak up.

Apart from these broad and potentially far-reaching contributions, this dissertation also makes several more specific contributions to various related research streams, such as leader-member exchange (LMX) theory, managerial self-efficacy, implicit voice theories, and self-promotion climate. These contributions are discussed in detail in the empirical chapters.

I would like to note that this dissertation primarily focuses on examining unsolicited voice-that is, suggestions, opinions, or concerns voluntarily expressed by employees and not as a response to a manager's request for their input. Hence, employee voice and associated effects discussed in the following do not apply to situations when managers explicitly request their employees to critically assess existing practices and procedures. Furthermore, although the voice phenomenon and associated effects are considered as universal and generally hold across cultures and contexts, I would like to note that there can be certain differences in managers' reactions to public (vs. private) voice depending upon the cultural context in which managers are operating.

In the following, this chapter presents a literature review of the concept of voice behaviour. The literature review first introduces the concept of voice, outlines its key attributes, and highlights its challenging nature. The review continues by discussing the role of managers' behaviours and dispositions in promoting employee voice and presents research findings on managers' reactions to voice. In the final part of the literature review, the concept of public versus private voice is introduced and discussed in the light of the related research streams. The review concludes with an explanatory study, which provides preliminary evidence that the social setting in which voice occurs affects how voice is evaluated.

\subsection{Employee Voice: From the Origins to the Current Conceptualization}

The first reference to the concept of voice was made by Adam Smith in his publication Wealth of Nations where he highlights that employers often do not listen to or even ignore employees' input (Smith, 1776). However, a formal theory of voice was only introduced two centuries later by Hirschman (1970) in the Exit-Voice-Loyalty model where he conceptualized voice as one of potential responses to organizational dissatisfaction. This model stimulated various studies, which demonstrated that voice was positively associated with prior job satisfaction and job involvement (Rusbult, Farrell, Rogers, \& Mainous, 1988; Withey \& Cooper, 1989). Nearly three decades later, after the seminal work by 
Hirschman (1970) was published, Van Dyne and Le Pine (1998) renewed scholarly interest in voice by shifting its conceptualization from response to dissatisfaction, to a form of extra-role behaviour. The authors differentiated voice from in-role behaviours and demonstrated its distinctiveness from less challenging forms of extra-role behaviours such as helping behaviour (Van Dyne \& LePine, 1998). This study was a starting point for a new stream of research in organizational behaviour investigating voice behaviour as a form of challenging extra-role behaviour.

Given the extensive scholarly interest in understanding the concept of voice, there are multiple definitions of voice. Yet, most of these definitions share three core attributes (Morrison, 2011). First, employees express their voice verbally. Second, voice is a discretionary behaviour such that employees decide whether and how to speak up. Third, employees voice with an intent to bring constructive change. Drawing from these attributes, Morrison (2014) defines voice "as an informal and discretionary communication by an employee of ideas, suggestions, concerns, information about problems, or opinions about work-related issues to persons who might be able to take appropriate action, with the intent to bring about improvement or change" (p.174). In the present dissertation, I use this definition of voice and focus on voice directed toward one's manager (i.e., upward voice behaviour). Furthermore, because employee voice and employee silencethat is, "the manifestation of a hesitation to speak up about an issue that is of some importance to the individual but that seems risky to speak about in their organizational or institutional context" (Milliken \& Morrison, 2003, p. 1564)-represent two sides of the same coin (Morrison, 2014), in this dissertation I consider silence as the opposite of voice.

\subsection{Challenging Nature of Voice and Efficacy-Safety Calculus}

Although voice is constructive in its intent, it is a form of challenging extra-role behaviour (Van Dyne \& LePine, 1998). Employee voice involves a direct challenge of the status quo and frequently manifests as questioning or criticizing existing processes, practices, and policies in an organization (LePine \& Van Dyne, 1998). Managers, due to their position, often identify with the status quo and thus, may perceive voice as an indirect critique of their performance (Edmondson, 2003). In particular, managers may see employee voice as a challenge to their prior decisions and actions (Morrison \& Milliken, 2000). Moreover, when employees highlight a need for improvement, employees implicitly emphasize issues that managers may have overlooked (Burris, 2012) and thus indirectly raise questions about managers' credibility and competence. Given the challenge inherent in voice, managers do not always welcome voice and may react defensively by punishing employees for speaking up or denigrating their input (e.g., Burris, 2012; Fast et al., 2014; Seibert et al., 2001). As a result, employees often fear that expressing their ideas, opinions, or 
concerns may cause negative personal repercussions such as receiving low performance evaluations, being viewed as troublemaker, as well as damaging personal relationships at the workplace (Detert \& Treviño, 2010; Grant, 2013; Milliken et al., 2003).

Hence, voice creates a dilemma for employees. On the one hand, employees want to voice their ideas, suggestions, and concerns to improve practices or procedures in their work-group and organization (LePine \& Van Dyne, 1998). At the same time, employees do not want to suffer from potential negative outcomes associated with voice (Shore, Barksdale, \& Shore, 1995). Confronted with this dilemma, employees will often be cautious about whether to voice. In deciding, employees make judgments on two aspects: voice efficacy and voice safety (Morrison, 2011, 2014). Voice efficacy refers to the extent to which an employee believes that speaking up is likely to bring about change (Morrison, $2011,2014)$. Voice safety refers to the extent to which an employee believes that speaking up is risky and possibly leads to negative repercussions (Morrison, 2011, 2014). The higher the level of voice efficacy and voice safety, the more likely employees are to engage in voice behaviour.

\subsection{The Role of Managers' Behaviors}

In the last years, there has been an increasingly growing body of research examining factors that affect employees' judgments about voice efficacy and safety and, consequently, their willingness to voice (see Morrison, 2011, 2014). This research has indicated that along with such factors as employees' attributes (e.g., Tangirala et al., 2013) and voice climate (e.g., Morrison et al., 2011), managers' beliefs and behaviours play a critical role in promoting as well as discouraging employees from speaking up. In particular, the existing literature suggests that employees voice more when managers encourage them to provide suggestions, display openness to their ideas, and signal that their input matters and will be considered (see Morrison, 2011, 2014).

For example, an early study on voice suggested that employees are more likely to express their ideas or concerns when they perceive their managers to be approachable and responsive to voice (Saunders, Sheppard, Knight, \& Roth, 1992). Across both qualitative and quantitative studies with cardiac operating surgery teams, Edmondson (2003) showed that coaching behaviour of team leaders facilitates voice of team members. Detert and Burris (2007) showed, in a study on restaurant chain employees, that perceived manager openness increases employees' psychological safety, which, in turn, leads to more voice. In a more recent study, Tangirala and Ramanujam (2012), using multisource survey data from nurses and their managers, demonstrated that manager consultation positively affects employees' voice by enhancing employees' perceived influence. 
Apart from managers' openness and responsiveness to voice, transformational leadership plays an important role in predicting employee voice. Detert and Burris (2007), for example, showed that when managers demonstrate transformational leadership, they create a psychologically safe environment which consequently enhances employees' voice. Liu, Zhu, and Yang (2010), studying MBA students at Chinese universities, extended these ideas by demonstrating an indirect effect of transformational leadership on voice via enhanced employee identification with one's manager.

Voice frequency was shown to also be influenced by the extent to which employees feel treated with respect by their managers (Takeuchi, Chen, \& Cheung, 2012). In particular, the authors demonstrated that employees' evaluation of interpersonal justice in the interactions with one's manager is positively associated with voice. Walumbwa and Schaubroeck (2009) showed, in a study of managers and employees working for a major financial institution in the United States, that ethical leadership leads to higher psychological safety and, consequently, enhances voice. Similarly, Avey, Wernsing, and Palanski (2012), using a sample of working adults across organizations, found ethical leadership to be positively associated with voice. In contrast, Burris, Detert, and Chiaburu (2008), sampling managers working in the restaurant industry, found that abusive leadership enhances psychological detachment, in turn negatively affecting employees' voice.

Apart from the way employees perceive managers' behaviours, employee voice has been linked to manager dispositions as well as affective states. Fast and colleagues (2014) found that low managerial self-efficacy leads to less solicitation of voice due to enhanced ego-defensiveness, which, in turn, reduces voice. Liu and colleagues (2017) using an experience sampling method, demonstrated that managers' positive affect influences perceived psychological safety via employees' own affective states, which, in turn, enhances voice. This study is important in that it is the first to examine voice by taking a withinindividual approach.

Employees may also voice more when they entertain close, trusting relationships with their manager. For example, Van Dyne, Kamdar, and Joireman (2008) found a positive association between LMX and voice. Similarly, Botero and Van Dyne (2009) examined the effect of LMX on voice in the United States and Colombia. They demonstrated that, across the two countries, employees with high LMX demonstrate higher levels of voice. Burris and colleagues (2008) extended these findings by demonstrating that psychological detachment from one's organization mediates the relationship between LMX and voice. Presumably, when employees have poor relationships with their managers, they are more inclined to leave the organization and, as a result, are less interested in voicing their suggestions or concerns to improve their immediate work environment.

Thus, the above review provides strong evidence that the frequency of voice depends on how employees perceive their managers, such that employees engage more in voice when they view their managers as open, supportive, and responsive to voice. Next to this, 
managers' transformational and ethical behaviours have been shown to be positively associated with voice. Furthermore, the current review also suggests that manager dispositions, affective states as well as relationship quality with one's manager provide employees with social cues about managers' responsiveness to voice and thus affects voice behaviour.

\subsection{Managers' Reactions to Voice}

As managers' openness and responsiveness play an important role in predicting employee voice, extensive research has focused on examining when and why managers react favorably (vs. defensively) to employee input (see Morrison, 2011, 2014). This research stream has focused on two forms of managerial reactions. First, earlier work on voice examined reactions in terms of employee outcomes including managers' evaluation of employee performance, level of competence, expertise as well as career outcomes (e.g., Seibert et al., 2001; Whiting, Maynes, Podsakoff, \& Podsakoff, 2012). Second, more recent work focused on examining how managers react to the voiced idea by looking at voice endorsement (e.g., Burris, 2012; Fast et al., 2014; Sijbom et al., 2015a, 2015b). Voice endorsement refers to a manager's willingness to consider and address employee's suggestions, which may include communicating these suggestions to top management as well as allocating resources for its implementation (Burris, 2012). In the following, I will outline the main research findings with regard to both forms of managerial reactions.

\subsubsection{Employee Outcomes}

Drawing on the perspective that voice is an improvement-oriented behavior, some studies have shown voice leading to positive employee outcomes. For example, Van Dyne and LePine (1998) found a positive effect of voice on managers' evaluations of employees' performance, above and beyond the effects of employees' in-role behaviors as well as helping extra-role behavior. Whiting, Podsakoff, and Pierce (2008) conducted an experimental study where participants were presented with critical incidents describing performance of employees. In these incidents, authors manipulated low versus high levels of voice. Similarly to the findings by Van Dyne and LePine (1998), results indicated a positive effect of voice on performance evaluations, above and beyond the effects of employees' task performance and helping others. However, there is also evidence that voice may negatively affect employee outcomes. For example, in a time-lagged study, Seibert, Kraimer, and Crant (2001) revealed that employee voice is negatively associated with career promotion and salary increase. 
To shed light on the above-mentioned contradictory findings, scholars have called for research into moderating factors that may explain when voice leads to positive (vs. negative) employee outcomes. For example, Burris, Detert, and Romney (2013) revealed the role of manager-employee agreement and disagreement around voice. In particular, the authors found that employee voice leads to higher performance evaluations when employee and manager agree about the employee's high level of voice and when the employee underestimates his/her voice frequency relative to the managers' evaluations. By contrast, employees who overestimate their voice volume receive worse performance evaluations.

Whiting, Maynes, Podsakoff, and Podsakoff (2012), seeking to make sense of some of the mixed findings on how voice influences employee outcomes, drew from persuasion research to develop a more comprehensive model. They outlined the importance of examining how attributes of the voice source (i.e., the employee), the receiver (i.e., the manager), the message, and the context may affect performance evaluations of voicing employees. Consistent with this approach, I will present research findings on the effects of these four factors on employee outcomes.

Employee attributes. With respect to the attributes of the voicing employee, research has focused on the level of expertise, trustworthiness, ability to regulate one's emotions, as well as status of the employee. In particular, in a set of experimental studies, Whiting and colleagues (2012) found a positive association between expertise of the voicing employee and their subsequent performance evaluations. The results of the experiments also provided support for the proposition that trustworthiness of the voicing employee leads to increased levels of liking of the employee and evaluations of the message as more constructive. This, in turn, positively affects performance evaluations. Other studies similarly suggest that close and trusting employees are evaluated more positively when engaging in voice behaviour. For example, using a scenario-based experiment with a sample of middle managers working in South Korea, Kim and colleagues (2009) showed that when employees are seen as trusting rather than cynical, managers are more likely to attribute employee voice to moral concerns (rather than to personal attacks), which, in turn, leads to less social undermining and more social support for the voicing employee. Furthermore, Burris, Rodgers, Mannix, Hendron, and Oldroyd (2009) found that managers perceive inner-circle employees to make better contributions to group discussions, and, consequently, managers reward such employees with larger bonuses.

Grant and colleagues (2013) focused on how employees' emotion regulation knowledge affects voice outcomes. Using multisource field data from a health care company, they showed that voice leads to more positive performance evaluations when employees know how to effectively regulate their emotions while speaking up. Additionally, Grant, Parker and Collins (2009) showed that voice leads to higher performance evaluations when employees display strong prosocial values and low negative affect. Howell, 
Harrison, Burris, and Detert (2015) more recently proposed that employee status positively affects managers' recognition of voice, which, in turn, leads to more favourable performance appraisals. Authors indeed found that for higher status employees, voice was associated with higher performance appraisals. This is because managers recognize their voice more than voice from lower status employees.

Manager attributes. Although there are multiple studies on how employee attributes affect the way that managers evaluate voicing employees, the research on the effects of manager attributes is scarce. In particular, to my knowledge, the only work addressing this question was the study conducted by Fast and colleagues (2014). The authors proposed that managers with low levels of self-efficacy are more averse towards employee voice, which results in negative employee outcomes. In support of their proposition, the authors showed that managers' self-efficacy is negatively associated with denigration of the competence of voicing employee and this effect is driven by managers' enhanced ego defensiveness.

Voice message attributes. Several studies have demonstrated how voice message attributes may affect managerial evaluations of voicing employees. For example, Whiting and colleagues (2012) found that employees who speak up with solutions instead of problems receive higher performance evaluations, and that this effect is driven by enhanced ratings of perceived voice constructiveness, employee liking, and attribution of prosocial motives. Further, across three studies, Burris (2012) examined how managerial evaluations of employees' performance differ depending on the content of voice message. In particular, he examined the effects of two types of voice: challenging of status quo and supportive of status quo. Results indicated that employees who engage in challenging rather than supportive voice are evaluated as worse performers and the effect is mediated by perceived lack of employee's loyalty.

Voice context attributes. Contextual and situational factors may play an important role in shaping the meaning and interpretation of organizational behaviour (Johns, 2006). Yet, research on how such factors affect managerial reactions to voice is limited. To my knowledge, the study by Whiting and colleagues (2012) is the only one looking at how contextual factors may affect managerial evaluations of voicing employees. In particular, the authors showed that the timing of voice influences the performance appraisals of employees, such that employees who raise suggestions in an early rather than late project stage are rated more favourably. This is due to the fact that voice in an early project stage is perceived as more constructive.

\subsubsection{Voice Endorsement}

To outline when managers are more or less likely to endorse employees' input, I will again use the framework suggested by Whiting and colleagues (2012). Given that, to my knowledge, there are no studies examining how contextual factors may affect managers' 
voice endorsement, I will focus only on the effects of attributes of the voicing employee, the manager, and the voice message.

Employee attributes. Entertaining a close, trusting relationship with the manager was found to positively affect evaluations of the voiced input. In particular, Burris and colleagues (2009) showed that managers have a tendency to evaluate input from inner-circle employees more favourably as compared to input from out-circle employees irrespective of the strength of the argumentation.

Manager attributes. Fast and colleagues (2014) found that managers with low (vs. high) self-efficacy are less likely to endorse voice because of enhanced threats to their ego. Sijbom, Janssen, and Van Yperen (2015a) proposed that managers' achievement goal orientation affects their reactions to employee creative ideas (which I discuss here as a specific type of voice). As proposed, across two studies, they showed that mastery goal managers, relative to performance goal managers, are more interested in employees' voiced ideas and, as a result, are more likely to adopt and less likely to oppose employees' input. Further, the authors showed that performance goal managers are more likely to react positively to employees' voice when employees speak up considerably (i.e., politely, respectfully) rather than aggressively. To further explicate how managers' achievement goal orientation affects their reactions to employees' voice, Sijbom and colleagues (2015b) in a different paper found that performance goal managers, as compared to mastery goal managers, demonstrate less responsiveness and support to employee voice. This effect is mediated by managers' appraisal of image threat and learning opportunity. Further, the authors showed that the negative effect of performance goal orientation on voice receptiveness is reduced when employees voice creative ideas without highlighting problems.

Voice message attributes. Burris (2012) showed that managers' propensity to endorse voice depends on the extent to which voice supports or challenges the existing status quo. In particular, Burris showed that employees who have a tendency to engage more in challenging rather than supportive voice elicit higher levels of threat in managers and are seen as less loyal, which, in turn, negatively affects voice endorsement.

Reviewing the literature, we see that prior research has primarily focused on the impact of voice frequency, personal attributes of managers and employees, and voice content on managerial reactions to voice. Research investigating the effects of voice context on managerial reactions to voice is, however, limited. In particular, how does the context in which voice is enacted affect managers' voice endorsement? Are there certain contexts that increase employees' capacity to initiate change by expressing voice? Furthermore, we lack an understanding about the factors that determine an employee's tactics to express their voice in one context and not in others. Addressing these questions is important for theoretical and practical reasons. From a theoretical perspective, contextual factors play an important role in shaping and interpreting the meaning of organizational 
behaviour (Johns, 2006). Furthermore, studying the effects of contextual factors, such as specific situational variables, may help to capture variance in behaviours that cannot be detected by studying the effects of individual differences (Johns, 2006). From a practical perspective, the examination of contextual factors makes research more applicable as it provides practitioners with guidelines about the context in which specific findings from research may hold or not (Johns, 2006). Hence, in this dissertation, I address this gap in the voice literature by examining the role of the social setting - public versus private-in which voice occurs in predicting managers' reactions to voice.

\subsection{Introduction to Public versus Private Voice}

About four centuries ago, Galileo Galilei publicly challenged the Catholic Church's belief about the earth being the stationary centre of the universe with all other planets and the sun revolving around it by presenting his theory that the earth and all other planets revolve around the sun (Galilei, 1967). Today we consider Galileo Galilei as one of groundbreaking revolutionary scientists in human history who built up the foundation for modern physics and astronomy. However, when he presented his ideas and challenged the Church's view, he was summoned before the Roman Inquisition. When looking at this example from history, we may wonder whether the outcomes would be different if Galileo Galilei chose not to express his ideas publicly. In particular, what if Galileo Galilei expressed his ideas only to some representatives of the Catholic Church? Would we know about him and his theory today? At the same time, would he be summoned before the Roman Inquisition?

In the example described above, Galileo Galilei expressed his ideas publicly. Similarly, today, employees may choose to express their ideas, opinions, or concerns in public or in private settings. In the present dissertation, by public voice I refer to situations where voice is communicated in the presence of people besides the voicing employee and the manager. When voice is expressed in public, other people are immediately exposed to the raised ideas, opinions, or concerns. By the term "others", I refer to co-workers, other managers or superiors, or customers. In contrast, private voice refers to situations where the employee communicates voice only to the manager, such that no other person is, in that particular situation, exposed to the raised ideas, opinions, or concerns.

The general notion in the voice literature is that expressing voice in public settings is inappropriate and disloyal and, thus, might be more risky for employees rather than expressing voice in private (Detert \& Edmondson, 2011). In particular, employees often hold implicit theories that managers do not like to be challenged or receive bad news in front of others but prefer to have employees discuss these issues with them in private first (Detert \& Edmondson, 2011). However, as with Galileo Galilei-where we cannot know 
what the outcome would have been if he had spoken up in private only-there are no systematic studies that would shed light on how managerial reactions to voice differ when employees express their ideas, opinions, or concerns in public versus private.

Although there are no systematic studies in the voice literature on the distinction between private and public voice, several studies from related research streams suggest important differences in managerial reactions to public versus private voice. In particular, the issue-selling literature suggests that issues expressed in public raise managers' sense of accountability (i.e., perceived pressure to consider the issue), and, as such, issues sold in public have more chances to be considered by managers (Dutton \& Ashford, 1993). At the same time, when issues are raised in public, managers are more likely to feel threatened and, as a result, may punish employees (Dutton \& Ashford, 1993). In a related vein, Piderit and Ashford (2003), using a qualitative design approach, showed that many female managers consider raising gender-equity issues in private settings as a softer strategy than doing so in public settings.

Furthermore, literature on feedback-seeking behaviour has demonstrated that people tend to seek less feedback when it is delivered in the presence of others (Ashford \& Northcraft, 1992; Levy, Albright, Cawley, \& Williams, 1995). In a lab experimental setting, Ashford and Northcraft (1992) demonstrated that the presence of an audience that a person believes is evaluating him/herself reduces the feedback seeking of this person. Similarly, Levy, Albright, Cawley, and Williams (1995), using a computer-simulated time management task, found that individuals were reluctant to receive feedback in public even if they realized its instrumental value. Such reactions were trigged by high image costs associated with public feedback. Hence, there is some indirect support for the idea that managerial voice reactions may differ depending upon whether voice is expressed in public or private.

\subsection{Exploratory Research into Public versus Private Voice}

To develop our intuition on how private voice may differ from public voice, I conducted an exploratory study into how speaking up in public versus private would be seen by others. In particular, I assessed whether and how the setting in which voice is enacted (private vs. public) influences the way that the voicing employee is evaluated. Could it be that an employee's perceived competence, warmth, positive dominance, and negative dominance depend, all else being equal, on whether the employee raises voice in public versus private? To find out, I recruited 470 undergraduate students from a Dutch university of which 465 participants (51\% female, 58\% German, 16\% Dutch, Mage $=20.04$ ) provided reliable data ( 5 participants needed to be excluded because of a response pattern known to indicate insufficient effort; Huang, Bowling, Liu, \& Li, 2015). I adapted a scenario 
study from Sijbom and colleagues (2015b) asking participants to imagine that they were the head of a marketing department in a company specializing in frozen fast food, responsible for planning the marketing strategy of the company, and managing the work of the department's 12 employees. The scenario describes how, one day, one of the employees approached the manager to raise concerns about the marketing strategy that the manager developed and proposed an alternative strategy instead ${ }^{1}$.

I randomly assigned participants to one of two voice setting conditions. In the private ( $N=232$ ) condition, I informed participants that the employee approached them privately to communicate their suggestion. In contrast, in the public condition ( $N=233$ ) participants instead read that the employee expressed voice publicly. To establish that our participants understood the social setting as intended (private vs. public), I used a two-item measure (i.e., "Lucas [Lisa] publicly spoke up about the marketing strategy in front of other employees" and "Lucas [Lisa] spoke up about the marketing strategy privately to you, one-on-one" [reversed]; $\alpha=.95$ ) with a 7-point Likert scale ( 1 = "Strongly Disagree" to 7 = "Strongly Agree"). As expected, participants in the public condition evaluated the setting as more public $(M=5.92, S D=1.57)$ than participants in the private condition ( $M$ $=1.73, \mathrm{SD}=1.18), F(1,463)=1057.58, p<.001$.

To learn how employees were perceived when they voiced across the two conditions, I asked participants to rate the employee on various attributes, including competence (i.e., capable, intelligent, competent), warmth (i.e., warm, kind, friendly, understanding, helpful), positive dominance (i.e., leading, self-assured, self-confident, persistent, firm, independent), and negative dominance (i.e., competitive, aggressive, domineering, forceful, dominant, assertive). I based this choice of attributes on insights from the Revised Interpersonal Adjective scale (Wiggins, Trapnell, \& Phillips, 1988) and the literature on gender bias at the workplace (e.g., Eagly \& Karau, 2002; Heilman, 2001). Participants rated the extent to which the above attributes describe the employee using a 7-point Likert scale (1 = "Not at All" to 7 = "To a Very Great Extent").

Results indicated a significant difference in the employee's evaluation across the two conditions (i.e., private vs. public voice), $F(20,443)=11.44, p<.001$; Wilk's $\Lambda=0.659$, partial $\eta^{2}=.34$. As seen in Figure 1.1, when being approached in public, as compared to in private, participants rated the employee lower in terms of perceived competence (i.e., capable, intelligent, competent) and warmth (i.e., warm, kind, friendly, understanding, helpful), and higher in terms of perceived negative dominance (i.e., competitive, aggressive, domineering, forceful, dominant, assertive). With regard to evaluations on perceived positive dominance, participants in the public condition rated the employee as more leading, self-assured, and self-confident than did participants in the private condition. No differences were revealed in terms of evaluating the employee as persistent,

\footnotetext{
${ }^{1}$ For a more detailed description of the scenario, please see p. 53.
} 
firm, and independent. Hence, the results of the explorative study suggest that employees who express voice in public settings are perceived differently than those who express voice in private settings. This provides some preliminary support for my proposition that the setting in which voice is enacted matters such that managerial reactions to voice might also differ depending upon whether voice is expressed in private or public settings.

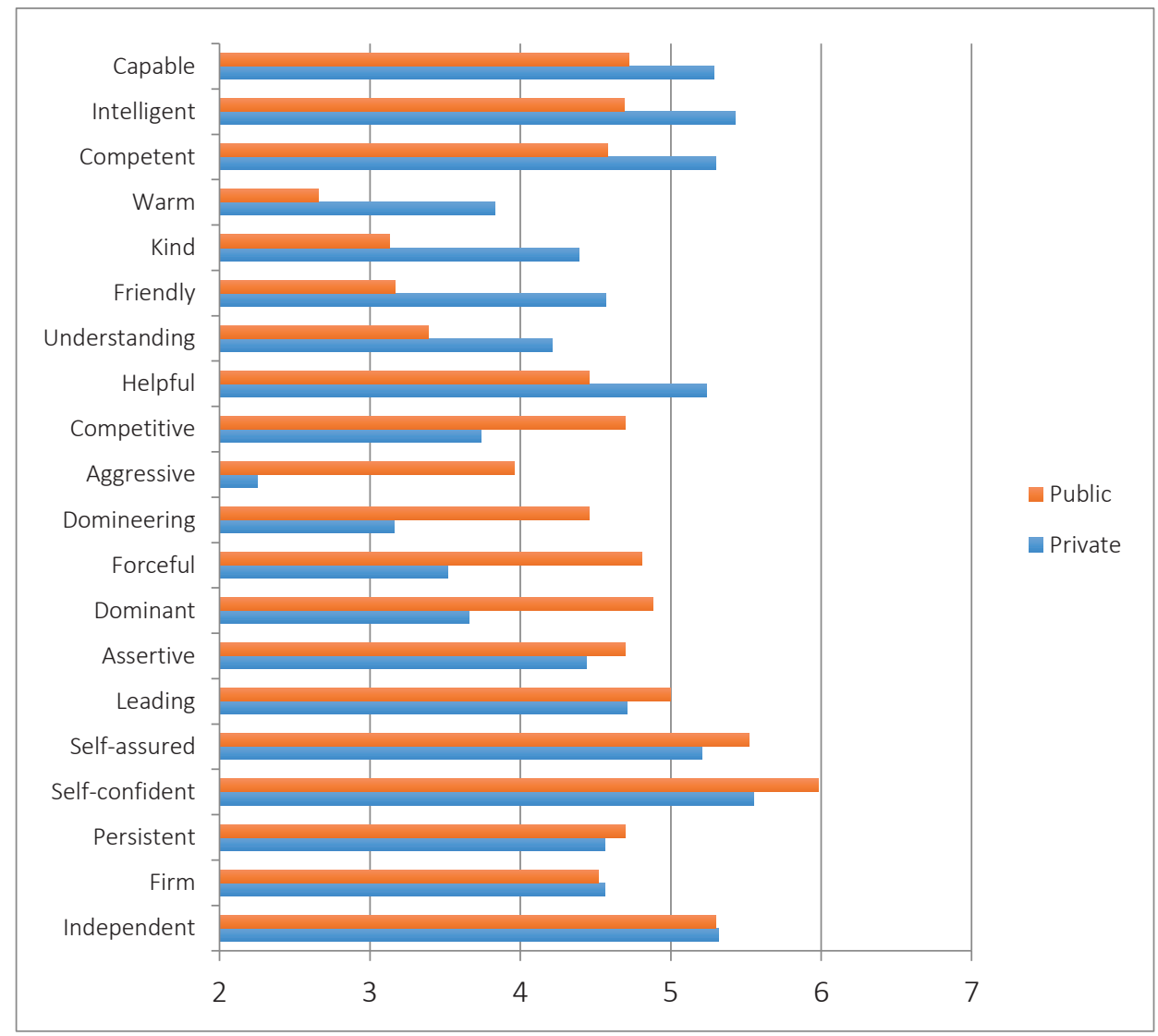

Figure 1.1 Effect of voice setting on employee's evaluation

\subsection{Conclusion}

Although there have been several references in the voice literature as well as in the related research streams discussing the importance of studying public versus private voice, systematic research into the differences between two types of voice is scarce. Thus, this 
dissertation will study how the social setting in which voice occurs affects managers' reactions to voice. Furthermore, in this dissertation, I also examine factors that may explain why employees prefer one type of voice over the other (i.e., private vs. public voice). Next, I outline in more detail the three empirical chapters of this dissertation, all focusing on the distinction between private and public voice. In the end of the next chapter, I present an overall theoretical model of this dissertation. 

Chapter

Dissertation Overview 



\subsection{Introduction}

Having employees who openly express their ideas, opinions, or concerns is imperative for effective organizational functioning (Edmondson, 2003; Liu et al., 2017; Morrison \& Milliken, 2000). Yet, due to the challenge inherent in voice, managers do not always welcome employee voice and may react in dysfunctional ways by denigrating the voicing employee and the provided input (Morrison \& Milliken, 2000). To unveil when managers react defensively (vs. favourably), previous research has examined the effects of voice frequency, the attributes of people involved (i.e., the voicing employee and the manager), and the voice message (Burris, 2012; Fast et al., 2014; Seibert et al., 2001; Sijbom et al., 2015a, 2015b). Although this research has made important strides toward explaining managers' reactions to voice, still little is known about the role of situational factors that may explain when and why managers react favourably (vs. defensively) to voice.

The main objective of this dissertation is to expand our understanding of managers' reactions to voice by examining how the social setting in which voice occurs - that is, whether voice is expressed privately versus publicly - affects the consequences of voice. This dissertation looks at how managers' voice endorsement differs when voice is communicated in public rather than in private settings, as well as how employees' general preference for public (vs. private) voice affects their capacity to initiate change. Furthermore, to get a better understanding on the distinction between private and public voice, this dissertation also examines factors that affect employees' preference for one or another type of voice. In studying both consequences as well as antecedents of public versus private voice, I outline factors that moderate and mediate the examined relationships. For example, I show that managers' enhanced image threat mediates the effect of public (vs. private) voice on voice endorsement.

I employ a variety of research designs and methods including event reconstruction, experimental vignette, as well as cross-sectional field methods. Moreover, this dissertation uses three different forms of operationalization of the distinction between public versus private voice. In Chapter 3, I treat public versus private voice as a binary variable (i.e., private-no one is present, besides a manager and a voicing employee, during a particular voice event; public - one or more people are present, besides a manager and a voicing employee, during a particular voice event). In Chapter 4, we look at public versus private voice as a continuum evaluated as the number of people present during a particular voice event. In Chapter 5, we focus on studying employees' general preference for public versus private voice. These three different forms of operationalization of public versus private voice permitted a more nuanced investigation of possible effects and antecedents of voice social setting. For example, in this dissertation we disentangle and contrast the consequences of public (vs. private) voice events from the consequences of the general tendency of employees to engage in public (vs. private) voice. 
In the following, I provide an overview of each of the three empirical chapters by highlighting how these chapters together provide a rich and comprehensive view on the consequences and antecedents of public versus private voice. Figure 2.1 illustrates the overall theoretical model of this dissertation and depicts theoretical models of the three empirical chapters. Importantly, as all three empirical chapters have been prepared as separate manuscripts, these chapters may be read independently of each other. 


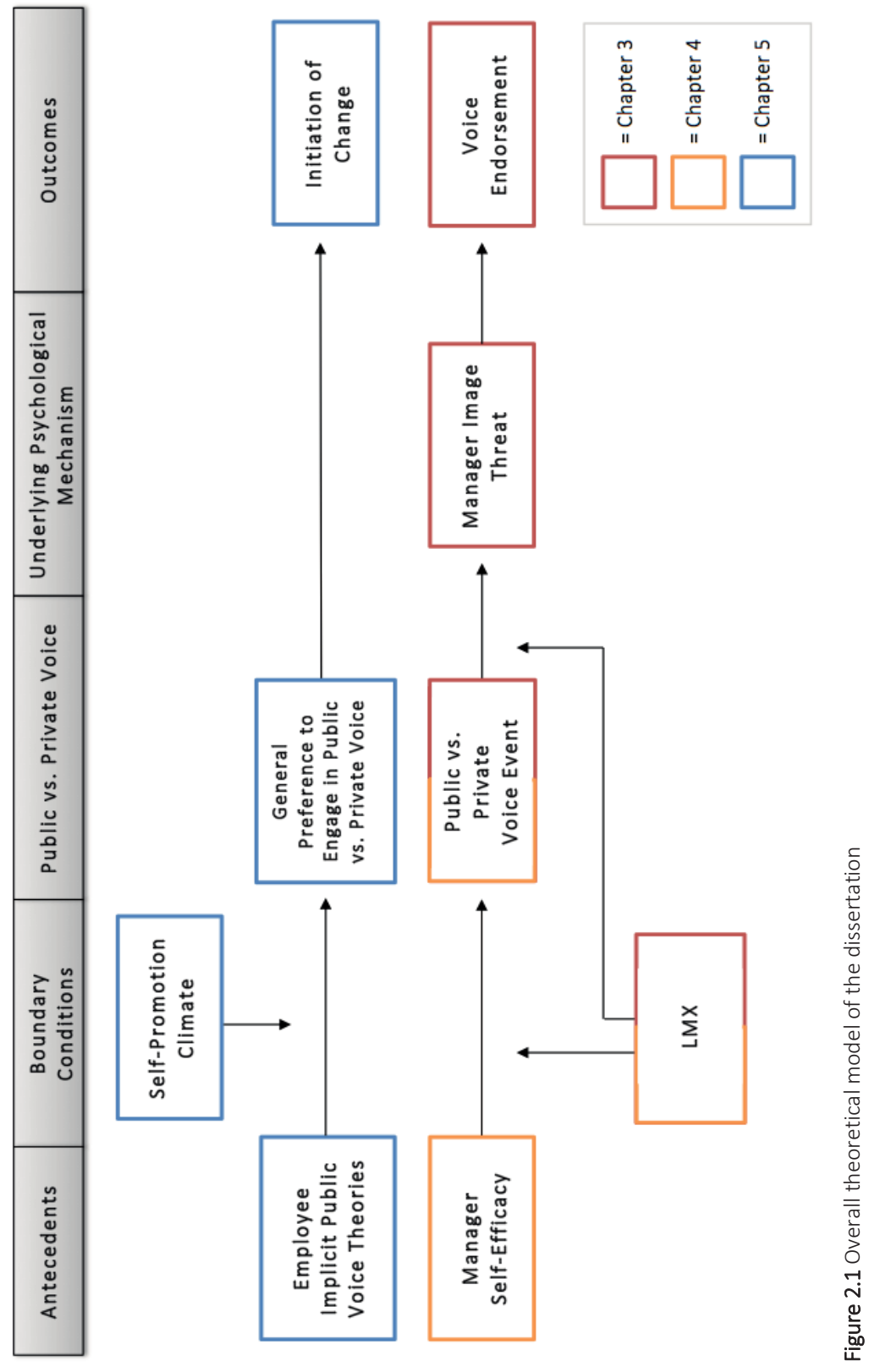




\subsection{Overview of the Empirical Chapters}

\subsubsection{Chapter 3. Keeping It between Us: Managerial Endorsement of Public versus Private Voice}

In chapter 3, we, together with my co-authors, study how the social setting (private vs. public) in which voice is enacted affects voice endorsement via manager's experience of image threat (i.e., manager's concerns that others' impression of them as effective and credible managers may suffer). Building on the broader social psychology literature (Goffman, 1959, 1967; Sproull et al., 1996; Triplett, 1898; Uziel, 2007; Zajonc, 1965), we suggest that when employees express voice in public settings, such voice is more likely to elicit in managers image-related concerns (as compared to voice expressed in private settings). This, in turn, makes managers respond more defensively by denigrating the provided input. Furthermore, we theorize and examine two competing predictions on how the nature of the relationship between the manager and the voicing employee (LMX quality; Graen \& Uhl-Bien, 1995) may moderate the manager's reactions to public voice. To reassure internal and external validity, we conducted three studies using different methods (i.e., experimental and correlational) and populations (i.e., undergraduate students and working managers). Across three studies, results indicate that managers are less likely to endorse voice expressed in public rather than in private. This effect is explained by managers' enhanced image concerns in response to public voice. To rule out alternative explanations, we also show that this effect is not due to enhanced ego threat-concerns about one's own decisions, choices, and self-worth. We find that this type of threat, as compared to image threat, does not explain voice aversion evoked by the social setting in which voice occurs (private vs. public). Furthermore, our results indicate a buffering account of LMX such that entertaining a close, trusting relationship with an employee mitigates managers' image concerns associated with public voice. We discuss findings in the light of the existing literature on managerial reactions to voice and outline theoretical and practical implications.

\subsubsection{Chapter 4. When Do Employees Speak Up Publicly: The Role of Manager Self-Efficacy and Leader-Member Exchange}

In chapter 4, we examine the antecedents of employees' preference to engage in public (vs. private) voice. Previous research suggests that when faced with the opportunity to speak up, employees choose between two opposing options, that is, they either express their ideas and opinions or they remain silent (see Morrison, 2014). We challenge this perspective by arguing that employees' choice is not binary (i.e., voice vs. silence), but, instead, more continuous in that employees can choose between different voice tactics. 
In particular, employees may also minimize risks associated with voice by carefully adjusting the social setting (private vs. public) in which to speak up. In building on the work by Fast and colleagues (2014), we argue that managers' sense of self-efficacy-that is, one's belief about one's ability to perform well on specific tasks (Bandura, 1977) provides employees with social cues about voice riskiness, and, as a result, affects employees' preference about the setting in which to voice. That is, we propose that the lower a manager's self-efficacy is, the more likely the employee will speak up in private rather than in public (and vice versa). Furthermore, we test two competing predictions on how the effect of manager's self-efficacy on public (vs. private) voice is moderated by the quality of relationship between the manager and the employee (i.e., LMX quality; Graen \& Uhl-Bien, 1995). To test our model, we conducted an event-based study with 221 voice events nested within 112 employees of 52 managers. As expected, results indicate a positive effect of managers' self-efficacy on public voice. Furthermore, the positive effect of managers' self-efficacy on public (vs. private) voice is mitigated when LMX quality is high.

\subsubsection{Chapter 5. Employees' Misplaced Loyalty: Perceived Costs and Actual Benefits of Public Voice}

In chapter 5, we examine how employees' implicit public voice theories - that is, takenfor-granted beliefs that voicing in public is inappropriate and disloyal (Detert \& Edmondson, 2011) - affect employees' preference to voice privately rather than publicly, which, in turn, impacts employees' capacity to initiate change. Given that employee voice involves challenging the status quo and because managers may identify with the status quo, they may think of voice as disloyal. Silence, on the contrary, may be seen as an expression of loyalty, and this idea has been taken up in prior research. Here, in contrast to this perspective, we propose that employees may actually display loyalty by voicing ideas, suggestions, and concerns privately (i.e., when no one else is present besides the manager) instead of publicly (i.e., when other people are present besides the manager). We argue that employees' implicit public voice theories explain when employees are more likely to voice in private. Yet, we also argue that private voice is less effective, in comparison to public voice, in engendering managerial attention, and, as a result, employees who voice in private are less likely to initiate change. Utilizing multisource data from 110 manager-employee dyads, we find that employees' implicit public voice theories are associated with less public voice, and, consequently, negatively with employees' initiation of change. We further show that this indirect effect is mitigated by the work-group selfpromotion climate-a shared belief that it is appreciated to display behaviours that signal one's competence. 


\subsection{Conclusion}

To conclude, the aim of this dissertation is to examine how the social setting in which voice occurs may shape managers' reactions to voice. To provide a better understanding of the distinction between private and public voice, this dissertation also outlines factors affecting employees' preference for one or another type of voice. To build up a strong theoretical foundation for our proposed theoretical models and explain the hypothesized relationships, this dissertation draws on and integrates theories and findings from the literatures on voice behaviour, leadership, issue-selling, impression-management, and related research streams. The remainder of this dissertation is structured as follows. In chapters 3, 4, and 5, we present three separate empirical manuscripts. Chapter 3 describes how the social setting in which voice is enacted (private vs. public) affects its endorsement via managers' enhanced image concerns. Chapter 4 looks at how manager self-efficacy and LMX interactively predict employee public (vs. private) voice. Chapter 5 outlines how implicit public voice theories affect employees' initiation of change via impacting employees' general preference to voice in private (vs. public) settings. In chapter 6 , we present a general discussion and conclusion, summarizing the main findings of the three empirical chapters. This concluding chapter also outlines implications for theory and practice, limitations of the conducted studies, and directions for future research. 


\section{Chapter}

\section{Keeping It between Us: Managerial Endorsement of Public versus Private Voice}

This chapter is based on the manuscript: Isaakyan, S., Sherf, E. N., Tangirala, S., \& Guenter, H., Keeping It between Us: Managerial Endorsement of Public versus Private Voice. 



\subsection{Introduction}

Imagine that Taylor, head of Human Resources, developed a talent management program to identify high-potential employees. Taylor's team has been implementing the program across the company. One day, an employee on that team, Alex, comes to Taylor's office and privately, one-on-one, expresses concerns about possible flaws in the program and proposes significant revisions. How likely is Taylor to endorse Alex's suggestions and revise the program? Alternatively, imagine another situation in which all the circumstances are identical except that Alex raises concerns about Taylor's program and proposes significant revisions publicly, in the presence of others such as Taylor's and Alex's peers. How likely is Taylor to endorse Alex's suggestions and revise the program now?

Both these situations describe voice, employees' upward expression of ideas, opinions, or concerns about work-related issues (Morrison, 2014). When employees voice, they draw on their experience and proximity to work operations, and thus communicate valuable information in the form of actionable suggestions based on their uniquely held viewpoints and knowledge (Edmondson, 1996). Voice can thus help organizations avoid errors (Edmondson, 2003), enhance innovation (Liu et al., 2017), and increase performance as indexed by sales, profits, and customer satisfaction (Detert, Burris, Harrison, \& Martin, 2013; Frazier \& Bowler, 2015; Lam \& Mayer, 2014; MacKenzie, Podsakoff, \& Podsakoff, 2011). Crucially, for voice to have such an impact, it needs to be endorsed (Detert et al., 2013; Dutton \& Ashford, 1993) because employees often lack the influence needed to turn their ideas or opinions into real constructive changes (Morrison, 2014; Tangirala \& Ramanujam, 2012).

Managers are the ones who often allocate resources to implementing employees' suggestions, and when necessary, act as sponsors of ideas to the top management (Mollick, 2012; Sparrowe \& Liden, 2005). Managers are thus key gatekeepers holding the potential to unlock voice's organizational effects by endorsing it. Yet, the voice literature has documented managers' negative reactions to employee voice, including their tendency to discount employees' ideas and opinions and to avoid endorsement of employees' ideas (Morrison \& Milliken, 2000). Accordingly, scholars have recently begun to explore factors that influence managerial voice endorsement (e.g., message characteristics, manager dispositions). For instance, Burris (2012) showed that when employees engage in more challenging - rather than supportive-voice, managers are more threatened, see employees as less loyal, and support their ideas less. Fast and colleagues (2014) found that managers with low (vs. high) self-efficacy are more likely to experience threats to their ego and, thus, less likely to endorse employees' voice. This nascent research has made important strides in our understanding of managers' endorsement of voice, but has mainly focused on the attributes of the message or the receiver. At the same time, it 
has so far neglected to examine how the social setting in which voice occurs influences voice endorsement.

Take, for example, the two situations described at the outset of this paper, which are identical in terms of actors and message. In the first situation, Alex speaks up in private (i.e., when no one else besides Taylor is present), whereas in the second situation, Alex speaks up in public (i.e., in the presence of Taylor's and Alex's peers). Would the difference in the social setting (private vs. public) affect Taylor's (the manager) likelihood of endorsing Alex's (the employee) idea? If so, this could have important implications for our understanding of voice and its effects. In fact, many discussions of voice and related constructs often assume that voice is public, rather than private. For example, research suggests that dissent expressed in groups facilitates more in-depth discussions, thus increasing decision quality (Nemeth, Connell, Rogers, \& Brown, 2001) and innovation (De Dreu \& West, 2001a). In contrast, private dissent is often considered inefficient because of the need to organize additional meetings with relevant stakeholders (Eden \& Long, 2014).

Given that public voice carries such vital benefits, one would expect that managers appreciate and favour public voice. Yet, we propose that managers react particularly negatively to public voice because of potential challenge to managers' social standing inherent in public voice. We draw from the broader social psychology literature (Sproull et al., 1996; Uziel, 2007; Zajonc, 1965), which indicates that presence of others can make concerns about social image - that is, whether one is coming across to others as effective or competent-salient to individuals in ways that private settings do not. In particular, we propose that because of the putative criticism inherent in voice, voice expressed in a public setting elicits in managers an image threat-that is, worry that others' impression of them as effective managers will suffer and that they will lose their credibility or social status. Consequently, we argue that managers perceiving image threat will respond more defensively, with lower levels of endorsement. At the same time, we also highlight that managers' evaluation of new information is often coloured by how trustworthy and likable they perceive the source to be (Menon \& Blount, 2003). We thus propose that the nature of the relationship between the manager and the voicing employee likely affects the extent to which image concerns become salient when employees voice in public settings. Hence, we theorize how leader-member exchange (LMX; Graen \& Uhl-Bien, 1995) between the manager and the voicing employee might moderate managerial image threat experienced in public settings. Drawing on contrasting insights in the LMX literature suggesting that high LMX can accentuate or mitigate managers' experience of image threat at work, we develop and test competing hypotheses on LMX's moderating effects. Figure 3.1 illustrates our theoretical model. 


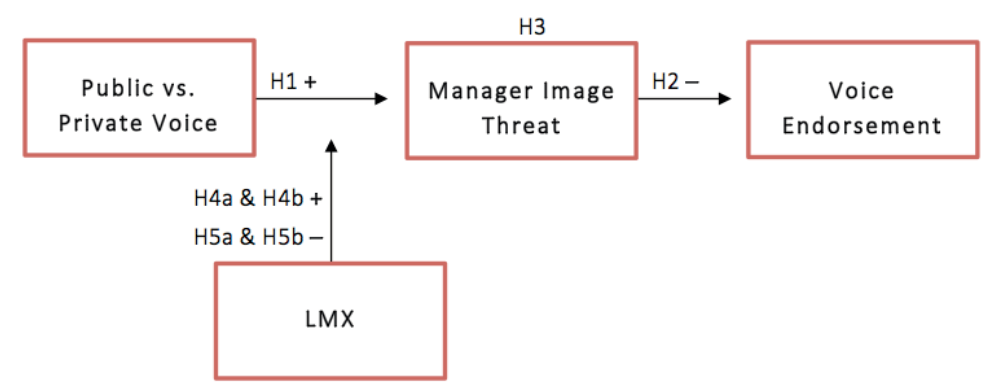

Figure 3.1 Proposed moderated mediation model

We contribute to the literature in several ways. First, emerging research has delineated that attributes of the people involved (i.e., who) or the content of voice (i.e., what is said) can impact managerial endorsement (Burris, 2012; Fast et al., 2014; Sijbom et al., 2015a, 2015b). We extend this research by highlighting the role of the social setting (i.e., where). Further, we explicate competing predictions about how public (vs. private) expression of voice from employees in the "in-group" (high LMX, in contrast to those in the "out-group", low LMX) can affect managerial endorsement of such voice. We thus nuance our understanding of the effects of relational attributes (who are involved in the voice event and how they are related) on voice endorsement. In this process, we address calls for a greater explication of the psychology underlying managers' reactions to employees' input and conditions under which voice incurs favourable (vs. defensive) reactions from managers (Ashford, Sutcliffe, \& Christianson, 2009; Morrison, 2014).

Second, we establish how threat posed by voice can come in a differentiated manner and that, when developing theory, it is important for research to specify the particular form of threat that a voice episode might induce in managers. In particular, we argue that voice in public settings evokes a special kind of threat, image threat, triggered by the presence of others. Image threat is distinct from other forms of threat that voice might elicit. For instance, voice from employees can also increase anxiety in managers about their own decisions, choices, and self-worth-that is, ego threat (Leary, Terry, Allen, \& Tate, 2009). We demonstrate that ego threat, although an important explanation for managers' defensiveness toward voice (e.g., Fast et al., 2014), would not specifically explain their negative reactions toward publicly expressed voice. In this way, we add to our understanding of the differing mechanism underlying managers' (lack) of voice endorsement. 


\subsection{Theoretical Background and Hypotheses Development}

Conveying a positive image to others is a fundamental human motive (Baumeister, 1982; Goffman, 1959, 1967). A positive image affords individuals with social advantages and desired outcomes, such as improved interpersonal relationships, belongingness and inclusion in relevant groups, as well as occupational successes (Baumeister, 1982; Baumeister \& Leary, 1995; Vohs, Baumeister, \& Ciarocco, 2005). As a result, to influence how others perceive them, individuals claim desired social images (Schlenker \& Leary, 1982). In work settings in particular, people closely consider the possible effects of their actions on their image (Bolino, 1999). People may even avoid engaging in otherwise functional actions when they believe that such actions might harm their image (Ashford, 1989). For example, although individuals may see instrumental benefits in seeking feedback, they are reluctant to seek it if they believe it might signal their incompetence or lack of personal confidence to others (e.g., Ashford, Blatt, \& VandeWalle, 2003).

Managers can be especially sensitive about their social image at work. Due to their position, managers are expected to project a sense of competence and appear in control of events and issues in their teams even when, in reality, they might objectively lack such control (e.g., Meindl, Ehrlich, \& Dukerich, 1985). Managers who create and maintain such an image gain status (Ashford, 1989; Greenberg, 1990) and obtain power and resources (Lucas \& Baxter, 2012). As a result, managers can experience an elevated pressure to come across as effective, autonomous, and self-assured even when such appearances come at the expense of achieving organizationally functional goals (Pfeffer, 1992).

Thus, from the managers' point of view, employee voice presents a tricky terrain to navigate. On the one hand, voice provides instrumental benefits to managers, as it can reveal new ideas, expose errors, and highlight previously unknown information (Morrison, 2011, 2014). At the same time, voice can be challenging for managers (Morrison \& Milliken, 2000). Given that via voice, employees, often on their own or proactively, bring up novel ideas and suggestions (Parker \& Collins, 2010), voice can shift the initiative or control over issues raised in the team from the managers to the employees. Moreover, voice involves a criticism (albeit constructive) of the status quo or the way things are at work (Van Dyne \& LePine, 1998). Managers, as occupants of positions of power within the team, often come to represent the status quo (e.g., Edmondson, 2003). Therefore, voice can come across as a challenge of prior managerial actions and put in question judgments or choices underlying such actions (Morrison \& Milliken, 2000). Hence, even as voice may contribute to the work-group effectiveness, it holds the potential to threaten managers' desired appearance as competent leaders who control the flow of events within their teams. 


\subsubsection{Public versus Private Voice and Image Threat}

In this regard, we suggest that not all occurrences of voice elicit similar levels of image threat. Instead, we propose that the presence of others is an important determinant of whether voice elicits image concerns, such that when voice occurs in public (vs. private) managers are more likely to experience image threat. By public voice we refer to situations where voice is expressed in the presence of other people besides the voicing employee and the manager. When voice occurs in public, other people become immediately privy to the ideas, opinions, or dissent raised by the employee. We use the term "others" broadly to refer to co-workers, other managers or superiors, or customers, who typically constitute salient social presence at the workplace. In contrast, by private voice, we refer to situations where voice is expressed only to the manager, such that no other person is, at that particular moment, exposed to the ideas, opinions, or dissent raised by the employee.

In public settings, individuals tend to feel as if they are on a stage and become conscious of how they are coming across or appearing to others (Goffman, 1959, 1967; Sproull et al., 1996; Triplett, 1898; Zajonc, 1965). This should especially be the case for managers who have to constantly project an image of a competent actor who is in control of events and issues in their team (e.g., Pfeffer, 1977). Hence, in public settings, managers should not only feel evaluation apprehension due to the social presence of others but also find their attention distracted from tasks or work goals toward threats to their selfpresentation (Uziel, 2007). Consequently, it is likely that in public settings (as compared to private settings) managers might fail to focus on the functional value or utility of voice that is coming their way (i.e., the extent to which such voice might help address problems or opportunities confronting the team), but rather focus on how such voice is making them look in front of the observing audience. That is, when an employee publicly challenges the status quo by expressing one's ideas, opinions, or concerns, and thereby indirectly the manager, the manager, rightly or not, might worry that others could read this as a signal of the manager's weakness or incompetence. Moreover, when the employee proactively and publicly presents or argues ideas or opinions, managers might feel that their ability to project a sense of control over issues or events in the team is jeopardized. Therefore, managers might feel an enhanced sense of image threat when confronted with voice that is publicly raised by their employees (in contrast with voice that is privately raised). Given possibilities of such adverse managerial reactions to public voice, it is not surprising that people frequently hold lay theories that managers might feel betrayed, humiliated, or blindsided when confronted with public voice (e.g., Detert \& Edmondson, 2011). Putting all this together, we propose the following:

H1: Employees' voice expressed in public (vs. private) settings enhances managers' image threat. 


\subsubsection{Image Threat and Voice Endorsement}

Employees often lack the influence needed to turn their ideas or opinions into real constructive change in a work-group or organization (Morrison, 2014; Tangirala \& Ramanujam, 2012). Hence, they rely on their managers to evaluate their opinions fairly, sponsor-where necessary-ideas to the top management, and allocate resources to testing or implementing their suggestions (Mollick, 2012; Sparrowe \& Liden, 2005). In other words, employees critically depend on their managers to endorse their voice for it to have any meaningful influence in the organization (Detert et al., 2013; Dutton \& Ashford, 1993). We suggest that image threat reduces manager's endorsement of voiced ideas.

People experiencing image threat are strongly motivated to defend their image and are likely to engage in defensive reactions (Goffman, 1967). Such reactions are characterized by negative emotions including anger and hostility toward objects that are perceived as causing image harm as well as counter attacks (Cupach \& Carson, 2002) or public discounting of the credibility or validity of any challenging information (Ilgen, Fisher, \& Taylor, 1979). For example, individuals who feel threatened by unfavourable evaluations become less receptive to feedback which they simply might ignore or dismiss (Ashford et al., 2003; DeNisi \& Kluger, 2000; Tuckey, Brewer, \& Williamson, 2002).

Consequently, we argue that in circumstances when employees' voice heightens managers' image threat, it should elicit lower endorsement from managers because, by endorsing such voice, managers might feel that they are legitimizing the implicit challenge or criticism inherent in such voice, thus solidifying harm to their social image. As a result, managers experiencing image threat, as a consequence of any particular form of voice, are likely to be motivated to maintain their image by rejecting employee's ideas or opposing to provide support and resources for their further implementation (Burris, 2012; Wolfe, Wright, \& Smart, 2006). In contrast, when voice does not elicit image threat, managers do not need to protect their image and thus are more likely to show receptiveness to the voice and endorse it. Using the above logic and combining it with our earlier arguments that managers are more likely to experience image threat as a result of public voice, we propose that managers will endorse voice in public (vs. private) settings less and that experience of image threat will explain this effect. Thus, we formally hypothesize:

H2: Managers' image threat is negatively related to voice endorsement.

H3: Managers' image threat mediates the negative relationship between employees' voice expressed in public (vs. private) settings and voice endorsement. 


\subsubsection{The Moderating Role of LMX: Two Competing Views}

Interactions between managers and employees do not occur in social isolation; rather, they are embedded within ongoing recurring relationships at work. Thus, the relationship the employee who speaks up in public has with the manager is likely to matter to the extent to which the manager find voice to be image threatening. In particular, people do not evaluate a new piece of information at face value. Instead, the relationship they entertain with the source of this information colours their evaluation (Menon \& Blount, 2003). That is, people react differently to similar messages by others who they perceive to be in their "in-group" versus "out-group."

For managers, the distinction between in-group and out-group members is a core part of LMX theory (Graen \& Cashman, 1975; Liden \& Graen, 1980). According to the theory, managers typically develop differentiated relationships characterized by loyalty, liking, respect, and mutual support with only a few members (e.g., Liden \& Maslyn, 1998). The relationships with other members, in contrast, are mostly based on formal job descriptions and prescribed employment contracts (Liden \& Maslyn, 1998). Generally, there is public awareness within teams of employees who constitute the loyal circle of confidants to the managers and those who fall outside such a circle (e.g., Duchon, Green, \& Taber, 1986; Herman, Ashkanasy, \& Dasborough, 2012; Hu \& Liden, 2013). Thus, LMX relationships are critical to understanding image threats because they explain how managers evaluate and interpret the actions of employees and because they affect how managers believe others will view these actions, as they create expectations about how employees and managers should behave toward each other.

Drawing from the LMX literature, we propose two perspectives leading to opposite predictions on how the LMX relationship moderates the way that the manager responds to publicly expressed voice. On the one hand, high LMX can enhance threats resulting from public voice. Manager likely expect the high LMX employee to behave in a loyal manner and refrain from public challenges. In other words, high LMX employees, more than others, are expected not to behave in ways that might potentially hurt or embarrass their managers (Bowler, Halbesleben, \& Paul, 2010; Z. Chen, Lam, \& Zhong, 2007). Consequently, due to such violation of expectations, public voice by high LMX employee might enhance managers' perceived image threat. On the other hand, high LMX can buffer threats resulting from public voice. Because high LMX employees are trusted, their actions are likely viewed more positively by the manager (e.g., Graen \& Uhl-Bien, 1995). As a result, managers might not perceive their voice as a challenge or threat to their image, reducing the negative effects of public voice. We expand on these two arguments and propose a set of competing hypotheses.

$L M X$ as threat enhancer. Employees with whom the manager shares high LMX might be especially socially expected to demonstrate public loyalty to their manager (Bowler et al., 2010; Z. Chen et al., 2007) because closer and more trusting relationships beget 
stronger obligations of loyalty and social support (P. Brown \& Levinson, 1987). As voice is a form of dissent, many people feel that in public settings, it holds potential to come across as a display of disloyalty intended to embarrass the manager (Detert \& Edmondson, 2011). In fact, publicly defending the manager (even when dissent, arguments, and disagreements might privately take place) is considered a critical and essential role of in-group members (Graen \& Scandura, 1987). Thus, from this social expectation of loyalty perspective, managers might experience greater image threat when they are the target of voice in a public setting from employees with whom they share a higher quality LMX relationship. Indeed, expectancy-violation theory (Jussim, Coleman, \& Lerch, 1987) suggests that when in-group (vs. out-group) individuals violate stereotyped expectations, their behaviours are evaluated more extremely. Further, people expect conflicts and challenges from out-group members, but not from in-group members, and when the latter disagree with them, they react more negatively (Phillips \& Loyd, 2006). Similarly, to the extent that an event falls out of an expected schema, it makes people closely evaluate given information and exaggerates people's reactions so that negative events elicit more intense negative affect (Kahneman \& Miller, 1986; M. G. Kim \& Mattila, 2010; Olson, Roese, \& Zanna, 1996; Ortony, Clore, \& Collins, 1988).

Moreover, such social expectations may have important influences on managers' beliefs about how others would interpret publicly expressed voice of high LMX employees. Therefore, managers might believe that a violation of the norm of public loyalty by a close employee will come across to observers as an indication of loss of faith even within the manager's in-group. That is, managers might feel that others will interpret such an act by the employee as a strong negative signal concerning their credibility and ability to retain firm control over issues and events within the team. In contrast, because managers do not have strong social expectations of public loyalty from low LMX employees, voice from such employees is less likely to come as a surprise for managers. Thus, we hypothesize that managers are more likely to experience image threat as a result of public voice from a high LMX employee as opposed to similar voice expressed by an employee with whom they do not share such a relationship that, in turn, will decrease endorsement of such voice:

H4a: LMX moderates the positive relationship between employees'voice expressed in public (vs. private) settings and managers' image threat such that the relationship is stronger when LMX is higher.

H4b: LMX moderates the mediated relationship between employees' voice expressed in public (vs. private) settings and voice endorsement via managers' image threat such that this relationship is stronger when LMX is higher.

LMX as threat buffer. Typically, managers treat employees with whom they share high-LMX relationships more favourably by providing them with tangible and intangible 
resources (Dulebohn, Bommer, Liden, Brouer, \& Ferris, 2012; Loi, Mao, \& Ngo, 2009). One such intangible resource is favourable evaluations. That is, managers might evaluate ideas and contributions of high-LMX employees more positively and attribute more benign intentions to such employees as compared to more distant employees (Burris et al., 2009; T. Kim et al., 2009; Whiting et al., 2012). As a result, it is likely that, in general, managers will evaluate voice from high LMX employees more favourably. Thus, from a threat as a judgment perspective, managers might experience lesser image threat when high-LMX employees voice in a public setting. That is, given that they perceive such voice in a favourable light, it is possible that its threat-inducing aspects are less salient to managers and they consequently might recognize it less as a challenge to their social standing in the group even when the employee expresses it publicly.

Extensive research suggests that people do not perceive reality in an objective manner, but instead view it through a veil of prior schemas that affect what they search for, what they notice, and the value or importance they assign to what they observe (Fiske \& Taylor, 2008; Nickerson, 1998; Snyder \& Swann, 1978). As managers are likely to expect employees with whom they share high quality relationship to be less controversial, they are likely to view voice from such employees in a more benevolent or open manner. Furthermore, because people often assume others share their beliefs and viewpoints of reality (L. Ross, Greene, \& House, 1977), managers, who might perceive voice from a highLMX employee as less of a personal challenge to them, would think that others in the team are equally likely to perceive such voice as less problematic. Hence, managers likely expect that observers would share their benevolent interpretation of voice, which should reduce experiences of image threat even when it occurs in a public setting. That is, the close, trusting relationship might positively colour managers' evaluations of voice in a public setting. In contrast, because managers are more likely to perceive voice from low LMX employees as a challenge, they would think that others in the team are also likely to view such voice as a criticism. Hence, we hypothesize that managers perceive public voice from an employee with whom they share high quality LMX as a weaker threat to their social image due to their positively biased interpretations of acts of such employees, and, consequently, might not penalize their public voice with lower endorsement as opposed to similar voice expressed by an employee with whom they do not share such a relationship:

H5a: LMX moderates the positive relationship between employees' voice expressed in public (vs. private) settings and managers' image threat such that the relationship is weaker when LMX is higher.

H5b: LMX moderates the mediated relationship between employees' voice expressed in public (vs. private) settings and voice endorsement via managers' image threat such that this relationship is weaker when LMX is higher. 


\subsubsection{Alternative Explanation: Ego Threat}

Our primary argument is that managers more likely experience image threat when confronted with public voice and this leads them to endorse such voice less. Hence, image threat plays a primary explanatory role in our arguments. However, threat might come in other forms rather than merely as image threat. For instance, individuals have a desire to maintain a positive self-view which is related to, but distinct from, their desire to maintain a positive social image (Kluger \& DeNisi, 1996; Leary et al., 2009; Lievens, Van Hoye, \& Anseel, 2007). When one's positive self-view is threatened, one may experience what is called ego threat, or an internal or private sense of doubt about one's choices and selfworth. Germane to our discussion, voice, in general, can also elicit ego threat in managers because voice is a form of challenge to existing work practices that are presumably linked to managers' (in)action (Ashford et al., 2009; Fast et al., 2014). We propose that although voice can, irrespective of the social settings (i.e., public vs. private) in which it occurs, elicit self-doubts in managers about their own ability, image threat-or managers' concern about how they are coming across to others-is more likely to vary as a function of such social setting. That is, managers can be sensitive to negative information that may diminish their self-worth or self-esteem irrespective of whether this information becomes known to others (Leary, Barnes, Griebel, Mason, \& McCormack, 1987). By contrast, image threat arises when social presence of others is salient, even when the negative information presented to managers does not affect their self-evaluations (Leary et al., 2009). Thus, ego threat may be triggered by voice irrespective of whether this event is observed by others; whereas, image threat is likely triggered only when voice is publicly expressed. In our studies, we test our putative explanation (i.e., image threat) against alternative threat-based explanations (i.e., ego threat) to establish support for our conceptual model more firmly.

\subsection{Overview of Studies}

To enhance internal and external validity, we conducted three studies using different methodologies and populations. First, we conducted two experiments (Studies 1 \& 2) to progressively provide causal evidence for our model. In Study 1, conducted with undergraduate students, we manipulated a voice event to be public or private and examined its indirect effects on endorsement via manager's experience of image threat. In Study 2, conducted with an online panel of managers, we manipulated both the voice setting and LMX quality and examined our two competing hypotheses regarding the moderating effects of LMX quality on endorsement of publicly expressed voice via its influence on image treat. In Study 3, conducted with a sample of managers, we implemented an event-based 
recall study. This allowed us to replicate findings from Studies 1 and 2 with managers recalling actual voice situations at their workplace.

\subsection{Study 1: Method}

\subsubsection{Sample}

We recruited 122 undergraduate students from a Dutch university to participate in Study 1. We excluded nine participants due to incomplete data and ten participants due to insufficient effort responding (Huang et al., 2015). This resulted in a final sample of 103 participants (65\% female, 46\% German, 23\% Dutch, $M_{\text {age }}=21.29$ ).

\subsubsection{Procedure}

Scenario studies are especially appropriate when testing psychological processes on which participants can provide direct information (Aguinis \& Bradley, 2014; Greenberg \& Eskew, 1993). Following Aguinis and Bradley's (2014) suggestion to "provide participants with adequate contextual background when using a between-subjects design" (p. 361), we adapted a scenario study (Appendix A) from Sijbom and colleagues (2015b). We asked participants to imagine that they were the head of a marketing department in a company specializing in frozen fast food and responsible for planning the marketing strategy of the company and managing the work of the department's 12 employees. The company was about to introduce a new product called "Fat Free French Fries" and the campaign for the new fries was very important which meant the manager devoted considerable time and effort to develop it. To promote the product, the manager decided to use an event strategy, which involved advertising the healthy features of the French fries at various sporting events where customers had the opportunity to sample the product. We emphasized that the manager chose this strategy because it had been successfully implemented in the past, and that this success had helped the manager to advance to the position of department head.

Next, we described how, one day, an employee named Riley ${ }^{2}$ approached the manager to raise concerns about the event strategy and to propose an online strategy instead. Riley emphasized the weaknesses and possible risks associated with the event strategy and supported the arguments with market research findings. In particular, Riley suggested replacing the event strategy with an online strategy involving the advertisement of the product using online banners on social media because this approach should elicit more customer attention than the strategy developed by the manager. Because this was

\footnotetext{
${ }^{2}$ We used a unisex name to rule out a possible effect of employee's gender on voice endorsement (e.g., Howell et al., 2015).
} 
a challenging but constructive form of upward communication with intent to benefit the organization, this behaviour fits our conceptualization of voice.

Manipulation of voice setting. We randomly assigned participants to one of two setting conditions. In the private $(N=53)$ condition, we informed participants that Riley approached them privately to communicate the suggestions:

Suddenly, Riley, one of the employees, approached you and asked to privately speak to you, one-on-one, about your campaign. Alone in your office, Riley said privately...

In contrast, in the public condition $(\mathrm{N}=50)$ participants instead read:

Suddenly, Riley, one of the employees, approached you and publicly, in front of the other 11 employees in the open office space, spoke up about your campaign. With the other 11 employees listening, Riley said publicly...

To verify that our manipulation (private vs. public) worked as intended, we used a two-item measure (i.e., "Riley publicly spoke up about the marketing strategy in front of other employees" and "Riley spoke up about the marketing strategy privately to you, one-on-one" [reversed]; $\alpha=.97 ; 1$ = "Strongly Disagree" to 5 = "Strongly Agree") ${ }^{3}$. Supporting the efficacy of our manipulation, participants in the public condition rated the setting as more public $(\mathrm{M}=4.61, \mathrm{SD}=.63)$ than participants in the private condition ( $\mathrm{M}$ $=1.21, \mathrm{SD}=.42), F(1,101)=1060.66, p<.001$.

\subsubsection{Measures}

Image and ego threat. We assessed image threat using three items from Sijbom's (2015b) adapted version of image threat appraisal measure (i.e., "...hurts my status as a department head", "...creates doubts in others about my ability to come up with a successful marketing strategy", and "...undermines my position as a manager"; $\alpha=.84$ ). To differentiate image threat from ego threat, we measured participants' experience of ego threat by adapting three items from Tuckey et al.'s (2002) ego defence motive measure (i.e., "I would feel negatively towards myself", "I would doubt my own self-worth as a manager", and "I would feel confident in my ability to set the marketing strategy" [reversed]; 1 = "Not at all" to $5=$ "To a great extent"; $\alpha=.77$ ).

Managerial voice endorsement. We told participants that in two days they would have a meeting with the top management team where they were asked to present only one potential strategy for the marketing campaign. We operationalized endorsement through participants' choice between presenting their own strategy (coded as 0) and presenting the strategy suggested by Riley (coded as 1).

\footnotetext{
${ }^{3}$ Unless otherwise indicated, all measures reported in this paper included these response anchors.
} 


\subsection{Study 1: Results and Discussion}

We used bootstrapped OLS regression to test the effect of voice setting on image threat. Supporting Hypothesis 1, employee's voice in public (vs. private) setting was positively related to image threat $\left(B=1.04, S E=.14, p<.001, R^{2}=.34\right)$. Second, we used bootstrapped binary logistic regression to test the effect of image threat on voice endorsement. In support of Hypothesis 2, image threat was negatively related to endorsement ( $B$ $\left.=-.70, \mathrm{SE}=.41, p=.048, \mathrm{R}^{2}=.07\right)^{4}$. Finally, to test whether voice setting (private vs. public) affects endorsement indirectly through manager's image threat, we used the PROCESS SPSS macro (Model 4, Hayes, 2013). Supporting Hypothesis 3, the indirect effect of voice setting condition on endorsement via manager's image threat was significant (-.89 [SE = .47], 95\% Cl: -1.86, -.07). As expected, ego and image threat were positively correlated ( $r$ $=.32, p<.001)$. To rule out the alternative explanation of ego threat, we tested the effect of voice setting on ego threat. The effect of employee's voice in public (vs. private) setting on ego threat was not significant $\left(\mathrm{B}=.21, \mathrm{SE}=.14, p=.137, \mathrm{R}^{2}=.02\right)$. Furthermore, even after adding ego threat as a control, image threat continued to predict voice endorsement.

Study 1 suggested that voice setting indirectly affects voice endorsement via image threat. That is, when learning that the employee spoke up in public, putative managers experienced more image threat (Hypothesis 1), and, as a result, endorsed voice less frequently (Hypotheses 2 and 3). As expected, in contrast to image threat, ego threat did not vary across private versus public settings, thus supporting our theoretical arguments that it is not the general threat inherent in voice that explains our results but specifically the image threat induced by the social presence of others.

Although via Study 1, a scenario-based experiment, we were able to demonstrate causality in our base-line (unconditional) relationships, participants imagined a hypothetical employee with whom they had no relationship. This limits its external validity and did not allow us to test hypotheses relating to LMX (which is potentially best captured in the context of real relationships between the manager and the employee at work). Therefore, we conducted Study 2, which replicated Study 1, but utilized working managers in the context of their actual relationships with employees.

\footnotetext{
${ }^{4} R^{2}$ in this case refers to estimate of Cox and Snell R-square.
} 


\subsection{Study 2: Method}

\subsubsection{Sample}

We recruited 398 participants via Prolific Academic, a crowdsourcing online platform designed for academic research. Recent studies indicate that quality of responses on this platform is higher than those obtained on other online platforms such as Amazon Mechanical Turk (Peer, Brandimarte, Samat, \& Acquisti, 2017). As opposed to other online platforms, Prolific Academic allows pre-screening based on selected criteria. We utilized the direct reports criteria to recruit active managers who worked full time and had at least 2 direct reports. We excluded 18 participants who spent less than 30 seconds (vs. an average of 126 seconds) on our scenario, resulting in a final sample of 380 participants ( $62 \%$ male; Mage $=36.28$ [SD = 10.05]; 58\% from the United Kingdom and 41\% from the United States; $94 \%$ having a college degree or higher; number of direct reports: $59 \%-$ between 2 and $6,41 \%-7$ or more).

\subsubsection{Procedure}

We implemented a 2 (voice setting manipulation: private vs. public) $\times 2$ (LMX: low vs. high) between-subjects design. Voice setting (private [ $N=188]$ vs. public [ $N=192]$ ) was manipulated using the same materials as in Study 1. To manipulate LMX, following previous research (e.g., Sherf \& Venkataramani, 2015), before we presented the scenario, we asked participants to think of an employee with whom they currently work together or with whom they worked in the past. Participants provided the initials for this employee and we embedded these initials to appear in the scenario as the name of the voicing employee (i.e., replacing "Riley" in Appendix A). We instructed the participants to take into account their real relationship with the employee when imagining the situation. Importantly, we manipulated LMX through the instructions so that in the low LMX condition $(N=187)$, we asked them to think about:

Someone whom you do (or did) NOT professionally trust or respect enough to have a close personal or working relationship with.

In contrast, in the high LMX condition ( $N=193)$, we instructed them to think about:

Someone whom you professionally trust(ed) and respect(ed) very much and have (had) a close personal or working relationship with.

This approach allowed us to capture and manipulate LMX, which can be especially difficult to represent outside real relationships at work, while still retaining the advantages of an (quasi) experimental set-up in which we could manipulate our other independent variable. 
Manipulation checks. To verify that the voice setting manipulation worked, we used the same two-item measure as in Study $1(\alpha=.99)$. As expected, participants in the public condition rated the setting as more public $(M=4.76, S D=.66)$ than did participants in the private condition ( $M=1.24, S D=.57), F(1,376)=3,061.50, p<.001$. Our LMX manipulation did not affect the extent to which participants perceived the setting as public versus private, $F(1,376)=.14, p=.710$. To establish that our LMX manipulation worked as intended we used the LMX-7 measure (Graen \& Uhl-Bien, 1995). Managers rated these items using a 7-point Likert scale ( 1 = "Strongly Disagree" to 7 = "Strongly Agree"). As expected, participants in the high LMX condition $(M=5.95, S D=.61)$ evaluated quality of the relationships with the employee more positively than did participants in the low LMX condition ( $M=4.16, \mathrm{SD}=1.03), F(1,376)=427.04, p<.001$. Our voice setting manipulation did not affect the $L M X$ ratings, $F(1,376)=1.08, p=.299$. These results indicate that our manipulations worked as intended.

\subsubsection{Measures}

Image and ego threat. We used the same 3-item measures of image $(\alpha=.88$ ) and ego ( $\alpha$ $=.80$ ) threat as in Study 1 ( 1 = "Strongly Disagree" to 7 = "Strongly Agree").

Managerial voice endorsement. We used the same measure of managerial endorsement as in Study 1, that is, that participants would present the employee's strategy to top management, not their own strategy. Additionally, we also asked participants to allocate a budget of $\$ 70,000$ per month between their strategy and the one suggested by the employee. This measure aligns with our conceptualization of endorsement as involving support to higher management and allocating resources to implement suggestions. We used the amount participants allocated to the employee's strategy as a support measure of endorsement. As there is no correct amount, this helps reduce socially desirability concerns, especially in between-person designs (Folger \& Skarlicki, 1998). The two measures of voice endorsement were strongly positively correlated with one another $(r$ $=.69, p<.001)$.

\subsection{Study 2: Results and Discussion}

As seen in Table 3.1, which displays the results of our bootstrapped moderated OLS regression analysis, supporting Hypothesis 1, participants in the public condition indicated more image threat as compared with those in the private condition $(B=1.43, p<.001)$. Furthermore, image threat was negatively related to both choice endorsement $(B=-.27$, $p=.003$ ) and budget endorsement measures ( $B=-1868.42, p=.005)$, supporting Hypothesis 2. To examine whether voice setting (private vs. public) impacts endorsement indirectly through manager's image threat we used the SPSS PROCESS macro (Hayes, 2013). 
The unconditional indirect effect of employee's voice in public (vs. private) on choice endorsement via manager's image threat was significant (-.45 [SE = .14], 95\% Cl: - .75, -.20). Also, the unconditional indirect effect of employee's voice in public (vs. private) on the budget endorsement measure via image threat was significant (-3351.19 [SE = 977.55], 95\% Cl: $-5451.37,-1540.61)$. These results support Hypothesis 3. The interaction between voice setting and $L M X$ conditions on image threat was significant $(B=-.52, p=.047)$. We plotted this interaction in Figure 3.2. Simple slopes analysis supported Hypothesis 5 a (but not 4 a) suggesting that when LMX was high the relationship between voice setting and image threat was weaker $(B=1.17, p<.001$ ) as compared to the same relationship when LMX was low $(B=1.69, p<.001)$.

To test our overall model, we estimated how the indirect effect of voice setting on endorsement via image threat varied across different levels of LMX using the SPSS PROCESS macro (Hayes, 2013). Results supported Hypothesis 5b (but not 4b) as the indirect effect of voice setting on manager's choice to present the employee's strategy was weaker when LMX was high (-.37 [SE = .12], 95\% Cl: - .65, -.17) as compared to when LMX was low $(-.53$ [SE $=.17$ ], 95\% Cl: $-.89,-.24)$. The index of moderated mediation (Hayes, 2013 ) indicated that the difference between the indirect effects at high and low LMX was significant (.17 [SE = .11], 95\% Cl: .01, .43). Similar results were revealed for the allocation of funds to the employee's suggested plan. In particular, the indirect effect was weaker when LMX was high $(-2763.58$ [SE $=896.97$ ], 95\% Cl: $-4873.78,-1261.52)$ as compared to when LMX was low $(-3998.87$ [SE = 1149.03], 95\% Cl: -6335.43, -1819.48). The index of moderated mediation (Hayes, 2013) indicated that the difference between the indirect effects at high and low levels of LMX was significant (1235.29 [SE = 737.39], 95\% Cl: 98.55, 3012.40).

As expected, ego and image threat were positively correlated $(r=.31, p<.001)$. To again rule out the alternative explanation of ego threat, we tested the effect of voice setting on ego threat. This effect was not significant $(\mathrm{B}=-.004, \mathrm{SE}=.08, p=.960)$. Also, the interaction term for voice in public (vs. private) and LMX on ego threat was not significant ( $\mathrm{B}=.09, \mathrm{SE}=.17, p=.587$ ). Even after adding ego threat as a control, image threat continued to significantly predict voice endorsement.

Results of Study 2 suggested again that managers experience more image threat as a function of publicly expressed voice. Furthermore, using two different forms of operationalization of voice endorsement, we found that image threat explains the effects of the setting in which voice is enacted (private vs. public) on voice endorsement. Additionally, the study provided support for the role of LMX as threat buffer - that is, it suggested support for a "threat as a judgment" perspective rather than for a "social expectation of loyalty" perspective. In support of Hypotheses 5a and 5b (but not 4a and 4b), the effect of a public setting on image threat was weakened when LMX quality with the voicing employee was higher. Together, Studies 1 and 2 provide internally valid evidence for our 
model. Furthermore, as expected, in contrast to image threat, ego threat did not vary across private versus public settings or as a function of $L M X$, supporting our theoretical arguments that image (but not ego) threat is a unique mechanism explaining the effect of social setting on voice endorsement. 


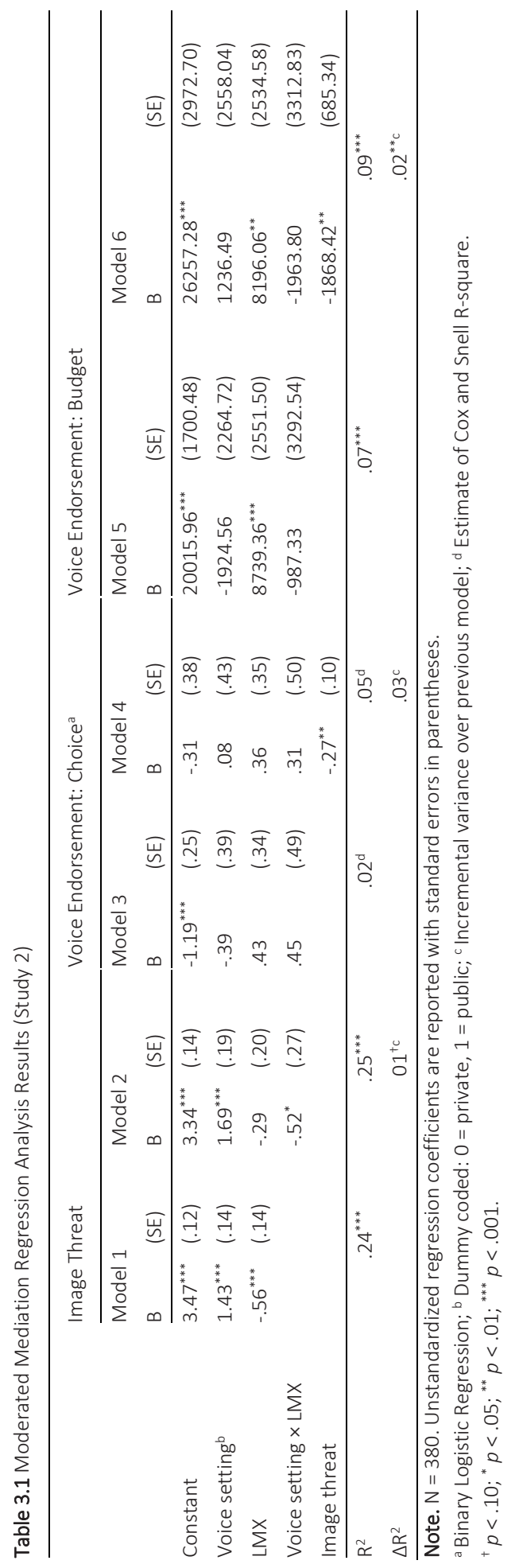




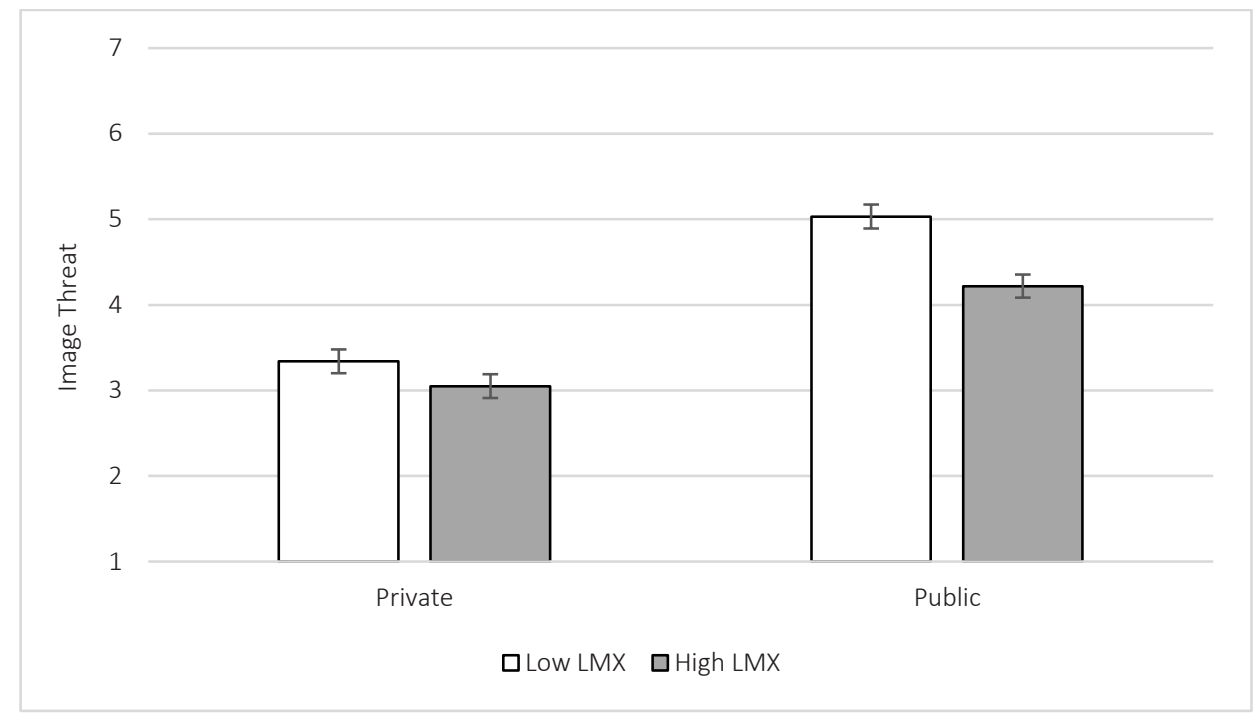

Figure 3.2 Interaction effect of voice setting and LMX on image threat (Study 2). Error bars indicate one standard error above and below the mean.

Although the use of a scenario-based experimental methodology provides control and thereby allows for greater internal validity, it might limit the external validity of our findings (Aguinis \& Bradley, 2014). In this context, research does suggest that people can imagine and experience threats from hypothetical situations involving receiving negative feedback and that responses to such hypothetical threats are similar to responses to threats in a real-life context (Gurmankin, Baron, \& Armstrong, 2004a, 2004b; Sedikides \& Green, 2004). However, it is entirely possible that participants (as managers) might not have felt as defensive merely by reading about a hypothetical voice situation (involving their putative employee) as they would when they have to react to publicly expressed voice in a real-life work context. To address this limitation, we conducted Study 3.

\subsection{Study 3: Method}

\subsubsection{Procedure}

We recruited managers to participate in Study 3 from a variety of industries in the Netherlands and Germany (e.g., industrial sector, retail and wholesale, healthcare, financial services) using a snowball sampling approach (e.g., Mitchell, Vogel, \& Folger, 2015). A recent meta-analysis has suggested that such samples are comparable to organizational 
samples (Wheeler, Shanine, Leon, \& Whitman, 2014). The research team contacted managers through personal networks to invite them to participate in a study on the role of leadership in facilitating open communication at the workplace. As a guideline, only respondents who held a formal managerial role and had some supervision experience were approached. We recruited participants in two stages. First, we sent potential participants an introductory letter, to explain the study's purpose and assure confidentiality. In return, we promised participants a report on the main study results including some advice on how to foster open communication. We directly sent a link with the survey to 250 managers who consented to participate. One month after, we sent out a reminder to managers who did not complete the survey. The survey was conducted in English.

Given that our research interest was in setting-specific reactions of managers (i.e., reactions towards voice in private vs. public), we used the event reconstruction method (ERM) developed by Grube and colleagues (2008). ERM is based on a general reconstruction approach (Kahneman, Krueger, Schkade, Schwarz, \& Stone, 2004) and implies explicit vivid re-experiencing of the specific job events from the past (Grube et al., 2008). We instructed managers to recall the very last time that one of their employees communicated "ideas, suggestions, concerns, information about problems, or opinions about workrelated issues." To make the recall task vivid, we asked managers to indicate when and where the voice event took place. Such recall cues activate access to episodic memory which reduces self-report and retrospection biases and facilitates re-experiencing thoughts and feelings associated with a specific event (Dinh \& Lord, 2012; Grube et al., 2008; lida, Shrout, Laurenceau, \& Bolger, 2012; Reis \& Judd, 2000). After managers reported about events, we asked them to complete measures on the focal variables and demographics, including the gender of the employees from the voice event ( $62 \%$ female).

\subsubsection{Sample}

Overall, 120 managers completed our survey, out of which we excluded ten participants due to incomplete data on focal variables. In addition, we removed three participants from the subsequent analysis as they provided conflicting responses (i.e., they indicated that the voice event was both private and public). This resulted in a final sample of 107 managers ( $58 \%$ male, $M_{\text {age }}=43.00$ years, Morganizational tenure $=11.00$ years, $M_{\text {work experience }}=$ 19.56 years, $M_{\text {number of employees }}=14.43$ employees $)$.

\subsubsection{Measures}

Voice setting. To the best of our knowledge, no measure existed to assess whether a certain event occurred in a private versus public setting, and most previous organizational research manipulated rather than measured private versus public setting as part of laboratory experiments (Ashford \& Northcraft, 1992; Hornsey, Frederiks, Smith, \& Ford, 
2007). We therefore assessed voice setting in multiple ways. First, we asked managers "How many people overall (besides you) heard the communication by your subordinate?" Responses ranged from 0 to $26,(M=2.07 ; S D=3.66)$. We dummy coded " 0 " responses as 0 and all other responses (i.e., $\geq$ " 1 ") as 1 . Second, we asked managers to indicate who else heard the communication, providing them with the following options: "a superior," "another employee," "another peer," "a client/customer," "another person," and "nobody." We dummy coded the responses with "nobody" as 0 and the other five options as 1. As mentioned earlier, three cases were excluded because these managers provided conflicting information regarding these two questions on the setting of voice.

Image and ego threat. To measure image and ego threat, we adapted Tuckey et al.'s (2002) 8-item measure of the defensive impression management motive scale (e.g., "During the communication episode I was concerned about my colleagues hearing the content of the suggestions and concerns I received" and "During the communication episode I was not concerned about what my colleagues would think of me" [reversed] ; $\alpha=.81 ; 1$ = "Extremely untrue" to $5=$ "Extremely true") and 8-item measure of ego defence motive scale (e.g., "During the communication episode it was hard to feel good about myself" and "During the communication episode it didn't really lower my self-worth [reversed]"; $\alpha=.85 ; 1$ = "Extremely untrue" to 5 = "Extremely true").

LMX. Participants rated LMX with their employees using the LMX-7 (Graen \& UhI-Bien, 1995). A sample item was: "What are the chances that you would use your power to help your subordinate solve problems in his/her work?" ( $\alpha=.78)$.

Endorsement. To assess voice endorsement, we asked managers to think of the event they described and, referring to it, respond to a 5-item endorsement measure developed by Burris (2012). A sample item was: "I supported (I am planning to support) this subordinate's comments" ( $\alpha=.95)$.

Control variables. We included several measures as controls to remove the influences of other factors related to voice endorsement. First, as male and female managers might differently judge ideas raised by their male and female employees due to possible gender biases (Howell et al., 2015), we controlled for manager and employee gender. Second, managers with low levels of self-efficacy are more aversive toward employee voice (Fast et al., 2014), which can result in experience of threat and lower endorsement. Therefore, we controlled for managerial self-efficacy using Chen, Gully, and Eden's (2001) 8-item general self-efficacy measure. Our results, however, were unaffected by these control variables and we present our results without control variables (Spector \& Brannick, 2011). ${ }^{5}$

\footnotetext{
${ }^{5}$ We assessed the distinctiveness of the five variables (voice setting, LMX, image threat, ego threat, and endorsement). For image and ego threat as well as LMX, we calculated item-parcels such that 3 indicators represented each factor (Landis et al., 2000). Analysis indicated that the five-factor model fit the data well $\left(\chi^{2}=90.08\right.$, $d f=81, p<.001, \mathrm{CFI}=.99, \mathrm{RMSEA}=.03, \mathrm{SRMR}=.05)$. Chi-square difference tests indicated that this model fit
} 


\subsection{Study 3: Results and Discussion}

Table 3.2 displays descriptive statistics and correlations for the focal variables. As seen in Table 3.3, which presents the results of our bootstrapped moderated mediation regression analysis, supporting Hypotheses 1 , managers reported more image threat when employees spoke up in public as compared to in private $(B=.24, p=.047$; Table 3.3 , Model 1). Furthermore, supporting Hypothesis 2 , image threat was negatively related to voice endorsement ( $B=-.36, p=.002$, Table 3.3, Model 4). To examine the indirect effect of voice setting on endorsement through manager's image threat, we used the SPSS PROCESS macro (Hayes, 2013). The unconditional indirect effect of employee's voice in public (vs. private) on endorsement via manager's image threat was significant (-.17 [SE = .10], 95\% Cl: -.40, -.02). Thus, Hypothesis 3 was supported. Moreover, a significant interaction between voice setting and $L M X$ on image threat emerged $(B=-.51, p=.016$; Table 3.3, Model 2). We plotted the interaction in Figure 3.3. Similar to the results of Study 2, in support of Hypothesis 5 a and contrary to Hypothesis 4a, simple slopes analysis suggested that when LMX was low manager's image threat was higher when voice was communicated in public versus private $(-1 S D ; B=.50, p=.004)$ but such differences between private and public settings did not emerge when LMX was high (+1SD; $B=-.02, p=.931)$.

Table 3.2 Descriptive Statistics, Correlations, and Reliabilities (Study 3)

\begin{tabular}{lllllll}
\hline & $M$ & $S D$ & 1 & 2 & 3 & 4 \\
\hline 1. Voice settinga & 0.51 & 0.50 & - & & & \\
2. Image threat & 2.53 & 0.73 & $.19^{*}$ & $(.81)$ & & \\
3. LMX & 3.83 & 0.51 & -.05 & $-.52^{* *}$ & $(.78)$ & \\
4. Voice endorsement & 3.78 & 0.87 & -.03 & $-.50^{* *}$ & $.60^{* *}$ & $(.95)$ \\
\hline
\end{tabular}

Note. $\mathrm{N}=107$. Numbers in parentheses along the diagonal are Cronbach's alphas.

a Dummy coded: 0 = private, 1 = public.

${ }^{*} p<.05 ;{ }^{* *} p<.01$.

the data better than alternative models that combined (a) image threat and ego threat $\left(\Delta \chi^{2}=32.29, \Delta d f=1, p\right.$ $<.001, \mathrm{CFI}=.96, \mathrm{RMSEA}=.07, \mathrm{SRMR}=.06)$, (b) image threat and endorsement $\left(\Delta \chi^{2}=61.66, \Delta d f=1, p<.001\right.$, $\mathrm{CFI}=.93, \mathrm{RMSEA}=.09, \mathrm{SRMR}=.08)$, and $(\mathrm{c}) \mathrm{LMX}$ and endorsement $\left(\Delta \chi^{2}=60.30, \Delta d f=1, p<.001, \mathrm{CFI}=.93\right.$, RMSEA $=.09, \mathrm{SRMR}=.08)$. This supports the discriminant validity of our measures. 
Table 3.3 Moderated Mediation Regression Analysis Results (Study 3)

\begin{tabular}{|c|c|c|c|c|c|c|c|c|}
\hline & \multicolumn{4}{|c|}{ Image Threat } & \multicolumn{4}{|c|}{ Voice Endorsement } \\
\hline & \multicolumn{2}{|c|}{ Model 1} & \multicolumn{2}{|c|}{ Model 2} & \multicolumn{2}{|c|}{ Model 3} & \multicolumn{2}{|c|}{ Model 4} \\
\hline & B & (SE) & B & (SE) & B & (SE) & B & (SE) \\
\hline Constant & $2.41^{* * *}$ & $(.08)$ & $2.40^{* * *}$ & $(.08)$ & $3.78^{* * *}$ & $(.10)$ & $3.73^{* * *}$ & $(.10)$ \\
\hline Voice setting $^{\mathrm{a}}$ & $.24^{*}$ & $(.12)$ & $.24^{*}$ & $(.12)$ & .00 & $(.14)$ & .09 & (.13) \\
\hline LMX & $-.74^{* * *}$ & $(.11)$ & $-.44^{* *}$ & $(.15)$ & $1.13^{* * *}$ & $(.24)$ & $.97^{* * *}$ & $(.26)$ \\
\hline Voice setting $\times \operatorname{LMX}$ & & & $-.51^{*}$ & $(.21)$ & -.18 & $(.31)$ & -.36 & (.30) \\
\hline Image threat & & & & & & & $-.36^{* *}$ & $(.11)$ \\
\hline$R^{2}$ & & $30^{* * *}$ & & $.33^{* * *}$ & & $.36^{* * *}$ & & $42^{* * *}$ \\
\hline$\Delta \mathrm{R}^{2}$ & & & & $.03^{* b}$ & & & & $06^{* * b}$ \\
\hline
\end{tabular}

Note. $\mathrm{N}=107$. Unstandardized regression coefficients are reported with standard errors in parentheses. All predictors were centered prior to analysis.

${ }^{\text {a }}$ Dummy coded: 0 = private, 1 = public; ${ }^{b}$ Incremental variance over previous model.

${ }^{*} p<.05 ;{ }^{* *} p<.01 ;{ }^{* * *} p<.001$.

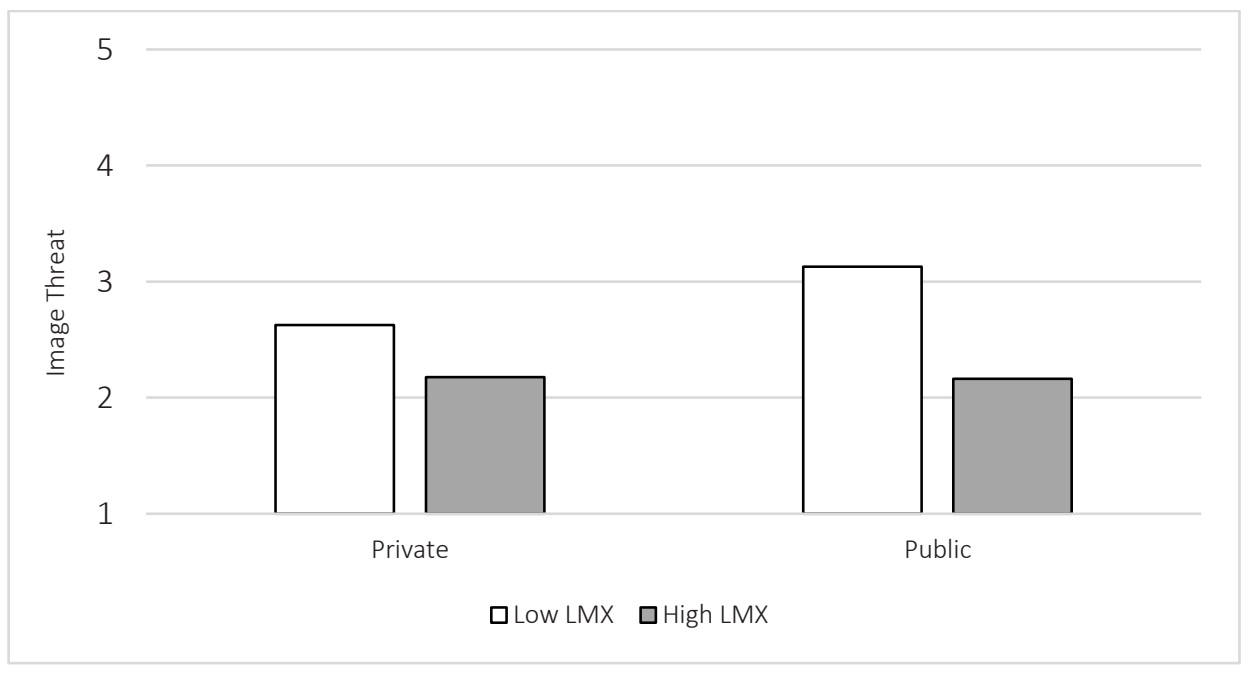

Figure 3.3 Interaction effect of voice setting and LMX on image threat (Study 3). High and low levels of LMX represent one standard deviation above and below the mean.

To test the overall model, we utilized the SPSS PROCESS macro (Hayes, 2013) and estimated how the indirect effect of voice setting on endorsement (via manager's image threat) varied across different levels of LMX. The indirect effect was not significant when LMX was high (+1SD, .01 [SE = .10], 95\% Cl: -.21, .19) but was negative when LMX was low 
(-1SD, -.31 [SE = .12], 95\% Cl: -.59, -.12). We calculated the index of moderated mediation (Hayes, 2013) which suggested that the difference between the indirect effects at high and low levels of LMX was significant (.31 [SE = .13], 95\% Cl: .09, .62). Thus, Hypothesis $5 b$, but not $4 b$, was supported.

As expected, ego and image threat were positively correlated $(r=.56, p<.001)$. To again rule out the alternative explanation of ego threat, we tested the effect of voice setting on ego threat. This effect was not significant ( $\mathrm{B}=.11, \mathrm{SE}=.12, p=.347$ ). Also, the interaction term for voice in public (vs. private) and LMX on ego threat was not significant ( $\mathrm{B}=-.35, \mathrm{SE}=.25, p=.162)$. After adding ego threat as a control, image threat continued to significantly predict voice endorsement.

The results of Study 3, conducted with working managers recalling actual voice events, were consistent with Studies 1 and 2. Employee voice in public (vs. private) settings was associated with a stronger experience of image threat. Manager's image threat, in turn, was related to lower levels of voice endorsement. Finally, LMX acted as threat buffer - that is, our findings support a "threat as a judgment" perspective rather than a "social expectation of loyalty" perspective. Specifically, the indirect negative effect of employee's public voice on endorsement via image threat was significant when LMX was low as compared to when it was high. Moreover, ego threat, in contrast to image threat, did not vary across public versus private settings, supporting our arguments that image threat is a unique explanatory variable for the effects induced by the social presence of others.

\subsection{General Discussion}

We explored whether and when the setting in which voice is expressed influences voice endorsement by managers. We theorized and found that managers' endorsement of voice differs depending on whether voice is communicated in a public versus private setting. In particular, public setting increased the likelihood that voice will be associated with image threat, and, consequently, with reduced managerial endorsement of such voice. Furthermore, our findings indicated that managers felt less of a threat to their image as a consequence of public voice when they had a high quality LMX with the voicing employee. Our paper makes a number of theoretical contributions.

\subsubsection{Theoretical Contributions}

Challenging assumptions about managerial endorsement of voice. Managers play an important role as linking pins in organizations, connecting frontline employees with upper management. Therefore, delineation of the conditions under which they endorse em- 
ployees' ideas, suggestions, and concerns can have important implications for organizational success (Morrison, 2014). Emerging research on the topic has primarily focused on the attributes of the receivers (managers) or the senders (employees) - that is, "who" is involved in the voice event, and the message (content of voice) - that is, "what" is being communicated (Burris, 2012; Fast et al., 2014; Sijbom et al., 2015a, 2015b). Hence, implicitly, this line of research ignores the possibility that situational features can also shape managerial endorsement of voice. Drawing on prior literature suggesting that behaviours and reactions can change when settings are public as opposed to private (Ashford et al., 2003; Markus, 1978; Platania \& Moran, 2001; Uziel, 2007), we argue that by examining "where" - that is, in which social setting-voice events occur, the psychology of managers' voice aversion can be understood in theoretically novel ways.

Research has noted that behaviours and reactions can change when settings are public as opposed to private (Ashford et al., 2003; Markus, 1978; Platania \& Moran, 2001; Uziel, 2007). Consistent with this work, our theory and findings suggest that the social setting in which voice occurs can affect managerial reactions to it. In our studies, voice that was communicated in public was endorsed less by managers than voice communicated in private. These findings empirically support lay theories people often hold about how managers do not like to be challenged or receive bad news in front of other people and prefer to have employees discuss these issues with them in private (Detert \& Edmondson, 2011).

Although we focused on endorsement, the impact of employees' voice on other work outcomes has been inconsistent. Whereas some studies indicate that voice is positively associated with managers' evaluation of employees (Whiting et al., 2012, 2008), other studies indicate voice has negative personal outcomes for employees (Seibert et al., 2001). One possible explanation for this is that prior research treated voice expressed in private and public settings similarly. Our studies indicate that, because of the image threatening nature of public voice, it might lead to outcomes that are more negative. We urge future research to consider how the social setting affects personal and organizational outcomes of voice.

Distinguishing image threat from ego threat. Our studies also delineate image threat, not ego threat, as the unique mechanism underlying our findings (Ashford et al., 2009). Although prior research has relied on a threat-based logic to explain managers' aversion to voice (e.g., Burris, 2012; Fast et al., 2014), it has not always articulated how voice can elicit differentiated forms of threat appraisal. Although voice, irrespective of "where" it is expressed, can possibly elicit ego threat or self-doubts in managers, we argue that when it is expressed publicly, it uniquely triggers managerial concerns about social image. Potential solutions to reducing ego threat (e.g., self-affirmation interventions; e.g., Fast et al., 2014) are likely distinct from potential solutions to reducing image threat (e.g., 
creating organizational conditions where managers feel that it is normative and not unusual for people to challenge each other publicly and that such circumstances are not socially negatively evaluated). Not surprisingly, given such practical implications, there have been recent calls in the social psychology literature to conceptually and empirically distinguish between these two forms of threat (Leary et al., 2009), which we answer via our studies.

$L M X$ and managerial reactions to voice. A growing line of research delineates the role that close relationships play in managerial reactions to voice (e.g., Burris et al., 2009). We contribute to this line of scholarship by testing two competing predictions about how LMX affects image threats elicited by public voice. Our findings indicate a buffering account of LMX (rather than an enhancing one) and suggest that high LMX relationships may mitigate image concerns associated with voice expressed in the presence of others. That is, our results provide support for a "threat as a judgment" perspective rather than for a "social expectation of loyalty" perspective. This highlights how public expressions of voice by in-group members may not be perceived by managers as strong violations of loyalty and mutual support expectations, but instead might be perceived as less threating to their social status. In line with our findings, prior research has indicated that employees having high quality relationships with their managers have a stronger sense of psychological safety and, as a result, are less concerned that their voice might be perceived as a threat by managers (Liu et al., 2017). We complement such studies by highlighting that high LMX with the voicing employee colours managerial evaluation of possible image threats associated with voice in public settings. Our study thus emphasizes the need for a dyadic level of analysis to account for relationship quality between managers and employees when studying managerial reactions to voice.

Although we did not find support for the competing prediction that publicly expressed voice from high LMX employees enhances managers' image threat, we do not preclude the possibility that, under certain conditions, this prediction may still hold. One possible reason for why we found that high LMX buffers image threats evoked by public voice could have to do with the characteristics of the audience in the reported voice events in our studies. For instance, managers might perceive publicly expressed voice from ingroup members more negatively when it is communicated in front of audiences with higher status (e.g., managers' peers or skip-level managers). Given that we did not directly measure or manipulate such audience characteristics, it would be useful for future research to continue testing the complex ways in which LMX might influence managerial reactions to public voice. 


\subsubsection{Limitations}

Our studies have several limitations. For instance, although our scenario studies (i.e., Studies 1 and 2) provide internal validity, their psychological realism is constrained. However, previous research suggests that people imagining such hypothetical events are able to accurately report on psychological states such as threat, and thus findings from such studies tend to generalize and replicate findings from studies conducted in a real-life context (Gurmankin et al., 2004a, 2004b; Sedikides \& Green, 2004). Additionally, we tried to leverage managers' existing relationships to make the experience of LMX more realistic in Study 2. Furthermore, Study 3 was cross-sectional. Future research can supplement our current package of studies by employing lagged designs that help better establish causality in real work settings.

In addition, findings from Study 3 might have been affected by common method bias because all of our variables were reported by managers (Podsakoff, MacKenzie, Lee, \& Podsakoff, 2003). Although we acknowledge this as a potential limitation, we believe that the only relationship that might have been affected by common method bias is the effect of manager's image threat on voice endorsement as interaction effects are robust to common-method bias (Siemsen, Roth, \& Oliveira, 2010). Furthermore, we should note that our decision to design Study 3 in this way was deliberate, as we believed that managers were the most reliable and precise source for our variables. Specifically, only managers could report their experience of image and ego threat, and the extent to which they endorsed or planned to endorse employees' suggestions (cf., Chan, 2009). Moreover, it was important to get managers' evaluation of LMX as our theory focused on managers' perceptions of the quality of the relationship (see Sin, Nahrgang, \& Morgeson, 2009). However, future research should explore other ways to capture some of the key variables, perhaps relying on more objective criteria for endorsement, which could reduce concerns about common method bias. Despite the above limitations of each of our studies, we believe that as a whole, they provide strong evidence to support our theoretical arguments. The fact that our findings were consistent, across populations and methods, increases the confidence in our results.

\subsubsection{Directions for Future Research}

Our study provides several opportunities for future research. First, our studies examined managerial reactions to a single voice episode. Managers' reactions to voice might vary based on whether an employee consistently brings up issues in the public or whether he or she does so infrequently. Future research should investigate how, over time, employees' tendency to raise issues publicly versus privately influences their ability to gain managerial endorsement for their ideas or concerns. 
Second, in this paper we conceptualized the distinction between private and public voice setting as binary variable based on number of people present during voice events. However, in reality the extent to which people view a setting as public may depend on who is present in the audience. In particular, when managers do not trust the audience then the setting is likely to be perceived as more public. Furthermore, an audience including managers' peers and employees might be perceived differently than an audience including managers' supervisors. All these factors may have implications on how managers react to voice in such settings. For example, managers in particular do not want to receive critical comments or bad news in the presence of their own supervisors (Detert \& Edmondson, 2011). Thus, we encourage researchers to examine the various aspects of public versus private voice setting and to examine how these aspects may moderate managerial reactions to voice.

Third, though we delineated image threat as an underlying psychological mechanism explaining the link between public voice setting and endorsement, it is also possible that there are other pathways. Earlier research on issue-selling has suggested that ideas communicated in public are more likely to be endorsed by managers than ideas communicated in private because in the presence of other people managers experience higher pressure to display responsiveness and consider employee's input (Dutton \& Ashford, 1993). We do not discount the possibility that a manager's sense of accountability could be an alternative pathway though which an employee's voice in public (vs. private) relates to managers' voice endorsement. Thus, it is possible that a manager's image threat and accountability may act as two mediators that lead to two opposing effects of public voice social setting on endorsement. Future studies should simultaneously examine image threat and accountability as to further extend our understanding of the effects of public voice setting. Furthermore, it is possible that when employees express voice in public, managers are more likely to attribute to such employees pro-self rather than prosocial intentions. Because when managers attribute more benign intentions to voicing employees, they react more favourably to provided input (Grant, Parker, \& Collins, 2009; T. Kim et al., 2009; Maynes \& Podsakoff, 2014; Whiting et al., 2012), as a result, such attributions can affect voice endorsement. Thus, future studies should explore these putative mediating mechanisms.

\subsubsection{Managerial Implications}

Our findings suggest that managers should be aware that their reactions to upward voice might depend on the setting in which it was communicated. To reduce the influence that the setting has on managerial reactions to voice, organizations can highlight to managers and employees that voicing in private as well as in public is welcomed and considered normative. This can potentially reduce managers' image concerns when employees do 
speak up in public and encourage managers to facilitate open airing of differing perspectives from their employees that prevents issues from remaining marginalized or lost to one-on-one private settings. Furthermore, managers need to be aware that their reactions to voice can be coloured by the quality of their relationships with employees. Managers may ignore and not promote constructive ideas and suggestions from employees who are not part of their in-group but express their voice in public. Finally, employees should be cognizant that, in certain circumstances, they can be more successful in gaining managerial endorsement by expressing their ideas, opinions, or concerns in private rather than in the presence of other people.

\subsubsection{Conclusion}

When an employee voices in public, managers experience image threat and endorse such voice to a lower extent. These relationships become weaker when the employee and the manager share a high LMX relationship. We highlight the importance of examining the social setting in which voice is expressed and hope that our findings will stimulate further research on how situational factors influence managerial endorsement of voice. 

Chapter

\section{When Do Employees Speak Up Publicly: The Role of Manager Self-Efficacy and Leader- Member Exchange}





\subsection{Introduction}

Organizational leaders may greatly benefit from having employees who approach them with suggestions or concerns on work-related issues. This is because frontline employees, due to their unique position in the organization, hold intimate knowledge about day-today processes and practices that managers cannot observe (Edmondson, 1996). Thus, employees' improvement-oriented upward voice - that is, the expression of constructive ideas, opinions, or concerns about work-related issues (Morrison, 2014) - helps organizational leaders to promptly respond to unexpected changes, detect hidden problems, identify emerging opportunities, and enhance learning (Edmondson, 1996, 2003; Milliken et al., 2003; Weick \& Sutcliffe, 2001).

However, voice implies a challenge to the status quo (Van Dyne \& LePine, 1998) and therefore is risky for employees. Managers often misread employee voice as a personal criticism to their own performance and, consequently, may react aversely (Milliken et al., 2003). Existing literature suggests that to avoid negative reactions, employees assess the riskiness of voice and based on that, decide to either speak up or remain silent (see Morrison, 2014). We challenge this perspective by arguing that employees mitigate such potential risks by also carefully adjusting their voice tactics.

In particular, voice can be carried out in public or private settings. The larger (smaller) the number of people present when an employee speaks up, the more public (private) the voice setting is ${ }^{6}$. We argue that it is riskier for employees to express voice in public settings as compared to private settings, because in the presence of others employees are more likely to evoke in managers image-related concerns, which may cause more defensive reactions (Detert \& Edmondson, 2006, 2011). At the same time, public voice may have benefits not present in private voice. For example, public voice creates opportunities for more in-depth discussions as involving more people is likely to supply a greater variety of solutions (V. R. Brown \& Paulus, 2002; Mesmer-Magnus \& DeChurch, 2009; Paulus, Levine, Brown, Minai, \& Doboli, 2010), which are often lost in private closed-door meetings. We thus believe that because of the risks as well as potential benefits associated with public voice, employees in general would try to "read the wind" and carefully consider the setting in which to voice. But how do employees read the windbased on what factors do employees decide in which setting to express voice?

We draw on previous research which suggests that managers' self-efficacy, which is one's belief about one's ability to perform well on specific tasks (Bandura, 1977), provides employees with social cues about managers' responsiveness to voice (Fast et al., 2014). The less managers believe that they are capable to meet expectations associated with

\footnotetext{
${ }^{6}$ Hence, in this paper we treat public-private voice as a continuum ranging from no people present (i.e., besides the voicer and the manager; i.e., private voice) to a relatively large number of people present during a particular voice event (i.e., public voice).
} 
their managerial role, the less they are responsive to employee input and the more averse they might be to voice (Fast et al., 2014). We expect employees to rely on cues that managers send when deciding in which setting to voice their ideas, suggestions, or concerns. In particular, employees should be less worried about speaking up in public towards managers with high self-efficacy, as these managers are more likely to send signals suggesting that voice is welcomed. In contrast, managers who send defensive cues, grounded in low managerial self-efficacy, are prone to discourage employees from expressing voice in public settings. As a result, employees will be more likely to choose a relatively low-risk voice tactic and thus speak up in more private settings. Furthermore, as existing research suggests that leader-member exchange (LMX) quality affects employee voice behaviour (e.g., Liu et al., 2015, 2017; Liu, Tangirala, \& Ramanujam, 2013), we integrate both literatures. To this end, we develop and test two competing hypotheses contrasting how LMX quality affects the extent to which employees rely on social cues associated with their managers' self-efficacy when choosing the setting in which to express voice. Figure 4.1 illustrates our conceptual model.

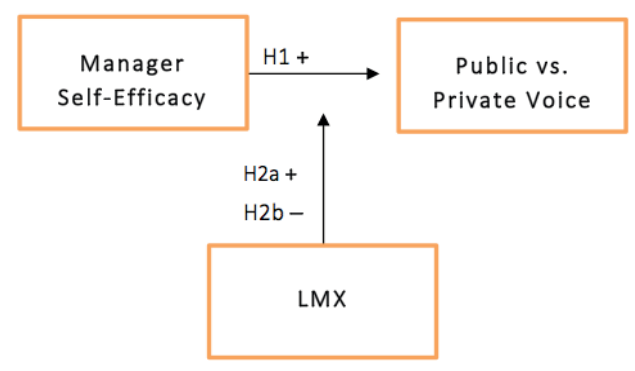

Figure 4.1 Proposed moderation model

We make several theoretical contributions to the voice literature. First, extant literature suggests that when employees have ideas, suggestions, or concerns, they have a binary choice to either speak up or remain silent (see Morrison, 2014). We challenge this view by arguing that employees can and often do choose from a wider repertoire of voice tactics, including whether to engage in more public (vs. private) voice. Thus, we underscore how voice research can enhance conceptual precision by studying not only employee voice frequency but also voice tactics (Morrison, 2011).

Second, we add to the existing voice research by studying managerial self-efficacy as a predictor of employees' preference to voice in more public (vs. private) settings. It is well known that manager self-efficacy influences employee voice behaviour (Fast et al., 2014). Prior research, however, has not examined its impact on employee voice tactics. 
We thus contribute to the nascent literature on manager self-efficacy and voice by highlighting that when managers' self-efficacy is low, employees may not necessarily voice less often, but they may change the way they speak up by giving preference to private over public voice.

Third, previous voice research has primarily focused on studying the main effect of manager-employee relationship quality on voice behaviour (Burris et al., 2008; Liu et al., 2013; Van Dyne et al., 2008). We extend this line of research by investigating two competing predictions on how LMX, in conjunction with manager self-efficacy, predicts public (vs. private) voice. By testing these predictions, we highlight how entertaining close, trusting relationships with managers affects the extent to which employees rely on social cues associated with their managers' self-efficacy when choosing the social setting in which to express voice.

\subsection{Theoretical Background and Hypotheses Development}

\subsubsection{Social Setting of Voice}

Voice is a discretionary behaviour (Morrison, 2011, 2014). This implies that employees can choose whether to engage in more public or private voice. Public voice refers to situations where employees speak up in the presence of a bigger audience besides the voicer and the manager. When voice is communicated in public settings, more people are exposed to the ideas, suggestions, or concerns raised by the voicer. We use the term audience broadly to refer to other people from the workplace including the voicer's peers, the manager's peers, people higher in the organizational hierarchy, or other employees or customers. In contrast, private voice refers to situations where employees speak up in the presence of a smaller audience, including situations when there is no one else present besides the voicer and the manager. When voice is communicated in private settings, fewer people (or no one other than the manager) are exposed to the voicer's ideas, suggestions, or concerns.

The choice of voice social setting may have implications for the self as well as for the work-group. In particular, engaging in more public voice is a high-risk strategy for employees (Detert \& Edmondson, 2006, 2011; Dutton \& Ashford, 1993). In public settings, individuals generally are more concerned about their social image than in private settings (Goffman, 1959, 1967; Sproull et al., 1996; Triplett, 1898; Uziel, 2007; Zajonc, 1965). As a result, when employees express their voice in the presence of other people, they are more likely to trigger in managers concerns that the employees' critical comments may bring to the fore their managerial flaws and weaknesses, thereby possibly questioning their credibility as effective managers. Managers may thus respond more negatively to public voice. In contrast, in private settings managers are less likely to be concerned that 
voice may detrimentally impact their social image, thus making private voice less risky for employees (Detert \& Edmondson, 2006, 2011; Dutton \& Ashford, 1993).

Although public voice may bear costs for the individual, it may be of advantage for the work-group (e.g., team or department). First, public voice, as compared to private voice, is more functional because it allows employees to tap on multiple perspectives and thus stimulates important collective processes. For instance, the larger literature on dissent indicates that when contrary opinions are expressed in the presence of others, they trigger more in-depth discussions, thus increasing decision quality (Nemeth et al., 2001) and innovation (De Dreu \& West, 2001) as well as generation of wider and more novel sets of solutions (V. R. Brown \& Paulus, 2002; Mesmer-Magnus \& DeChurch, 2009; Paulus et al., 2010). In contrast, voice that is privately expressed in the confines of closed-door oneon-one meetings with the manager can fail to similarly mobilize collective contemplation of issues. Furthermore, when employees withhold public displays of their ideas or concerns and instead wait to express their voice in one-on-one setting, their voice might come too late when managers can no longer implement it (Detert \& Edmondson, 2011). Second, early theorizing on related topics such as issue selling has suggested that managers are more likely to pay attention to and act upon ideas communicated in public settings because "selling an issue to top managers in front of an audience (public channel) increases the probability that top management will spend time on the seller's issue" (Dutton \& Ashford, 1993, p. 419). That is, this literature has suggested that accountability pressures force managers carefully consider and deliberate on employees' publicly voiced ideas or opinions because managers feel a need to justify their reactions to the observers in public settings; whereas, when employees raise issues in private, in the absence of pressure to justify one's actions to a broader audience, managers likely find it is easier to disregard and dismiss such input (Dutton \& Ashford, 1993).

In sum, it appears that public voice may hold certain advantages but also carry certain risks. Consequently, the question arises of how employees decide in which setting to voice. What cues do employees rely upon when making this decision?

\subsubsection{Manager Self-Efficacy and Public (vs. Private) Voice}

Managers may feel pressured to perform well and demonstrate their competence (Georgesen \& Harris, 2006) because this helps them in gaining status and compliance from their followers (Blader \& Chen, 2012; Lucas \& Baxter, 2012). Yet, not all managers perceive that they are capable to meet the expectations associated with their managerial role. In particular, managers differ in their level of self-efficacy-that is, one's belief about one's ability to perform well on specific tasks (Bandura, 1977).

Managers with high self-efficacy believe that they are capable to successfully accomplish managerial tasks, achieve assigned goals, demonstrate strong competence, and produce desired outcomes. Such managers are less concerned about how they appear to 
others but rather focus on task requirements (Bandura, 1977). In contrast, managers with a low self-efficacy experience a discrepancy between their actual and desired self-evaluation (Carver, Lawrence, \& Scheier, 1999). Such discrepancy is threatening for managers as it undermines their self-worth and therefore they do not want the perceived discrepancy to become salient to others (Fast et al., 2014; Schlenker \& Leary, 1982). This leads to performance anxiety in managers (Bandura, 1977), which implies that they fear potential failures. To counter these anxieties, managers may act in ways meant to demonstrate their competence. As a result, managers with low self-efficacy, in contrast to managers with high self-efficacy, may feel more vulnerable towards their employees and thus may be more likely to act defensively towards them (Cho \& Fast, 2012; Fast \& Chen, 2009).

In this regard, we propose that managers' self-efficacy provides employees with relevant social cues that help employees in deciding in which setting to express their voice. When interacting with a manager, the employee may closely monitor the manager's behaviours in order to judge how responsive the manager might be to voice (Burris et al., 2008; Detert \& Burris, 2007; Detert et al., 2013; McClean, Burris, \& Detert, 2012). Managers who are low on self-efficacy respond more aversely to voice by denigrating the voicer and by dismissing the input provided (Fast et al., 2014). Such defensive reactions are likely to signal to an employee that public voice is too risky and might have negative personal outcomes. Consequently, the employee is more likely to voice in more private settings, where voice is not brought directly to the attention of a bigger audience and thus is less likely to evoke aversive managerial reactions. In contrast, managers who are confident in their abilities to perform well demonstrate higher support of changes and continuous improvements in their work-group or organization (Paglis \& Green, 2002) and show higher solicitation and openness to their employees' voice (Fast et al., 2014). Such behaviours help reassure the employee that his/her input is welcomed and that public voice is rather unlikely to elicit defensive reactions. Consequently, the employee is more likely to voice in more public settings. Hence, we formally hypothesize:

H1: Managers' self-efficacy is positively related to employees' voice expressed in more public (vs. private) settings.

\subsubsection{The Moderating Role of LMX}

Drawing from the LMX theory (Graen \& Uhl-Bien, 1995), we argue that the effects of manager self-efficacy on employee public (vs. private) voice are contingent upon the relationship quality between a manager and the employee. LMX theory suggests that managers tend to develop different relationships with their employees (Dienesch \& Liden, 1986; Henderson, Liden, Glibkowski, \& Chaudhry, 2009; Kozlowski, Mak, \& Chao, 2016). Due to the scarcity of time and resources, managers typically do not invest in building high LMX relationships with all employees but only with a selected few. Relationships 
with these employees are characterized by loyalty, liking, and respect (Liden \& Maslyn, 1998). Managers perceive such high LMX employees as closer to them, trust them more, and believe them to engage in behaviours instrumental to the achievement of managerial goals; in contrast, relationships with low LMX employees are rather formal and are primarily based on official job descriptions and prescribed employment contracts (Liden \& Maslyn, 1998).

Employees typically have a good understanding of whether their managers consider them to be part of their favoured in-group or not (e.g., Duchon et al., 1986; Herman et al., 2012; Hu \& Liden, 2013). As a result, the quality of the LMX relationship that a manager entertains with the voicing employee is likely to influence the extent to which the employee will rely on social cues associated with the manager's self-efficacy. Here, drawing from prior research, we outline two competing perspectives on how LMX will moderate the link between manager self-efficacy and employee public (vs. private) voice.

LMX as risk enhancer. Close, trusting relationships develop over time and are based on certain patterns of interactions; thus, there is an element of predictability in high LMX relationships in terms of behaviours that managers and their employees expect from each other (Mayer, Davis, \& Schoorman, 1995). One such expectation relates to the idea that employees need to demonstrate support and loyalty towards their managers ( $P$. Brown \& Levinson, 1987). In other words, in-group employees sense that they, more than others, should not engage in behaviours that might potentially hurt or embarrass their managers (Bowler, Halbesleben, \& Paul, 2010; Z. Chen, Lam, \& Zhong, 2007). Thus, such employees may feel particularly torn between providing sensible input and maintaining a close, trusting relationship with their manager.

In this regard, public voice is particularly risky for high LMX employees. This is because in public settings high LMX employees are expected to defend and support their manager (Graen \& Scandura, 1987). Therefore, in-group members are likely to be especially concerned that their public voice may come across as a violation of loyalty expectations. Such a violation is likely to have especially negative implications for high LMX employees because when in-group (as opposed to out-group) individuals violate stereotyped expectations, such behaviours are evaluated more extremely (Jussim et al., 1987). In particular, expressing voice in public may harm the trusting, close relationship with one's manager. In this regard, high LMX employees are likely to feel a stronger need to monitor their mangers' behaviour in order to learn whether it is risky to voice publicly. Consequently, we expect high LMX employees would pay more attention to social cues associated with managers' self-efficacy, when choosing the social setting in which to express voice.

H2a: LMX moderates the positive relationship between managers' self-efficacy and employees' voice expressed in more public (vs. private) settings such that the relationship is stronger when LMX is higher. 
LMX as risk buffer. LMX positively biases the way managers perceive employee behaviour. In particular, managers are likely to view voice from high LMX employees more favourably and to ascribe more benevolent intentions to them, as compared to voice expressed by more distant employees (Burris et al., 2009; T. Kim et al., 2009; Whiting et al., 2012). Because managers evaluate input from their high LMX employees more favourably and show greater responsiveness towards it, these employees should feel more confident to express their voice. That is, high LMX employees believe that their voice is unlikely to be interpreted by managers as a criticism and thus unlikely to elicit defensive reactions. Hence, when an employee has a close, trusting relationship with the manager, the employee is less likely to feel the need to monitor social cues associated with the manager's self-efficacy level and thus should feel more confident to express voice in more pubic settings. In contrast, low LMX employees are more likely to be concerned that their voice expressed in more public settings may elicit negative reactions. Hence, low LMX employees would pay more attention to social cues grounded in managers' self-efficacy, when choosing the social setting in which to express voice.

Some indirect support for our proposition comes from research on the effects of manager affective states on employee voice behaviour (Liu et al., 2017). The study suggests that when a manager and an employee entertain high LMX relationships, the employee is less likely to use social cues, such as the manager's affective states, when deciding whether to speak up or not. This is because close, trusting relationships enhance employees' perceived psychological safety. Similarly, the effect of a peer's positive mood on the employee's intentions to engage in promotive voice toward that peer was stronger when the quality of the relationship between the peer and the employee was poor (Liu et al., 2015). Combining it with our arguments above, we hypothesize:

H2b: LMX moderates the positive relationship between managers' self-efficacy and employees' voice expressed in more public (vs. private) settings such that the relationship is weaker when $L M X$ is higher.

\subsection{Method}

\subsubsection{Procedures}

We collected data from managers located in Germany and Belgium across occupational fields, including the industrial sector, business and personnel services, government, and healthcare. Data was collected by two graduate students working on their master thesis under the supervision of the first author. Using a snowball sampling method (e.g., Grant \& Mayer, 2009; Mitchell et al., 2015), the two graduate students approached managers (i.e., working adults with a formal supervisory role) relying on their personal networks. 
The managers were invited to participate in a study on the role of effective leadership in fostering open communication at the workplace. To recruit managers, the students sent potential participants an introductory letter. In the letter, we explained the study's purpose and ensured anonymity and confidentiality. Furthermore, we indicated that, in return, participants would receive a consultancy report including the recommendations on how to facilitate open communication at the workplace.

We collected data over six consecutive days. On day 1, we sent a link with a general survey to managers who had consented to participate. In this survey, we asked managers to rate their level of manager self-efficacy and to provide LMX quality ratings for up to three of their employees (i.e., employees 1, 2, and 3). On days 2 to 6 , we sent participants an email with a link to the daily survey. In the daily survey, the managers were instructed to recall whether during the course of the day before, employees 1, 2, or 3 communicated to them "his/her ideas, suggestions, concerns, information about problems, or opinions about work-related issues." To help the managers re-experience the specific voice events, we asked them to describe where and in which setting the voice event occurred (Grube et al., 2008). Such recall cues have been found to reduce self-report (Reis \& Judd, 2000) and retrospection (lida et al., 2012) biases and help re-experience specific events more vividly (Dinh \& Lord, 2012; Grube et al., 2008). We asked managers to complete the measure on the extent to which the particular voice event was public (vs. private). Once the managers completed the survey for employee 1, we inquired whether employees 2 and 3 had also spoken up, and if so, invited managers to also fill in the survey with regard to employee(s) 2 and 3. Otherwise, the survey closed for that day. Overall, on each day managers had the possibility to report up to three different voice events each elicited by three different employees. When the managers indicated that no employees had spoken up, they were directed to the end of the survey. General and daily surveys and responses related to the same employee were matched based on a unique code.

The surveys were conducted both in English and in German. For the German version of the survey, we used validated translated scales. For the scales for which German versions were not available, we adopted the commonly used back-translation procedure (Brislin, 1980).

\subsubsection{Sample}

In total, 60 managers agreed to participate in the present study. Eight of them were excluded from the analysis, as the codes provided in the general survey did not match with the codes provided in their daily surveys. This resulted in a final sample of 52 managers (64\% male, Mage $=47.10$ years [SD $=8.29$ ], Morganizational tenure $=13.26$ years $[S D=11.02$ ],

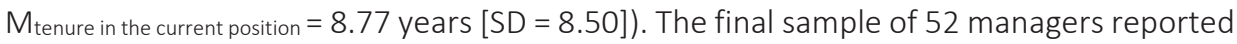
that 112 employees ( $59 \%$ female, Mage $=38.36$ years $[S D=9.85]$, Mrelationship tenure $=6.55$ 
years $[S D=7.56]$ ) spoke up between 1 and 5 times during 5 consecutive days. The managers reported between 1 and 13 voice events ( $M=4.25$ [SD = 2.74]). In total, we obtained information on 228 voice events. We removed seven voice events from the analysis because managers provided conflicting responses regarding the extent to which these voice events were public ${ }^{7}$. This resulted in a final sample of 221 voice events.

\subsubsection{Measures}

Manager self-efficacy. To assess manager self-efficacy, we used an 8-item general selfefficacy (GSE) scale developed by Chen, Gully, and Eden (2001). A sample item was: "I will be able to achieve most of the goals that I have set for myself" (from 1 = "Strongly Disagree" to 5 = "Strongly Agree," $\alpha=.78$ ). For the German version of the survey, we used a validated translation of the GSE scale by Urbig (2008).

LMX. Managers assessed LMX with their employees using the LMX-7 (Graen \& UhlBien, 1995). A sample item was: "What are the chances that you would use your power to help your employee solve problems in his/her work?" ( $\alpha=.74)$. For the German version of the survey, we used a validated translation of the LMX scale by Schyns (2002). Following the recommendations by Newman (2014) on how to treat missing data, non-responses for items of the LMX-7 scale were accepted (the maximum number of non-responses was two).

Voice setting. To measure voice setting (private vs. public), we asked managers "How many people overall (besides you) heard the communication by your subordinate?" Responses ranged from 0 to 18 . To reassure the fidelity of our measure of voice setting, we also asked managers to indicate who else heard the communication, providing them with the following options: "a superior," "another employee," "another peer," "a client/customer," "another person," and "nobody". This question allowed us to reveal conflicting responses. In particular, there were 20 cases where managers reported in the first question that there was one person who heard the communication by the employee, while indicating that no one else heard the communication in the second question. As managers might have misinterpreted this first question (i.e., thinking of themselves as this one person), we still coded these responses as $0^{8}$. Furthermore, there were seven cases where managers indicated in the first question that there were two other people present overhearing the communication, while indicating that no one else heard the communication in the second question. As mentioned earlier, these seven cases were excluded because of the conflicting information managers provided ${ }^{9}$.

\footnotetext{
${ }^{7}$ For more detailed information on the conflicting responses, see the voice setting measure description.

${ }^{8}$ Additional analyses indicated that coding these 20 cases as 0 or 1 did not affect the statistical significance of our results.

${ }_{9}^{9}$ Analysis indicated that including these seven cases did not affect the statistical significance of our results.
} 
Control variables. As managers and employees might differently assess public (vs. private) voice by male and female employees due to gender bias in work settings (Howell et al., 2015), we controlled for manager and employee gender.

\subsubsection{Analytical Approach}

Our data contained a hierarchical structure in which voice events were nested within employees and employees were nested within managers. In our models, voice setting was an event-level (Level 1) variable, LMX quality and employee gender were employee-level (Level 2) variables, and manager self-efficacy and manager gender were manager-level (Level 3) variables. We group-mean centred LMX quality, and we grand-mean centred manager self-efficacy ${ }^{10}$ (Enders \& Tofighi, 2007; Hofmann \& Gavin, 1998; Scott, Simonoff, \& Marx, 2013).

We first computed intraclass correlations (ICC), which indicated that differences across managers accounted for about $7.17 \%$ (ICC $=.07$ ) of the variability in voice setting (private vs. public), and differences across employees accounted for about $8.99 \%$ (ICC = .09). Results revealed that the between-manager variance in voice setting is $\tau_{\alpha}=.18$, the between-employee variance is $\tau_{\beta}=.23$, and the between-voice event variance is $\tau_{c}=2.14$. Hence, these results provide evidence for a nested data structure. Therefore, to test the effects of manager self-efficacy on employee public (vs. private) voice and the moderating hypothesis, we used hierarchical linear modelling (HLM; Raudenbush \& Bryk, 2002), assuming a negative binominal distribution. We used negative binominal distribution because voice setting is a discrete count measure ranging from 0 to 18 .

\subsection{Results}

Table 4.1 displays the means, standard deviations, and correlations among all study variables. Table 4.2 presents the regression results based on hierarchical linear modelling. Hypothesis 1 proposed that manager self-efficacy would be positively related to employee public (vs. private) voice. In support of this hypothesis, manager self-efficacy was positively related to employee public (vs. private) voice ( $\gamma_{002}=.71, p=.028$, Table 4.2, Model 2). Next, we tested two competing predictions on the moderating role of LMX. Results indicated that the cross-level interaction between manager self-efficacy and LMX was significant ( $\gamma_{022}=-1.85, p=.039$, Table 4.2, Model 3). We plotted the interaction in

\footnotetext{
10 We did not center manager and employee gender as the variables had a meaningful zero point because of the dummy coding.
} 
Figure 4.2 (Aiken \& West, 1991), which depicts voice setting (private vs. public) as a function of manager self-efficacy at low LMX (-1SD) and high LMX (+1SD). Results indicate that manager self-efficacy positively relates to employee public (vs. private) voice when LMX was low, but unrelated to public (vs. private) voice when LMX was high. Furthermore, Figure 4.2 shows that when $L M X$ is high, employees express voice in more private settings. Thus, Hypotheses $2 \mathrm{a}$ and $2 \mathrm{~b}$ were not supported.

Table 4.1 Descriptive Statistics and Correlations

\begin{tabular}{|c|c|c|c|c|c|c|c|}
\hline & $M$ & $S D$ & 1 & 2 & 3 & 4 & 5 \\
\hline \multicolumn{8}{|l|}{ Level 1: Event level } \\
\hline 1. Voice setting & 1.62 & 2.81 & - & & & & \\
\hline \multicolumn{8}{|l|}{ Level 2: Employee level } \\
\hline 2. Employee gender ${ }^{a}$ & 0.59 & 0.49 & .02 & - & & & \\
\hline 3. LMX & 4.16 & 0.48 & $-.15^{*}$ & -.01 & - & & \\
\hline \multicolumn{8}{|l|}{ Level 3: Manager level } \\
\hline 4. Manager gender ${ }^{a}$ & 0.37 & 0.49 & .00 & $.23^{* *}$ & -.09 & - & \\
\hline 5. Manager self-efficacy & 4.20 & 0.38 & $.15^{*}$ & $.19^{* *}$ & $.20^{* *}$ & .12 & - \\
\hline
\end{tabular}

Note. For the Level 1 variables, $\mathrm{N}=221$, for the Level 2 variables, $\mathrm{N}=112$, and for the Level 3 variables, $\mathrm{N}=52$. a Dummy coded: 0 = male, 1 = female.

${ }^{*} p<.05 ;{ }^{* *} p<.01$.

Table 4.2 Regression Analysis Results Based on Hierarchical Linear Modeling

\begin{tabular}{|c|c|c|c|c|c|c|}
\hline \multirow[b]{3}{*}{ Constant } & \multicolumn{6}{|c|}{ Voice Setting (Number of People Present) } \\
\hline & \multicolumn{2}{|c|}{ Model 1} & \multicolumn{2}{|c|}{ Model 2} & \multicolumn{2}{|c|}{ Model 3} \\
\hline & .23 & $(.18)$ & .24 & $(.17)$ & .25 & $(.18)$ \\
\hline Employee gender $\left(\nu_{\mathrm{c} 010}\right)$ & .01 & $(.20)$ & -.05 & $(.22)$ & -.08 & $(.23)$ \\
\hline Manager gender $\left(\gamma_{c 001}\right)$ & .14 & $(.25)$ & .12 & $(.26)$ & .12 & $(.26)$ \\
\hline Manager self-efficacy ( $\left.\gamma_{002}\right)$ & & & $.71^{*}$ & $(.32)$ & $.73^{*}$ & $(.31)$ \\
\hline $\operatorname{LMX}\left(\gamma_{020}\right)$ & & & $-.57^{*}$ & $(.28)$ & -.11 & $(.31)$ \\
\hline Manager self-efficacy $\times$ LMX $\left(\gamma_{022}\right)$ & & & & & $-1.85^{*}$ & $(.87)$ \\
\hline$-2 \times \log$ likelihood & \multirow{2}{*}{\multicolumn{2}{|c|}{841.68}} & \multicolumn{2}{|c|}{837.66} & \multicolumn{2}{|c|}{834.36} \\
\hline Difference of $-2 \times \log (d f)$ & & & \multicolumn{2}{|c|}{$4.02(2)$} & \multicolumn{2}{|c|}{$3.30(2)$} \\
\hline
\end{tabular}

Note. For the Level 1 variables, $N=221$, for the Level 2 variables, $N=112$, and for the Level 3 variables, $N=52$. a Dummy coded: $0=$ male, $1=$ female. Numbers in parentheses are robust standard errors.

${ }^{*} p<.05$. 


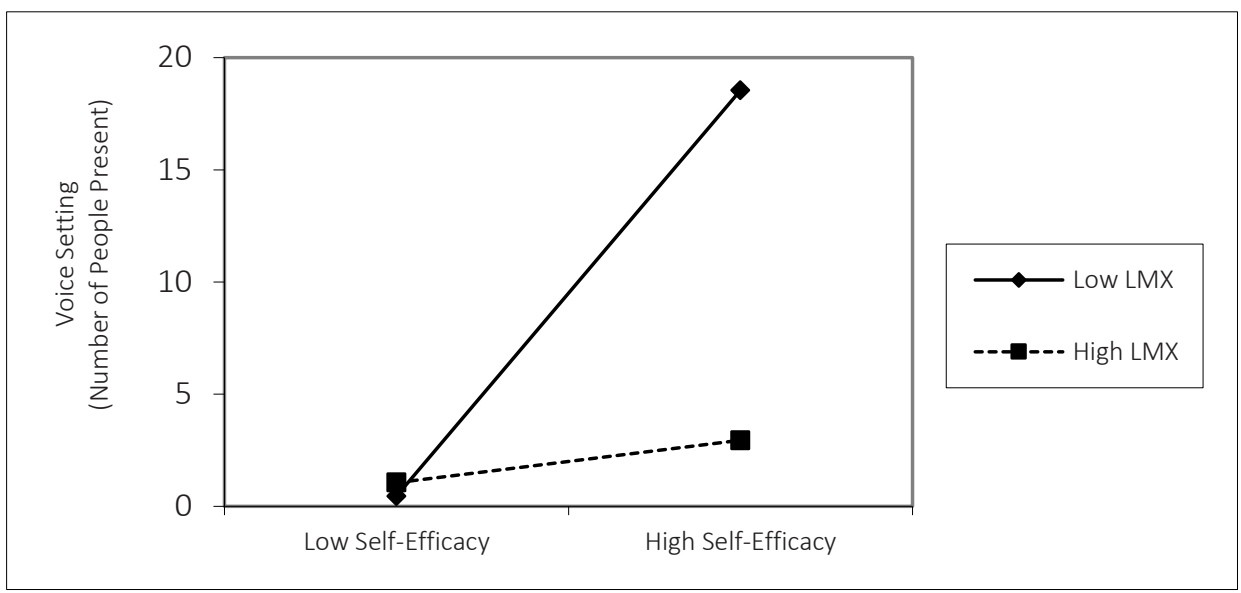

Figure 4.2 Interaction effect of manager self-efficacy and LMX quality on voice setting. High and low levels of LMX represent one standard deviation above and below the mean.

\subsection{Discussion}

Despite the significant progress made in voice research, organizational scholars have largely overlooked the factors that explain why employees would prefer a particular social setting over another when speaking up (Morrison, 2011). In this study, we theorized and examined the premise that the higher (lower) manager self-efficacy is, the more employees are likely to speak up in public (private). As hypothesized, manager self-efficacy was positively related to public (vs. private) voice. Further, high LMX quality mitigated the effects of manager self-efficacy on employee public (vs. private) voice such that when LMX was high, employees were reluctant to engage in public voice irrespective of their managers' level of self-efficacy. This finding goes against both of our competing predictions, thus suggesting a third perspective on the moderating role of LMX. In particular, the results highlight that high LMX employees are unaffected by whether their managers are higher on self-efficacy or not, and further indicate that it is likely that high LMX employees opt for more private forms of voice in general. One possible explanation for this finding is likely to rely in highly risky nature of public voice for high LMX employees. In particular, this finding suggests that, although high LMX employees may in general feel more psychologically safe to voice (Liu et al., 2017), they would be in general reluctant to voice publicly in order to preserve their close, trusting relationships. By demonstrating these effects, we make a number of theoretical contributions to the voice literature. 


\subsubsection{Theoretical Contributions}

Significant progress has been made in the voice literature by delineating how employees' voice safety and efficacy considerations affect their decision to voice or remain silent (Morrison, 2011). Extant literature suggests that employees are likely to remain silent when they perceive the risks of voice to outweigh its benefits (Morrison, 2014). We seek to complement this viewpoint by arguing that employees, when facing risks, not only have the possibility to remain silent but also can choose between differently risky voice tactics. In particular, we distinguish between whether employees speak up in a more private or public setting, two tactics that sharply differ in their riskiness. Our theorizing suggests that perceived favourability of voice setting positively impacts an employee's public (vs. private) voice. By studying when employees choose more public or private voice, our study responds to recent calls in the literature "to provide better understanding of employees' choices about how to communicate concerns and suggestions" (Morrison, 2011, p. 399). Consequently, we highlight the need and importance for a shift in the voice literature from a discussion of voice frequency to a discussion of voice tactics.

Second, this study enhances our understanding of the role of manager self-efficacy in affecting employee voice behaviour. Fast and colleagues (2014) demonstrated that managers with low self-efficacy show less voice solicitation and endorsement, which, in turn, discourages employees from engaging in voice behaviour. However, the effects of manager self-efficacy on voice tactics have remained unexplored. Our results demonstrate that manager self-efficacy is an important antecedent of employee public (vs. private) voice. Hence, we extend the study by Fast and colleagues (2014) by highlighting that the extent to which managers are confident in their abilities to perform well not only influences whether employees speak up or remain silent but also what tactics employees use when speaking up. We thus respond to multiple calls in the literature for a more nuanced investigation of how managers' characteristics and associated behaviours affect employee voice (Fast et al., 2014; Gao, Janssen, \& Shi, 2011; McClean et al., 2012).

Third, our study underscores the fact that managerial personal dispositions and relational characteristics may interactively predict employee voice tactics. In particular, we add to the voice literature by demonstrating how LMX affects the relationship between manager self-efficacy and public (vs. private) voice. A number of studies have associated close working relationships between managers and employees with employee voice behaviour (Burris et al., 2008; Liu et al., 2013; Van Dyne et al., 2008). Yet, these studies have paid little attention to examining how relationship quality shapes the way employees read and react to managers' social cues that convey information about their responsiveness to voice. Our theory and findings indicate that manager self-efficacy positively relates to public (vs. private) voice when LMX is low but is unrelated to it when LMX is high. This finding suggests that employees monitor and rely more on social cues associated with their managers' self-efficacy when they do not entertain close, trusting relationship with 
them. In particular, our results indicate that public voice is more likely when a manager has a high level of self-efficacy and the voicing employee is not part of the manager's ingroup. This suggests that high LMX employees generally are reluctant to engage in public voice as they fear undermining the loyalty-based relationship that they entertain with their managers (P. Brown \& Levinson, 1987; Burgoon, 2009; Cupach \& Carson, 2002).

\subsubsection{Limitations and Directions for Future Research}

As any other study, our study has several limitations. First, our focal variables were all reported by managers which suggests that some of the relationships might have been influenced by common-method bias (Podsakoff et al., 2003). Although we acknowledge this as a potential limitation, we believe that the only relationship that might have been affected by common-method bias is the main effect of manager self-efficacy on public (vs. private) voice as the interaction effects are robust to common-method bias (Siemsen et al., 2010). At the same time, common-method bias is unlikely to explain the main effect because we used an objective criterion (i.e., number of people who heard employee's voice) to assess the extent to which voice was public (vs. private).

Second, our theoretical arguments are based on the well-founded assumption that managers' self-efficacy manifests in their behaviour (see Fast et al., 2014), which, in turn, signals employees whether public (vs. private) voice is welcomed or not. However, empirically, we did not directly assess this assumption because we did not measure the possible mediators linking manager self-efficacy and employee public (vs. private) voice (e.g., manager openness to voice, employee judgment of public voice safety). Thus, future research should investigate these putative mediating mechanisms to provide a more nuanced understanding about the effects of manager self-efficacy on employee public (vs. private) voice.

Third, our theorizing suggests that the extent to which employees rely on managerial social cues (i.e., manager self-efficacy) when deciding whether to speak up in public or in private depends on the given relationship quality between leader and employee. In the present study, we operationalized LMX quality by asking for the manager's perception. Given that employees and managers may differ in their LMX evaluation (Sin et al., 2009), our findings should be taken with caution. At the same time, in our analysis we used group-mean centred values of LMX, thereby focusing on the relative managers' evaluations of perceived LMX. Given that employees are generally aware of their relative standing in a group (Henderson et al., 2009; Henderson, Wayne, Shore, Bommer, \& Tetrick, 2008; Herman et al., 2012; Vidyarthi, Liden, Anand, Erdogan, \& Ghosh, 2010), we believe that this issue is of lesser concern.

We believe that future research should further examine and extend our understanding of the antecedents of public (vs. private) voice. In the present study, we focused on the role of managers' self-efficacy, however, there are likely to be other factors that can 
potentially affect employees' preference to engage in more public (vs. private) voice. In particular, the results of the present study suggest that there are situational factors that explain a significant amount of the variance in employees' choice of voice social setting. Therefore, we urge scholars to examine and delineate situational factors, such as managers' and employees' affective states, that can explain within-person variability in engagement in public (vs. private) voice across situations.

It might be also fruitful for future research to use an alternative operationalization of our dependent variable. In particular, the extent to which voice is public (vs. private) could be captured not only by the number of people present during a particular voice event, but also by the extent to which the employee considers the audience to be part of the manager's in-group or out-group. In particular, it is possible that the employee perceives speaking up in front of one or two members from a different department as more public than speaking up in front of the manager's entire team.

\subsubsection{Practical Implications}

Our study holds several practical implications for managers and human resources specialists. Managers may find it interesting to learn that their level of self-efficacy might have implications for how employees speak up to them. Thus, managers should be heedful of how their self-efficacy manifests in their behaviour, because employees use such behavioural cues to decide whether to express voice in more public or private settings. Such awareness is particularly relevant for managers with low levels of self-efficacy because given their relative insecurity in their managerial role they might be especially likely to benefit from public voice. This is because public voice is more likely to provide them with multiple perspectives on the raised issues helping managers in making a carefully weighted decision. In a related manner, managers need to know that employees who are part of their in-group are reluctant to voice their suggestions or concerns in more public settings but would rather do so in private settings. This might result in not having constructive open discussions on the issues raised by high LMX employees as the ideas would be generally raised behind closed doors.

Finally, human resources managers should encourage employees to consider more criteria when deciding to speak up in public or private settings, than they normally would. The more strongly other employees might be affected by the suggested change, the more sensible it seems to bring up the issue in public so that everyone can have a say on the potential consequences of a given bottom-up change initiative. Encouraging both private and public voice should be possible by fostering an organizational culture where everyone feels that it is normal and commonly accepted to express suggestions and concerns both privately and publicly without any hesitation. Such interventions at the organizational level should reduce the effect of managers' self-efficacy on employees' public (vs. private) voice. 


\subsubsection{Conclusion}

Our results indicate that when managers have high self-efficacy employees engage more in public (vs. private) voice. This relationship disappears when the voicing employee belongs to the circle of the managers' close confidants. Our research highlights the importance of continued research into how managers' personal dispositions and behaviours associated with these dispositions inform and direct employees' voice behaviour. Finally, we hope that our findings will stimulate further theory-building and empirical research in the antecedents of public (vs. private) voice as well as other voice tactics. 
Chapter

\section{Employees' Misplaced Loyalty: Perceived Costs and Actual Benefits of Public Voice}





\subsection{Introduction}

In today's dynamic business environment, employee voice-an upward expression of ideas, opinions, and concerns about work-related issues (Morrison, 2014)-plays a critical role in effective organizational functioning (Morrison \& Milliken, 2000). The extent to which employees are motivated to voice their ideas and concerns impacts organizations' ability to detect and promptly respond to emerging problems and opportunities (Nemeth, 1997). This is because when employees speak up they aid their groups by preventing errors (Edmondson, 2003), facilitating learning and innovation (De Dreu \& West, 2001; Detert \& Edmondson, 2006), and improving performance (MacKenzie et al., 2011).

However, employee voice involves challenging the status quo and thus may indirectly question the manager's prior decisions and actions (Morrison \& Milliken, 2000). Given that criticism inherent in voice, scholars have argued that employee loyalty may manifest in silence (Boroff \& Lewin, 1997; Mayes \& Ganster, 1988). Such conceptualisation takes its roots in the seminal work by Hirschman (1970) who considered employee voice versus (silence-based) loyalty as two opposing responses to organizational dissatisfaction. This historical foundation inspired numerous research studies contrasting voice with silence. Such binary conceptualization, however, might mask the fact that employees can be loyal and outspoken - in terms of voice behaviour - at the same time.

Drawing on implicit voice theories (Detert \& Edmondson, 2011), defined as taken-forgranted beliefs about the risk or inappropriateness of speaking up, we propose that employees do not need to fall silent to show their loyalty, but instead they might speak up but do so in a way that might be more acceptable to managers, namely in private. Whether employees do so, we argue, will largely depend upon their implicit beliefs. Specifically, they will be guided by their belief about whether it is less appropriate to speak up in public settings (when other people are present besides the target manager) as compared to private settings (when no one else is present besides the voicing employee and the manager) (Detert \& Edmondson, 2011). Although Detert and Edmondson (2011) suggest that such beliefs are likely to manifest in silence, we expand this view by arguing that they may also affect the specific ways in which employees speak up, that is, by preferring private over public voice.

However, private voice might be less effective than public voice. We argue that employees who voice in private, rather than in public, will be less effective in initiating change within their work-group or organization because managers cannot easily dismiss voice expressed in public settings (Dutton \& Ashford, 1993). Thus, we suggest that employees with strong implicit public voice theories may face a problem of misplaced loyalty. In particular, employees who strongly believe that public voice is risky and who want to display their loyalty, will try to influence their managers by speaking up in private instead of in public. However, by giving preference to private over public voice, employees 
may fail to utilize the potential value of voice as private voice may be less effective in bringing about change.

We do not believe that implicit voice beliefs, no matter how powerful, will influence employee voice behaviour independent of the work context. In particular, we propose that self-promotion climate-that is, a shared belief that it is appreciated to display behaviours that signal one's competence-will moderate the indirect effect linking implicit public voice beliefs and voice effectiveness. That is, in organizations with a pronounced self-promotion climate, employees' implicit beliefs about public voice might be less likely to prevent employees from speaking up in public and bringing about change. Figure 5.1 illustrates our conceptual model.

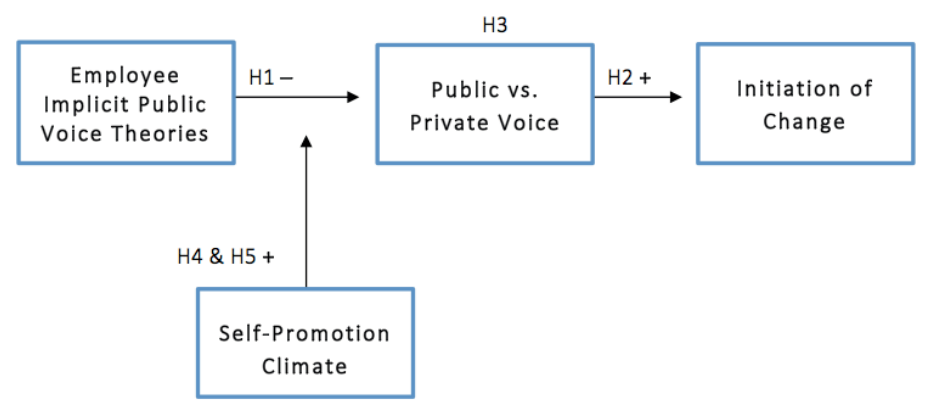

Figure 5.1 Proposed moderated mediation model

With this study, we contribute to the literature in several ways. First, prior research has mostly considered employee decision to voice as a binary choice, suggesting that employees either voice or remain silent (see Morrison, 2014). We add to the voice literature by suggesting that employees may choose from a spectrum of voice tactics, including private and public voice. Given that existing measures of voice are not sensitive to its public versus private nature, we may potentially miss out on why in some situations voice translates into certain outcomes and in others it does not. That is, employees might frequently engage in voice, but because they prefer to speak up in private, they may have a different capacity to engender changes than employees who speak up equally often but prefer to do so in public settings. Thus, we may be able to draw a more complete picture of voice by considering various voice tactics instead of thinking of voice and silence in a binary fashion.

Second, the current voice literature implicitly assumes that expressing voice in the presence of other people is likely to lead to negative personal repercussions for employees (Detert \& Edmondson, 2006, 2011). We challenge this perspective by highlighting the fact that public voice may also have potential benefits. In particular, we bring to the fore 
the functional side of public voice by showing that employees who give preference to public over private voice are more likely to bring about organizational change.

Third, we contribute to an increasing number of studies investigating how group climate may modify the effect of individual-level factors on employees' voice behaviour (Frazier \& Bowler, 2015; Frazier \& Fainshmidt, 2012; Morrison et al., 2011; Tangirala \& Ramanujam, 2008; Wang \& Hsieh, 2013). We extend this line of research by examining how self-promotion climate moderates the relationship between employees' public voice beliefs and their public (vs. private) voice behaviour. Hence, we respond to recent calls "to consider more fully the optimal level of voice climate specificity " (Morrison et al., 2011, p. 188) by theorizing and studying self-promotion climate and its role with regard to employees' tendency to speak up in public (vs. private).

\subsection{Theoretical Background and Hypotheses Development}

Voice is constructive in its intent and holds great potential for improving group and organizational performance (Van Dyne \& LePine, 1998). Employees who speak up tend to do so because they wish to bring about change and help improve the organization. Thus, voice is often driven by prosocial motivation (Van Dyne, 2003), duty orientation (Tangirala et al., 2013), as well as felt obligation for constructive change (Liang, Farh, \& Farh, 2012). Yet, voice also carries costs. Employees are aware that by voicing their ideas or concerns they might come across as disloyal to the extent to which managers perceive their voice as criticism of existing processes, practices, and policies for which managers often feel responsible (Edmondson, 2003). This might be especially the case when voice is expressed in the presence of other people as it is likely to be seen by managers as a challenge of their social standing (Detert \& Edmondson, 2011). Employees should be likely to take into account these image-related concerns of their managers, because evoking such concerns may have negative repercussions for employees, such as, being viewed as a troublemaker, being reprimanded in public, and having a bruised relationship with their manager (Detert \& Treviño, 2010; Grant, 2013; Milliken et al., 2003). As a result, such reactions may discourage employees from voicing because employees want their managers and organizational leaders to think of them as loyal (Bolino \& Turnley, 1999; Bolino, Turnley, \& Niehoff, 2004), as loyalty can engender higher rewards (Shore et al., 1995), better performance ratings (Whiting et al., 2008), and consideration as high potential (Shore et al., 1995). Hence, voice represents a tricky terrain for employees to navigate. In this regard, we argue that employees may minimize potential risks associated with voice by communicating their ideas or concerns in private versus public, and that implicit public voice theories are likely to explain when employees prefer one type of voice over the other. 


\subsubsection{Implicit Public Voice Theories and Public (vs. Private) Voice Behavior}

Employees often hold implicit voice theories - "taken-for-granted beliefs about when and why speaking up at work is risky or inappropriate" (Detert \& Edmondson, 2011, p. 461). Similar to other implicit theories (Chiu, Hong, \& Dweck, 1997; Levy, Chiu, \& Hong, 2006; M. Ross, 1989), implicit voice theories are cognitive structures or knowledge schemas that help individuals to process information and interpret their own and others' behaviour. In comparison to scientific (explicit) theories, implicit voice theories represent subjective perceptions that reside in the minds of employees and, thus, do not necessarily reflect the objective reality (Detert \& Edmondson, 2011). Although implicit voice theories might be incorrect and untested, employees rely on these naïve models when assessing potential outcomes associated with voice (Detert \& Edmondson, 2011).

Prior research has identified five implicit voice theories, each referring to different situational features that individuals associate with voice riskiness. One of these theories - the implicit public voice theory "Don't embarrass the boss in public" - highlights the role of the social setting in which voice is enacted and refers to taken-for-granted beliefs that one should not speak up with ideas, suggestions, or concerns in public settings when other people are present besides the voicing employee and the manager (i.e., co-workers, other managers or superiors, and/or customers) (Detert \& Edmondson, 2011). Implicit public voice theories are based on cause and effect assumptions indicating that when voice occurs in public, such voice may come across as implicit criticism of managers' prior decisions and actions and question their social standing, thus, making managers react in a more defensive manner. As a result, employees who hold such beliefs assume that speaking up in public is inappropriate as it may call in doubt their loyalty (Detert \& Edmondson, 2011).

We thus propose that implicit public voice theories affect in which settings employees express their ideas and concerns by preferring private over public setting. Prior research has demonstrated that holding such beliefs is likely to reduce voice frequency and result in silence (Detert \& Edmondson, 2011). In contrast to this view, we argue that, instead of falling silent, employees may revert to private voice, and this is for two reasons. First, in one-on-one settings concerns about how one may appear to others are minimized (Goffman, 1959, 1967; Sproull et al., 1996; Triplett, 1898; Uziel, 2007; Zajonc, 1965). In other words, when speaking up in private, employees are less likely to worry that their voice may embarrass the manager or put him/her in a bad light. Second, employees holding lay theories about public voice may perceive private voice as a better tactic than silence as it still allows them to raise their issues or concerns and thus helps one's work group or organization. Hence, employees should perceive private voice as a safe option, which allows minimizing potential risks and nourishing benefits of voice. Consequently, we expect that implicit public voice theories will not only affect the frequency with which 
employees speak up, but will also affect in which settings employees express their voice. Thus, we formally hypothesize:

H1: Employees' implicit public voice theories are negatively related to employees' public (vs. private) voice.

\subsubsection{Public (vs. Private) Voice Behavior and Initiation of Change}

New challenges in business create new demands for employees (Ilgen \& Pulakos, 1999). It is no longer sufficient for employees to demonstrate high performance on their core job tasks; they are also expected to leverage their impact on the workgroup and organizational level (Griffin, Neal, \& Parker, 2007). In other words, when making decisions about employees' promotion and other career outcomes, organizational leaders place special emphasis on employees' initiation of change-that is, the extent to which employees contribute to the workgroup and organizational effectiveness by working towards futuredirected change, finding new innovative ways to do things, and introducing better processes and procedures (Welbourne, Johnson, \& Erez, 1998).

In this regard, voicing can be one of the potential ways in which employees can bring about constructive change in procedures or practices within their work-group or organization (Morrison, 2014). Yet, some employees are considered as more successful than others in turning their ideas into real change (Dutton \& Ashford, 1993; Dutton, Ashford, O’Neill, \& Lawrence, 2001). To be effective change agents, employees need at a minimum to get their managers to recognize their voice (Burris, Rockmann, \& Kimmons, 2017; Dutton \& Ashford, 1993; Dutton et al., 2001; Howell et al., 2015). This, in fact, is often one of the main obstacles that employees face because managers have limited time and resources (Pfeffer, 1992), which makes it hard or impossible for them to address all the issues at hand. Hence, when employees voice, it is important for them to get managers' attention among all other potential issues (Burris et al., 2017; Dutton \& Ashford, 1993). To make managers recognize the raised issue, employees may use different voice tactics (Dutton \& Ashford, 1993; Dutton et al., 2001). We propose that public voice may represent a voice tactic that will increase the chances that one's voice is recognized, thus making it more likely for employees who prefer public to private voice to bring about change to their work-group or organization.

We base our argument on the idea that public voice, as compared to private voice, raises managers' sense of accountability - that is, "an implicit or explicit expectation that one may be called on to justify one's beliefs, feelings, and actions to others" (Lerner \& Tetlock, 1999, p. 255). Managers possess power and greater access to resources and, thus, are expected to demonstrate consideration and support for the needs of their employees (Epitropaki \& Martin, 2004; Judge, Piccolo, \& Ilies, 2004; Tost, 2015). Consequently, when ideas are brought to the attention of managers in the presence of others, 
managers may find it more difficult to ignore the input because they need to factor in how this may affect their social standing (Dutton \& Ashford, 1993). That is, the presence of other people puts elevated pressure on managers to consider voice. As a result, when voice is communicated in public, they are more likely to devote time and attention to the raised suggestions or concerns. In contrast, when employees speak up in private, managers may find it somewhat easier to disregard voice because perceived pressure to justify one's actions is lower (Dutton \& Ashford, 1993). In other words, when no one else is present besides the voicer and the manager, managers are less likely to experience the need to consider employees' input. Hence, employees who prefer public to private voice are more likely to create instances in which it is harder for managers to simply ignore and dismiss their voice (Dutton \& Ashford, 1993). Consequently, input from such employees is more likely to get managers' attention, which is a minimum prerequisite for turning voice into real change (Burris et al., 2017; Dutton \& Ashford, 1993; Dutton et al., 2001; Howell et al., 2015). Hence, we expect that employees who engage in public voice more often than in private voice are more likely to initiate change within their work-group or organization.

The core argument of our theoretical model is that employees holding implicit public voice theories engage more in private rather than in public voice, and this has negative implications on employees' effectiveness in initiating change. Thus, employees' preference for private over public voice is the main explanatory mechanism in our argument. However, when investigating the effects of public (vs. private) voice on employees' initiation of change, one has to take into account employees' general voice frequency. This is because the more employees speak up, the more they are likely to bring about positive constructive change in their work-group or organization (Dyne, Ang, \& Botero, 2003; Morrison \& Milliken, 2000; Van Dyne, Cummings, \& Parks, 1995; Van Dyne \& LePine, 1998). Given the above outlined arguments, we expect the effect of employees' general preference of public over private voice on the extent to which employees initiate change to be beyond and above the effect of voice frequency.

H2: Employees' public (vs. private) voice is positively related to employees' initiation of change, and this effect is beyond and above the effect of voice frequency on employees' initiation of change.

Using the above logic and combining it with our earlier arguments that holding implicit pubic voice theories attenuates public (vs. private) voice behaviour, we propose that implicit pubic voice theories will be negatively associated with initiation of change, and that public (vs. private) voice will explain this effect.

H3: Employees' public (vs. private) voice mediates the negative relationship between employees' implicit public voice theories and employees' initiation of change. 


\subsubsection{The Moderating Role of Self-Promotion Climate}

Up to this point, we have argued that employees with strong implicit public voice theories are less likely to engage in public voice but instead prefer to voice privately. However, although individual beliefs are strong predictors of employees' behaviours, group-level perceptions are likely to also affect the extent to which individual beliefs manifest in employee behaviour (Ajzen, 1991). In particular, it is likely that the effect of implicit public voice theories on public (vs. private) voice might be weakened if those employees work in groups or organizations that value and appreciate employees who engage in public voice. Such misalignment between employees' individual beliefs and beliefs shared in their current work-group may occur because employees' individual beliefs are often formed during earlier socialization processes and depend on interactions with authority figures in the past (Detert \& Edmondson, 2011). In this regard, we propose that self-promotion climate is likely to capture values and norms which welcome public voice and, consequently, we argue that self-promotion climate moderates the effect of implicit public voice theories on public (vs. private) voice.

Following research on social climate (e.g., Frazier \& Fainshmidt, 2012; Morrison et al., 2011) and self-promotion (e.g., Giacalone \& Rosenfeld, 1986; Turnley \& Bolino, 2001), we refer to self-promotion climate as a shared belief that it is appreciated to display behaviours that signal one's competence. In other words, work-groups with a self-promotion climate encourage the norm of engaging in impression management by displaying one's competence (Giacalone \& Rosenfeld, 1986). In such a climate, employees are more likely to play up their abilities, strengths, and talents as well as point out their prior achievements and honours (Godfrey, Jones, \& Lord, 1986; Rudman, 1998; Turnley \& Bolino, 2001). In this regard, engagement in public voice is likely to represent a form of self-promotion behaviour. This is because when an employee speaks up about issues that other employees and managers have overlooked, it is likely to signal to others that the employee is competent (Burris, 2012; Stamper \& Dyne, 2001).

Hence, the behaviour of employees, who hold beliefs that public voice is risky and who work in a group with a high self-promotion climate, is likely to be affected by two opposite forces. That is, their implicit public voice theories suggest that they need to engage in private voice, whereas the norms and values shared in their work-group favour public voice as a welcomed and appreciated form of speaking up. As a result, when the self-promotion climate is high, it may counteract the negative effects of employees' implicit public voice theories on public (vs. private) voice behaviour such that the relationship will be weakened. In contrast, if the self-promotion climate is low, employees' implicit public voice theories are much more likely to show in their behaviour. Thus, we hypothesize: 
H4: Self-promotion climate moderates the negative relationship between employees' implicit public voice theories and employees' public (vs. private) voice such that this relationship is weaker when self-promotion climate is higher.

H5: Self-promotion climate moderates the mediated relationship between employees' implicit public voice theories and employees' initiation of change via employees' public (vs. private) voice such that this relationship is weaker when self-promotion climate is higher.

\subsection{Method}

\subsubsection{Procedure}

We tested the hypotheses using dyadic survey data collected from managers and their employees, most of them working in the Netherlands and Germany in various occupational fields (e.g., banking and financial services, consulting, education). The participants in this study comprised alumni from a Dutch university and a convenience sample of working adults. Furthermore, to increase the number of respondents, we utilized a snowball sampling technique (e.g., Grant \& Mayer, 2009; Mitchell et al., 2015) by asking manager-respondents to invite their colleagues in managerial positions to participate in our study.

Potential manager participants (i.e., working employees who held a formal managerial role and had at least one direct report) received an email inviting them to participate in a study on "Leading for organizational impact" with a link to an online survey. The managers who agreed to participate were asked to choose one of their employees and rate the extent to which this employee initiates change. After the managers completed the survey, they were asked to redirect the employee survey link to this particular employee. Employees self-rated their implicit public voice theories, public (vs. private) voice, and self-promotion climate of their work-group. We used dyadic data sources to minimize common-method biases (Podsakoff et al., 2003). Unique identification numbers allowed us to match responses from managers and their employees. All participants were reassured that their responses would remain confidential and anonymous. In return for their participation, participants were promised an executive research report with actionable recommendations on how to lead for organizational impact. We sent up to three reminders to managers and their employees who did not complete the survey. The surveys were conducted in English. 


\subsubsection{Sample}

In total, 337 managers and 114 employees provided usable responses. After matching across these two sources, our sample resulted in 110 manager-employee dyads ${ }^{11}$. Of the managers, $75.5 \%$ were male, $90 \%$ had middle management positions or higher, and $96 \%$ completed a college degree or higher. Their mean age was 42.82 years (SD $=9.58$ ), the mean organizational tenure was 11.00 years $(S D=9.06)$, the mean work experience was 17.86 years $(S D=9.55)$, and the mean number of employees was 11.01 ( $S D=12.39$ ). Of the employees, 56\% were male, and $91 \%$ completed a college degree or higher. Their mean age was 36.03 years (SD $=11.15)$, the mean organizational tenure was 7.50 years $(S D=8.34)$, and the mean work experience was 12.14 years $(S D=9.57)$.

\subsubsection{Measures}

Implicit public voice theories. Employees rated their implicit public voice theories using a 4-item subscale "Don't embarrass the boss in public" from the implicit voice theories measure (Detert \& Edmondson, 2011) with a 5-point Likert scale (1 = "Strongly Disagree" to 5 = "Strongly Agree"). A sample item was: "You should always pass your ideas by [the manager] in private first, before you speak up publicly at work" ( $\alpha=.75)$.

Self-promotion climate. To measure self-promotion climate, we used Bolino and Turnley's (1999) 5-item measure of self-promotion strategy from the impression management behaviour scale. As this scale was originally used to assess individual self-promotion behaviour, we adapted it so that it would serve as a climate measure. Employees rated selfpromotion climate in their work-group using a 5-point Likert scale ( 1 = "Strongly Disagree" to 5 = "Strongly Agree"). A sample item was: "In my work-group it is valued and appreciated when people let others know that they have a reputation for being competent in a particular area" $(\alpha=.82)$.

Public (vs. private) voice and voice frequency. We measured employees' public (vs. private) voice and general voice frequency by using a 5-item constructive voice measure developed by Maynes and Podsakoff (2014). We asked employees to rate their public (vs. private) voice and voice frequency, as we believe that employees can provide the most reliable and precise ratings for these variables. This is because previous research suggests that managers do not always recognize employees' voice, and, thus, employees and managers have different perceptions of frequency and quality of employee voice. To assess

\footnotetext{
${ }^{11}$ We compared whether the sample of managers whose employees did not participate in the study differed substantially from the sample of managers whose employees participated in the study. We compared both samples regarding the ratings of initiation of change and demographics. Results indicated that the managers whose employees participated in the study were older $(M=42.88, S D=9.55)$ as compared to the managers whose employees did not participate $(M=39.56, S D=8.50 ; F(1,321)=10.29, p=.001)$. However, there were no significant differences between the samples in the ratings of initiation of change, gender distribution, managers' position in the organizations, and their level of education.
} 
public (vs. private) voice, we asked employees to rate in which setting, over the last three months, they engaged in voice behaviour using an adapted 5-point Likert scale ( 1 = "Always in Private", 2 = "Usually in Private", 3 = "Equally Often in Private and in Public", 4 = "Usually in Public", 5 = "Always in Public"). We provided the participants with definitions of private and public settings to reassure that they understood the question as intended. To assess voice frequency, we asked employees to rate how frequently, over the last three months, they engaged in voice behaviours using a 5-point Likert scale ( 1 = "Very Rarely" to 5 = "Very Frequently"). A sample item was: "I spoke up to the manager with recommendations about how to fix work-related problems" ( $\alpha_{\text {public }}$ (vs. private) voice $=.93 ; \alpha_{\text {voice }}$ frequency $=.88$ ).

We conducted a pilot study to evaluate the psychometric properties of our public (vs. private) voice scale and to show that public (vs. private) voice is distinct from voice frequency. We also examined the discriminant validity of public (vs. private) voice from commitment towards one's manager because previous research suggests that commitment is highly correlated with different forms of organizational citizenship behaviour (e.g., O’Reilly \& Chatman, 1986; Shore et al., 1995). We recruited 384 participants via MTurk (53\% male; Mage = 37.49 [SD = 11.40]; 65\% having a full-time job, 61\% working 30 hours and longer, and $46 \%$ having no supervisory responsibilities). For the public (vs. private) voice and voice frequency measures, we used the same scales as in the main study. To measure commitment towards one's manager, we used a 4-item commitment scale developed by Klein, Cooper, Molloy, and Swanson (2014). A sample item was: "How committed are/were you to your manager?" ( $\alpha=.95)$. We conducted a confirmatory factor analysis (CFA) to estimate the distinctiveness of the three variables. The analysis indicated that the three-factor model fit the data well $\left(\chi^{2}=160.27, d f=74, p<.001, \mathrm{CFI}=.99\right.$, RMSEA $=.06$, SRMR $=.03)$. Chi-square difference tests indicated that this model fit the data better than alternative models that combined (a) public (vs. private) voice and voice frequency $\left(\Delta \chi^{2}=1705.82, \Delta d f=1, p<.001, \mathrm{CFI}=.68\right.$, RMSEA $\left.=.25, \mathrm{SRMR}=.25\right)$, and $(\mathrm{b})$ public (vs. private) voice and commitment to the manager $\left(\Delta \chi^{2}=1638.94, \Delta d f=1, p<\right.$ $.001, \mathrm{CFI}=.69, \mathrm{RMSEA}=.25, \mathrm{SRMR}=.23$ ).

Initiation of change. We asked managers to assess the extent to which their employees initiate change using an adapted 3-item measure of the extent of work-unit change by Caldwell, Herold, and Fedor (2004) with a 5-point Likert scale ( 1 = "Strongly Disagree" to 5 = "Strongly Agree"). A sample item was: "The employee brings changes in my workunit's / organization's processes and procedures" ( $\alpha=.81)$.

Control variables. To exclude alternative explanations, we controlled for several variables. First, we controlled for manager and employee gender as male and female managers might differently assess public (vs. private) voice by male and female employees due to gender bias in work settings (Howell et al., 2015). Second, quality of relationships that managers entertain with their employees might also affect the way that managers 
evaluate their behaviour (Burris et al., 2009; T. Kim et al., 2009; Whiting et al., 2012). Thus, to ensure that relationship quality would not confound our hypothesized effects, we asked employees to rate quality of their relationship with their managers by using the LMX-7 (Graen \& Uhl-Bien, 1995).

Confirmatory factor analysis. We performed a confirmatory factor analysis to estimate the distinctiveness of the five variables (implicit public voice theories, self-promotion climate, public (vs. private) voice, voice frequency, and initiation of change) in the main study. We calculated item-parcels such that implicit public voice theories, public (vs. private) voice behaviour, and voice frequency factors were represented with three indicators, and the self-promotion climate factor was represented with two indicators (Landis, Beal, \& Tesluk, 2000). The analysis indicated that the five-factor model fit the data well $\left(\chi^{2}=94.17, d f=67, p=.016, \mathrm{CFI}=.95, \mathrm{RMSEA}=.06, \mathrm{SRMR}=.07\right)$. Chi-square difference tests indicated that this model fit the data better than alternative models that combined (a) public (vs. private) voice and voice frequency $\left(\Delta \chi^{2}=74.56, \Delta d f=1, p<.001\right.$, $\mathrm{CFI}=.82, \mathrm{RMSEA}=.12, \mathrm{SRMR}=.10$ ), (b) public (vs. private) voice and initiation of change $\left(\Delta \chi^{2}=109.67, \Delta d f=1, p<.001, \mathrm{CFI}=.75, \mathrm{RMSEA}=.14, \mathrm{SRMR}=.13\right)$, and (c) implicit public voice theories and self-promotion climate $\left(\Delta \chi^{2}=10.53 \Delta d f=1, p=.001, C F I=.93\right.$, RMSEA $=.07, \mathrm{SRMR}=.08)$. Hence, these results provided support for the expected factor structure of the variables.

\subsection{Results}

In Table 5.1, we provide descriptive statistics and correlations for the focal variables. As seen in Table 5.2, implicit public voice theories were negatively related to public (vs. private) voice ( $\mathrm{B}=-.18, p=.044$; Table 5.2, Model 2), supporting Hypothesis 1 . In contrast, the main effect of implicit public voice theories on voice frequency was not significant ( $B$ $=-.02, \mathrm{SE}=.09, p=.801$ ). In support of Hypothesis 2, public (vs. private) voice was positively related to initiation of change ( $B=.24, p=.025$, Table 5.2 , Model 6 ). To examine the indirect effect of implicit public voice theories on initiation of change through public (vs. private) voice, we utilized the SPSS PROCESS macro (Hayes, 2013). Supporting Hypothesis 3, the unconditional indirect effect of implicit public voice theories on initiation of change via public (vs. private) voice was significant (-.04 [SE $=.03$ ], 95\% Cl: $-.12,-.001$ ). Further, the implicit public voice theories interacted with self-promotion climate to predict public (vs. private) voice ( $B=.27, p=.039$; Table 5.2, Model 3). In contrast, the interaction term for implicit public voice theories and self-promotion climate on voice frequency was not significant ( $\mathrm{B}=.10, \mathrm{SE}=.13, p=.466$ ). Figure 5.2 illustrates the first interaction (Aiken \& West, 1991). In support of Hypothesis 4, simple slopes analysis indicated that implicit public voice theories were negatively related to public (vs. private) 
voice when self-promotion climate was low $(-1 S D ; B=-.29, p=.013)$ but not when selfpromotion climate was high (+1SD; $\mathrm{B}=.05, p=.721)$.

Table 5.1 Descriptive Statistics, Correlations, and Reliabilities

\begin{tabular}{|c|c|c|c|c|c|c|c|c|c|c|}
\hline & $M$ & SD & 1 & 2 & 3 & 4 & 5 & 6 & 7 & 8 \\
\hline 1. Employee gender ${ }^{a}$ & 0.44 & 0.50 & - & & & & & & & \\
\hline 2. Manager gender ${ }^{a}$ & 0.25 & 0.43 & $.26^{* *}$ & - & & & & & & \\
\hline 3. LMX & 4.04 & 0.52 & -.01 & .18 & $(.88)$ & & & & & \\
\hline 4. Implicit public voice theories (IPVT) & 2.95 & 0.78 & -.04 & -.07 & -.19 & $(.75)$ & & & & \\
\hline 5. Self-promotion climate & 3.65 & 0.63 & .12 & .19 & $.31^{* *}$ & $-.24^{*}$ & $(.82)$ & & & \\
\hline 6. Voice frequency & 3.13 & 0.72 & -.11 & -.01 & .04 & -.03 & $.24^{*}$ & $(.88)$ & & \\
\hline 7. Public (vs. private) voice & 2.37 & 0.72 & .06 & .05 & .08 & $-.20^{*}$ & $.29^{* *}$ & $.32^{* *}$ & $(.93)$ & \\
\hline 8. Initiation of change & 3.37 & 0.74 & -.12 & -.03 & .10 & .16 & .14 & $.28^{* *}$ & $.22^{*}$ & $(.81)$ \\
\hline
\end{tabular}

Note. $\mathrm{N}=110$. Numbers in parentheses along the diagonal are Cronbach's alphas.

a Dummy coded: 0 = male, 1 = female.

${ }^{*} p<.05 ;{ }^{* *} p<.01$. 


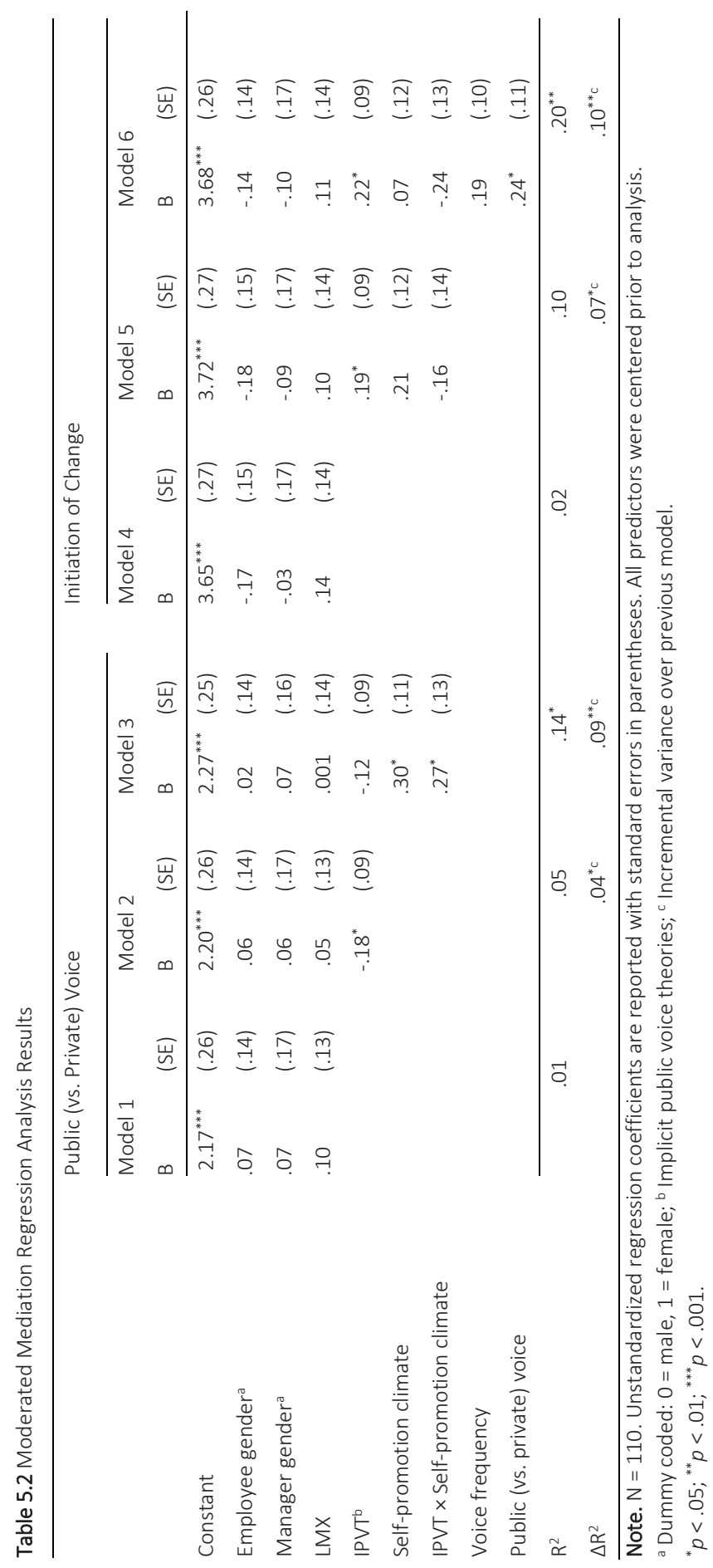




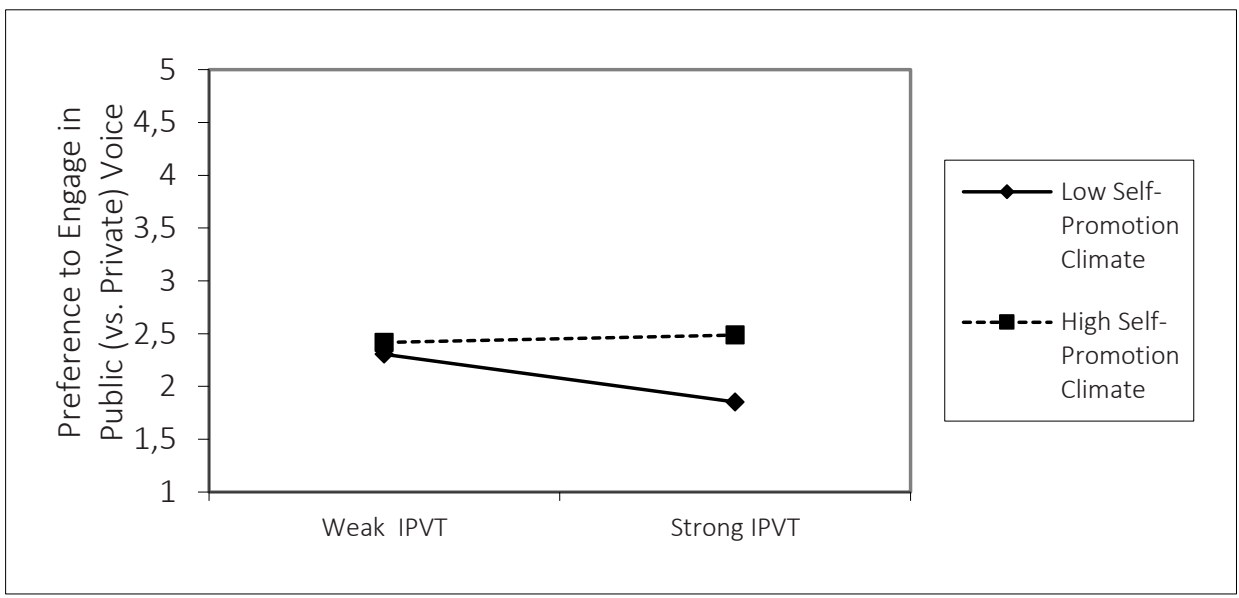

Figure 5.2 Interaction effect of implicit public voice theories and self-promotion climate on employee preference to engage in public (vs. private) voice. High and low levels of self-promotion climate represent one standard deviation above and below the mean. "IPVT" is "implicit public voice theories".

Finally, to test our overall model, we estimated how the indirect effect of implicit public voice theories on initiation of change via public (vs. private) voice varied across different levels of self-promotion climate. We examined this indirect effect using the SPSS PROCESS macro with 1000 bootstrapping iterations (Hayes, 2013). Results indicated that the indirect effect of implicit public voice theories significantly differed as a function of selfpromotion climate. That is, the indirect effect was not significant when self-promotion climate was high (+1SD, $\mathrm{B}=.004$ [SE $=.03$ ], 95\% Cl: $-.05, .06$ ), but was negative when selfpromotion climate was low (-1SD, B = -.06 [SE = .04], 95\% Cl: -.19, -.01). The index of moderated mediation (Hayes, 2013) indicated that the differences between the indirect effects at high and low levels of self-promotion climate were significant ( $B=.05$ [SE =.03], $95 \% \mathrm{Cl}: .002, .14)$. Thus, Hypothesis 5 was supported.

\subsection{Discussion}

In the present paper, we investigated the premise that employees who believe that speaking up in public is inappropriate would prefer private to public voice and, as a result, will be less effective in initiating change. As hypothesized, we found that implicit public voice theories led to less public and more private voice, which, in turn, reduced the extent to which managers evaluated these employees as initiating change. We further showed that this indirect effect was weakened when employees work in groups with a high selfpromotion climate. Our paper makes a number of theoretical contributions. 


\subsubsection{Theoretical Contributions}

First, scholars have generally treated employee voice and silence as dichotomy implicitly suggesting that employees have a binary choice to either voice their ideas, suggestions, and concerns, or to withhold them (see Morrison, 2014). In particular, extant literature suggests that when employees perceive that voice is risky and might be associated with potential negative outcomes, employees are likely to remain silent. This idea traces back to Hirschman (1970) who proposed three responses to job dissatisfaction-exit, voice, and loyalty-and indicated that loyalty often manifests in silence. However, in reality, engaging in voice behaviour is not an "either-or" decision: employees may use a myriad of ways to speak up (Morrison, 2011). In this paper, we challenge the "either-or" perspective and argue that employees may react to risks associated with voice by carefully choosing a social setting in which to express voice. In particular, we found that holding lay theories that public voice is inappropriate and disloyal towards one's manager does not only affect voice frequency but also makes employees more inclined to voice privately. This is important as our theory and findings suggest that by focusing solely on employee voice behaviour as a binary decision without considering relevant voice tactics, we may draw an incomplete picture of how potential antecedents may affect employee voice. In this regard, by outlining private voice as an alternative to employee silence we respond to calls in the voice literature for a more extensive discussion of the role of potential voice tactics (Morrison, 2011).

Second, prior theorizing has primarily focused on the costs of public voice by highlighting that voicing in the presence of others is more risky and is likely to trigger defensive managerial reactions (Detert \& Edmondson, 2006, 2011). We challenge this view by exploring the potential benefits of public voice. In particular, our study shows that employees who engage more in public rather than in private voice are more likely to bring about change. That is, we demonstrate that, although public voice might be seen as more risky behaviour, it is more effective in calling for managers' attention. This finding is in line with the issue-selling literature which suggests that issues raised in public have more chances to be addressed by managers (Dutton \& Ashford, 1993). By the same token, we add to the voice literature by focusing on initiation of change as an outcome variable. Earlier work has studied the effect of voice on employees' general in-role performance (e.g., Burris, 2012; Whiting et al., 2012), career outcomes (e.g., Seibert et al., 2001), and managers' willingness to implement ideas (e.g., Burris, 2012; Fast et al., 2014). However these studies have not explored the extent to which employees actually succeed in introducing change within their work-group or organization. Hence, we respond to the calls in the literature to focus more specifically on the conditions under which voice is more or less effective in initiating change (Morrison, 2014) by underscoring the utility of public voice. 
Third, our finding that self-promotion climate moderates the relationship between implicit public voice theories and public (vs. private) voice behaviour contributes to voice research studying the interactive effects of individual factors and social climate (Frazier \& Bowler, 2015; Frazier \& Fainshmidt, 2012; Morrison et al., 2011; Tangirala \& Ramanujam, 2008; Wang \& Hsieh, 2013). Our study demonstrates that looking at the selfpromotion climate can be fruitful and relevant when studying the distinction between private and public voice (e.g., Frazier \& Bowler, 2015). That is, our results indicate that the self-promotion climate cancels out the negative effects of employees' implicit public voice theories on their public (vs. private) voice behaviour.

Furthermore, in the existing literature, self-promotion, similar to other impression management tactics, has a somewhat negative connotation (e.g., Bolino, 1999). In particular, it is often associated with bragging and showing off (Hernez-Broome \& McLaughlin, 2006). Furthermore, this literature suggests that engagement in self-promotion behaviour leads to lower performance evaluations (Ferris, Judge, Rowland, \& Fitzgibbons, 1994; Wayne \& Ferris, 1990). By contrast, our study highlights that workgroups and organizations may also benefit from a self-promotion climate as it makes public voice appear more legitimate. In this regard, our study makes also an important contribution to the impression management literature by demonstrating the functional side of self-proportion climate.

\subsubsection{Limitations and Directions for Future Research}

As with any research, this study has several limitations. First, as we employed a crosssectional design, this limits our ability to establish causality in the studied relationships. Still, the expected direction of causality is well aligned with theoretical considerations (Levy, Stroessner, \& Dweck, 1998), as it seems implausible to assume that public voice behaviour would alter the deeply held taken-for-granted beliefs of employees. In a similar vein, there is strong theoretical evidence suggesting that employee voice leads to change in one's work-group (e.g., De Dreu \& West, 2001; Detert \& Edmondson, 2011; MacKenzie et al., 2011).

Second, another potential limitation stems from the fact that we asked employees to provide evaluations of the independent variables (i.e., implicit public voice theories and self-promotion climate) as well as of the mediator (i.e., private vs. public voice). Although we acknowledge that the resulting common-method bias may be a potential limitation (Podsakoff et al., 2003), we note that this issue is relevant only for the first stage of the mediation as we used managers' ratings to measure the dependent variable (i.e., initiation of change). Moreover, given that interaction effects are not affected by commonmethod bias (Siemsen et al., 2010), the only potentially affected relationship is between implicit public voice theories and public (vs. private) voice. However, we believe that this issue is of lesser concern as existing literature provides strong evidence on the effect of 
individual beliefs on actual behaviour (Levy et al., 1998). Finally, we took statistical precautions and conducted a confirmatory factor analysis in support of the discriminant validity of our measures reducing further potential common-method concerns.

Third, in the present study we introduced private voice as alternative means (other than silence) to display loyalty and to minimize potential risks associated with voice. Future research could extend this work by studying under which conditions beliefs about inappropriateness of public voice make employees speak up privately instead of falling silent and the other way around. Furthermore, future research should further examine other potential factors that may explain why and when employees would prefer private voice over silence (and vice versa).

Fourth, we did not explicitly examine the underlying mechanisms that may explain why employees who voice in public are more effective in initiating change compared to their colleagues who go and see the manager in private. Although we provide solid theoretical arguments and explain this relationship by the fact that public voice is more likely to raise managers' sense of accountability (Dutton \& Ashford, 1993), we believe that future research should examine this putative mediating mechanism.

\subsubsection{Practical Implications}

Our research highlights that employees' willingness to display loyalty towards their managers and avoid potential risks by preferring private to public voice may potentially work against them in the long run. This is because the stronger implicit public voice theories are, the more likely employees are to speak up in private rather than in public, which, in turn, limits employees' capacity to affect change. The finding that implicit public voice theories-public (vs. private) voice relationship was not significant for employees working in a self-promotion climate suggests that human resources specialists willing to break the effect of employees' ingrained beliefs about public voice should foster a self-promotion climate among employees. Our results also highlight that for employees to make their managers hear their input, it is important to engage more frequently in public rather than in private voice. At the same time, previous research also suggests that public voice is more likely to threaten managers' image and trigger defensive reactions (Detert \& Edmondson, 2006, 2011). Hence, employees need to be aware of both benefits and downsides associated with public voice and strive to speak up in the presence of others in a way that is less image threatening for managers. For example, employees may choose to frame the issue in such a way that managers do not perceive it as a criticism of their performance. 


\section{0 | Chapter 5}

\subsubsection{Conclusions}

Our study highlights a distinction between employees' beliefs about outcomes of public voice and the actual outcomes of public voice. In particular, our results suggest that employees who consider public voice to be disloyal and inappropriate engage more frequently in private than in public voice, which, in turn, negatively affects employees' capacity to bring about change. Our results also indicate that this indirect relationship is mitigated when employees work in groups with a high self-promotion climate. Overall, the present study highlights that the antecedents and consequences of public versus private voice are much more complex and diverse than previously considered in the literature. Hence, we hope that our study will encourage further research on the distinction between private and public voice. 
Chapter

General Discussion and Conclusions 



\subsection{Introduction}

In the last decades, there has been a growing interest in studying employee voice behaviour and in particular how managers respond to employee voice. Multiple studies have outlined factors that affect managerial reactions to voice by primarily focusing on the role of voice frequency and attributes of the voicing employee, the manager, or the message itself. Although research on managers' reactions to voice is on the rise, we still lack a systematic understanding about the role of situational factors that may explain when and why managers react favourably (vs. defensively) to voice. Hence, the main research goal of this dissertation is to examine how the social setting in which voice occurs influences managers' reactions to voice. By addressing this research goal, we studied how managerial voice endorsement differs when voice is expressed in public as compared to private settings and how an employee's tendency to voice in public versus private settings affects his/her capacity to initiate change. Furthermore, as the distinction between private and public voice is novel to the existing literature, we also examined and outlined factors that affect employees' preference to engage in one or another type of voice. Hence, this dissertation provides a comprehensive view of the distinction between private and public voice by highlighting both its consequences and antecedents. Next, we outlined the moderating and mediating factors of the examined relationships. This dissertation draws from theories and findings from the previous literature on voice behaviour, leadership, and other related research streams. Finally, regarding methodology, we aimed for increasing both, internal and external validity, and, thus, we used a complementary set of designs and methods including event reconstruction, experimental vignette, as well as the crosssectional field methods. This approach also enabled us to look at the distinction between private and public voice on two levels: voice events and employees' general preference for one or another type of voice.

By combining different theoretical perspectives and methodological approaches, the three empirical chapters that constitute the core of this dissertation highlight the unique role that the distinction between private and public voice plays in explaining managerial reactions to voice as well as employee voice behaviour. In the following, an overview of the main findings of each of the three empirical chapters is provided. Furthermore, the theoretical implications to the voice literature and related research streams as well as limitations together with directions for future research are discussed. Finally, practical implications of this dissertation for employees, managers, and human resources specialists are outlined. 


\subsection{Overview of Main Findings}

\subsubsection{Chapter 3. Keeping It between Us: Managerial Endorsement of Public versus Private Voice}

In Chapter 3, we studied whether and when the setting in which voice occurs influences managers' voice endorsement. Drawing from the broader social psychology literature (Goffman, 1959, 1967; Sproull et al., 1996; Triplett, 1898; Uziel, 2007; Zajonc, 1965), we hypothesized that managers' voice endorsement differs depending on whether voice is expressed in a public versus private setting. The logic behind this hypothesis is grounded in threat-based thinking (e.g., Burris, 2012; Fast et al., 2014). That is, we proposed that due to a desire to maintain a positive image, managers find the putative criticism inherent in voice that employees express in public, rather than in private, especially threatening, which makes them to react to such voice more defensively. Across three studies (experimental and correlational), we demonstrate that managers endorse ideas raised in public rather than in private less and that this effect is explained by managers' experience of image threat. To rule out alternative explanations, we also examined the indirect effect of public (vs. private) voice on endorsement via managers' perception of ego threat. Results indicated that ego threat, as compared to image threat, does not explain lower levels of voice endorsement in public settings. This implies that image threat, not ego threat, is the unique mechanism underlying managers' aversion to public voice. This finding supports Leary and colleagues' (2009) assertion that it is important to conceptually and empirically distinguish between these two forms of threat.

We also explicated how managers' endorsement of public (vs. private) voice varies as a function of their leader-member exchange quality (i.e., LMX; Graen \& Uhl-Bien, 1995) with the voicing employee. Building on the LMX literature, we tested two theoretical perspectives suggesting opposing predictions about the moderating role of LMX: high LMX may either accentuate or mitigate managers' experience of image threat triggered by public voice, depending on the theoretical standpoint taken. We found support for the mitigating argument in our data, that is, high-quality manager-employee relationships weaken the effect of public voice on image-related concerns. In other words, managers show a positive bias toward their in-group members - that is, public voice from such employees is less likely to trigger threat in managers about their social standing. This is in line with findings from the prior research indicating that managers evaluate input from their in-group members more favourably and attribute more benevolent intentions to those employees (Burris et al., 2009; T. Kim et al., 2009; Whiting et al., 2012). 


\subsubsection{Chapter 4. When Do Employees Speak Up Publicly: The Role of Manager Self-Efficacy and Leader-Member Exchange}

Chapter 4 outlines an event-based study examining the antecedents of employees' preference for public versus private voice. Extending the work by Fast and colleagues (2014), we argued that managers' self-efficacy affects not only employees' binary choice between voicing ones' ideas, opinions, and concerns or remaining silent, but also employees' choice in which setting to express voice. As predicted, we found that managers' selfefficacy was positively associated with public (vs. private) voice. These results once again suggest that the level of managerial self-efficacy provides employees with social cues about voice riskiness and, thus, affects their voice behaviour. Furthermore, the results indicate that the nature of the relationship between a manager and a voicing employee (i.e., LMX quality; Graen \& Uhl-Bien, 1995) moderates the effect of the manager's selfefficacy on public (vs. private) voice such that the relationship holds only when LMX is low, but not when it is high.

\subsubsection{Chapter 5. Employees' Misplaced Loyalty: Perceived Costs and Actual} Benefits of Public Voice

In Chapters 3 and 4, we examined consequences and antecedents of public versus private voice, respectively, by using an event-based perspective (i.e., focusing on specific voice events). In Chapter 5, by contrast, we study the general tendency of employees (i.e., across events) to engage in public versus private voice. In particular, we theorized that the more employees have internalized the belief that public voice is inappropriate (as it may harm managers' social standing and thus lead to defensive reactions), the more they will be likely to voice privately because in private settings image-related concerns are minimized (Goffman, 1959, 1967; Sproull et al., 1996; Triplett, 1898; Uziel, 2007; Zajonc, 1965). Yet, public voice is more likely to be heard and recognized as compared to private voice because in the presence of other people managers feel higher pressure to consider the provided input and cannot simply dismiss it (Dutton \& Ashford, 1993). Consequently, we argue that employees who prefer public to private voice are more likely to initiate change in their work-group or organization. As our findings revealed, employees holding implicit public voice theories prefer private voice, which, as a result, limits employees' capacity to initiate change, as compared to employees who voice publicly. We also found that the negative effect of implicit public voice theories on public voice behaviour is moderated by self-promotion climate (i.e., a shared belief that it is appreciated to display behaviours that signal one's competence) such that the effect holds only when employees work in organizations with a low self-promotion climate. Thus, results indicate that shared beliefs on the work-group level about the appropriateness of engaging in self- 
promoting behaviours mitigate the effects of employees' individual beliefs on public voice.

\subsection{Theoretical Contributions}

The findings of these three empirical chapters advance the voice literature by distinguishing between private and public voice and by highlighting their role in explaining managerial reactions to voice. Although research has suggested that examination of the social setting is important for understanding voice and its consequences, no systematic research has addressed this topic. Therefore, this dissertation is the first to provide a comprehensive view on the distinction between private and public voice by looking at both its consequences and its antecedents. While in earlier sections the chapter-specific contributions were outlined, here, I take a "macro" perspective and discuss implications and contributions of this dissertation in more general.

\subsubsection{New Perspectives on Managers' Reactions to Voice}

Managers play a central role in shaping voice behaviour and its effects. Managers act as liaisons by carrying voice upward to top management and by providing resources needed to implement the ideas (Detert et al., 2013; Dutton \& Ashford, 1993). Next, managers have formal power and authority to punish as well reward employees for engaging in voice behaviour (Seibert et al., 2001; Van Dyne \& LePine, 1998; Whiting et al., 2008). Therefore, to better understand the implications of voice behaviour, it is necessary to identify the conditions under which managers respond favourably versus defensively to voice (Morrison, 2014).

Prior studies on managerial reactions to voice have primarily focused on the effects of voice frequency, the attributes of the manager, the voicing employee, and the content of the voice message (Burris, 2012; Fast et al., 2014; Seibert et al., 2001; Sijbom et al., 2015a, 2015b). Hence, although important strides have been made towards getting a better understanding about managers' responsiveness to voice, little to no studies have addressed how situational features may shape managers' reactions to voice. We argue and show that by focusing on situational variability, we may enhance our understanding of the psychology of managerial reactions to voice in theoretically meaningful ways.

In this dissertation, we focused on a fundamental situational aspect that might explain variance in managers' reactions to voice- public versus private setting (Breckler \& Greenwald, 1986; Triplett, 1898; Zajonc, 1965). Research in other domains has established that individuals' behaviours and reactions differ when they encounter situations that are public as opposed to private (Ashford et al., 2003; Markus, 1978; Platania \& Moran, 2001; Uziel, 2007). Supporting this work, this dissertation demonstrates that the 
social setting in which voice occurs does matter. First, our findings suggest that voice expressed in public triggers image concerns in managers, and, as a result, makes them endorse public voice less (Chapter 3). This is consistent with the shared perspective in the voice literature that public voice is riskier as managers do not like it when employees challenge them in the presence of other people (Detert \& Edmondson, 2006, 2011).

Although Chapter 3 suggests that public voice leads to more negative outcomes in terms of managers' voice endorsement, the findings of Chapter 5 highlight that still employees who prefer public to private voice are more effective in bringing about change to their work-group or organization. Thus, findings of Chapters 3 and 5 point to a more complex picture about the potential consequences of public voice. In this respect, it is important to note that Chapter 3 focused on studying the consequences of public voice within particular voice events as compared to Chapter 5, which examined the effects of employees' general tendency to voice publicly (vs. privately). Hence, our findings seem to suggest that, when employees voice publicly, managers are likely to show voice aversion due to enhanced image-related concerns in that particular situation; however, although public voice is more threatening for managers, they feel higher pressure to consider the issue raised, quite in contrast to private voice events, in which voice can be more easily dismissed and ignored (Dutton \& Ashford, 1993). Consequently, employees who prefer public to private voice are more likely to create instances in which their voice calls on their managers' attention, and, as a result, in the long run, such employees are more effective in initiating change in their work-group or organization. This dissertation thus highlights how the social setting in which voice occurs affects in complex ways managers' reactions to voice. Our finding emphasizes the need for a more elaborate conversation in the voice literature on why and how situational factors shape managers' reactions to voice.

\subsubsection{Shifting Focus from Voice Frequency to Voice Tactics and Outlining Antecedents of Public (vs. Private) Voice}

Scholars have generally treated employee voice and silence as dichotomy implicitly suggesting that employees have a binary choice to either voice their ideas, suggestions, and concerns or to withhold them (see Morrison, 2014). In particular, extant literature suggests that when employees perceive that voice is risky and might be associated with potentially adverse outcomes, employees are likely to remain silent. However, in reality, engaging in voice behaviour is not an "either-or" decision: employees may use a myriad of voice tactics (Morrison, 2011). In this dissertation, we challenge the "either-or" perspective and argue that employees may react to risks associated with voice by carefully choosing a social setting in which to express voice. In particular, we found that employees were more likely to voice in more private settings when their managers had a low sense of self-efficacy (Chapter 4). Furthermore, we found that holding lay theories that public 
voice is inappropriate and disloyal towards one's manager does not only affect voice frequency but also makes employees more inclined to voice privately (Chapter 5). Interestingly, both these factors have been identified in previous research as antecedents of employee voice frequency (Detert \& Edmondson, 2011; Fast, Burris, \& Bartel, 2014). This is important as our theory and findings suggest that by focusing solely on employee voice behaviour as a binary decision without considering relevant voice tactics, we may draw an incomplete picture of how potential antecedents may affect employee voice. Hence, this dissertation highlights that it is important to shift the focus of existing research from studying only voice frequency to also exploring voice tactics. In this regard, by outlining private voice as an alternative to employee silence, we respond to calls in the voice literature for a more extensive discussion of the role of potential voice tactics (Morrison, 2011).

By the same token, we contribute to research on the distinction between private and public voice. The existing research suggests that when employees communicate their ideas, suggestions, or concerns in the presence of other people, such voice is more likely to evoke defensive reactions (Detert \& Edmondson, 2006, 2011). However, this research has neglected to explore factors that may affect employees' preference for one or another type of voice. Thus, our findings that managers' self-efficacy (Chapter 4) and employees' implicit public voice theories (Chapter 5) impact employees' choice of voice social setting advance our knowledge on the distinction between private and public voice by delineating its antecedents.

\subsubsection{Public (vs. Private) Voice and LMX}

A number of studies have provided evidence that employees who entertain close, trusting relationships with their managers feel more psychologically safe and thus are more likely to engage in voice behaviour (Burris et al., 2008; Liu et al., 2013; Van Dyne et al., 2008) and that managers, in turn, react to input from such employees more positively (Burris et al., 2009; T. Kim et al., 2009; Whiting et al., 2012). However, this research has neglected to study whether such effects hold when considering public voice. This is important as, due to the elevated challenge inherent in public voice (Detert \& Edmondson, $2006,2011)$, such voice might be seen differently by managers and employees. In particular, our findings suggest that high LMX employees, as opposed to more distant employees, do not rely on social cues associated with their managers' self-efficacy when deciding in which setting to voice, but, instead, in general prefer more private voice (Chapter 4). This implies that, although high LMX employees may in general feel safer when engaging in voice behaviour, they are reluctant to voice publicly as they are concerned that it may come across as a violation of loyalty and social support expectations associated with high $L M X$ relationship and thus harm the relationship with their managers. At the same time, findings of Chapter 3 indicate that public voice expressed by high LMX employees reduces 
managers' experienced image threat associated with public voice and, as a result, leads to more voice endorsement. Hence, these findings from Chapters 3 and 4 add to the voice and LMX literature by highlighting differences in how managers and employees perceive public (vs. private) voice expressed by in-group members. Therefore, it would be useful for future research to further examine divergence in managers' and employees' evaluation of public voice communicated by high LMX employees.

\subsection{Limitations and Directions for Future Research}

Notwithstanding the above-mentioned theoretical contributions of the dissertation, we should mention several limitations and new avenues for future research. First, in the three empirical chapters, the field studies that we conducted were cross-sectional, which may limit our ability to infer causality. However, we believe that this issue is of lesser concern as we provided strong theoretical evidence against the possibility of reverse causality and also addressed this potential limitation by replicating the findings in experimental settings (Chapter 3 ) or by measuring variables at different time points (Chapter 4).

Second, given the within-person implications of our arguments (e.g., Chapter 3), it might be fruitful for future research to conduct longitudinal studies that would complement our between-person design and would examine within-person variability across situations (e.g., experience sampling).

Third, although we demonstrated that image threat is an underlying psychological mechanism explaining the link between public (vs. private) voice setting and endorsement (Chapter 3), Chapter 5 suggests that there are other possible pathways through which an employee's voice in public (vs. private) relates to managers' reactions to voice. In particular, in Chapter 5 we theorized that a manager's sense of accountability (Tetlock, 1983) influences the manager's recognition of the raised issues. In particular, Dutton and Ashford (1993) suggest that when employees attempt to voice in the presence of others, they put higher pressure on managers to consider the raised idea. Hence, when voice is communicated in public, managers might feel more threatened, but also might feel more accountable as they cannot simply ignore the idea because of evaluation concerns. Thus, it seems possible that multiple mediating pathways (e.g., image threat, accountability) may act in parallel and possibly in opposite directions. This might also explain why we did not find the main effect of employee voice in public (vs. private) on endorsement in Studies of Chapter 3. Hence, future research should examine image threat and accountability as two parallel mediating mechanisms and delineate conditions under which one mechanism dominates the other. 
Fourth, future research should investigate how reactions of an audience affect managers' responses. The more employees speak up in public, as compared to in private, the more likely they are to initiate instances of collective voice. This is because issues raised by an employee are often relevant not only for this particular employee but often affect a wider group of stakeholders in the organization (Edmondson, 2003; Van Dyne \& LePine, 1998). As a result, when voice is communicated in public, it is more likely to attract the attention of other employees and managers and thus provoke more in-depth discussions on the issue raised, as compared to voice expressed in one-on-one settings (Detert \& Edmondson, 2011). Such public discussions often generate more acceptable solutions and reduce resistance to change (Furst \& Cable, 2008). As a result, other employees may also identify with the raised issue (Yukl \& Tracey, 1992) and thus support the employee in his/her attempts to address the issue. Creating such coalition may have implications on how managers react to voice.

Finally, we believe that future research should further examine and extend our understanding of the antecedents of public (vs. private) voice. Specifically, when examining variance in public (vs. private) voice events, it would be useful in future research to do a more nuanced investigation of other potential situational factors (e.g., manager and employee affective states) that may explain why in particular situations employees voice publicly (vs. privately). At the same time, when examining employees' general tendency to express voice in public (vs. private) settings, future research should investigate the role of employee personal dispositions (e.g., proactive personality, self-efficacy), position in a group (e.g., status) as well as manager characteristics (e.g., manager goal orientation).

\subsection{Practical Implications}

In the globalized and highly competitive world, it is critical for organizations to move quickly. Moving quickly involves avoiding costly mistakes and delays. In the knowledge economy in particular, with its complex supply chains and specializations, no individual can be expected to know everything. Managing a team with diverse skills and experiences in such a way that employees' input is shared openly and followed up with actions would allow organizations to improve their effectiveness. Hence, the better understanding of employee voice and managers' reactions to employee voice can help to build such environments. In this regard, this dissertation has meaningful practical implications for employees, managers, and human resources specialists.

Our findings suggest that public voice is associated with enhanced image concerns that make managers less likely to endorse employee voice. At the same time, employees who have a general tendency to voice publicly are more effective in initiating change as 
opposed to employees who typically prefer private voice settings. This suggests that employees interested in bringing about change to their work-group or organization might be more successful by speaking up in the presence of other people but in such way, that is less image threatening for their managers. For example, to minimize potential image concerns of managers, employees may choose to invest more time in developing a closer, trusting relationship with their managers.

Furthermore, managers should be cognizant that high LMX employees, instead of openly discussing emerging issues, ideas, and suggestions in public settings, tend to bring up the issues in private, irrespective of whether the managers come across as more or less open to public voice. Thus, reducing the opportunities to discuss the topic in public. Here, human resources specialists should consider utilizing interventions that reduce reluctance to voice publicly. For example, organizations may want to highlight that voicing not only in private but also in public is encouraged and welcomed. Although indirectly, our findings from Chapter 5 suggest that by promoting a self-promotion climate public voice may come to be considered as normative. Such interventions may also help to minimize the effect of employees' taken-for-granted beliefs about public voice on their tendency to voice privately.

\subsection{Conclusion}

This dissertation started with the quote suggesting that we not only choose between engaging in voice or remaining silent, but also between making "our moves" privately or publicly. Although scholars have acknowledged that employees might choose different social settings when engaging in voice behavior, we still lacked understanding about potential consequences of this choice. Drawing on prior voice literature and literature on the related research streams, this dissertation provides strong evidence that the social setting in which voice is expressed matters. In particular, this dissertation contributes to the voice literature by highlighting the complex nature of managerial reactions to public voice. Our findings suggest that managers are less inclined to endorse ideas, suggestions, or concerns expressed publicly; however, at the same time, employees who voice publicly (vs. privately) still have a higher capacity to bring about change to their work-group or organization in the long run. To further explicate the role of the public versus private voice distinction for voice research, we demonstrated that by carefully adjusting the social setting in which voice is expressed, employees might potentially minimize the risks associated with voice without necessarily falling silent. In this regard, we found that managers' self-efficacy and employees' lay theories about public voice affect not only how frequently employees engage in voice behavior but also in which settings they do so. Taken together, this dissertation provides a comprehensive theoretical framework and 


\section{2 | Chapter 6}

an empirical investigation of consequences and antecedents of public (vs. private) voice as well as underlying mechanisms and boundary conditions of the studied relationships. By highlighting the importance of examining public versus private voice for getting a better understanding of managerial reactions to voice as well as employee voice tactics, we believe that this dissertation builds a strong foundation for voice scholars to further examine the role of voice social settings. Finally, we hope that this dissertation will help practitioners to more effectively manage public voice in organizations by minimizing its potential risks and nourishing its benefits. 
Appendix | 123

Appendix 



\section{Appendix A: Scenario Texts}

You are the department head of the Marketing department of Xantippe, a company specializing in frozen fast food. As the head of the department, and its most experienced member, you plan and set the marketing strategy of the company and directly manage the work of the department's 12 employees.

For the last two months, you have worked hard on developing the company's most important marketing campaign for a new product called "Fat-Free French Fries". After giving it much thought and drawing on your experience, you decided to go with an event marketing strategy. This strategy involves organizing events where people can directly sample the product. In particular, to advertise healthy features of Xantippe's French Fries, you are planning to promote it at events related to a healthy lifestyle, with a special focus on sporting events. You have had your employees run the numbers and you are sure that this strategy will be a great success.

Your approach in the proposed campaign is based on similar strategies you have frequently used in this and in past roles with similar markets and products. This is the type of marketing strategy you are known for. Your ability to successfully implement and lead the marketing campaigns that use the event strategy is a big part of why you have advanced to the position of department head at Xantippe.

Earlier today, you walked into the open office space where your 12 employees work. You were casually talking to some of the employees, checking in on their work.

Suddenly, Riley, one of the employees, approached you and asked to privately speak to you, one-onone, about your campaign.

Alone in your office, Riley said privately:

Suddenly, Riley, one of the employees, approached you and publicly, in front of the other 11 employees in the open office space, spoke up about your campaign.

With the other 11 employees listening, Riley said publicly:

"I have been thinking about it and I have to say, I am really concerned about your current strategy for the new fries campaign. You are focusing on advertising our product at sporting events. But, do you truly believe people at these events really care about French fries? Recent market research shows that people don't pay attention and easily forget products that they try at these kinds of events.

I just can't see it working!

If it were up to me, I would go with an online campaign. Advertisement with online banners on social media like Facebook or Twitter should get customers attention much better than your current strategy. Going ahead with your strategy is a big risk. We know that this campaign is extremely important and I am worried that we will completely miss our sales targets!"

Baseline

scenario

Private

Condition

Public

Condition

Baseline scenario 



\section{Valorization Addendum}

In recent years, there were multiple cases in which whistle-blowers have brought media attention to major shortcomings of companies, government departments, and non-profit organizations. It would be naïve to suggest that openness and constructive responses to employee voice could have addressed all of the fundamental issues underlying these scandals. However, in many cases, a willingness to listen to employee voice, would have given organizations the chance to take steps to address problems away from the glare of cameras and social media. Many of the individuals who leaked stories to the press did so as a result of their frustration with internal processes that did not deliver appropriate action. While these may be dramatic examples of organizations resisting employee voice, they do demonstrate, at the extreme end of the spectrum, the destructive consequences of environments in which contrary opinions are not welcomed.

In fact, although many practitioners develop programs and tools focusing on improving communication up and down the hierarchy, today's organizations still often face problems with fostering open and transparent communication at the workplace, particularly when it comes to such challenging forms of communication as employee upward voice. One finds many examples of organizations that did not manage voice well, and, in consequence, experienced serious problems or faced disasters. Prominent examples are the Enron scandal, the explosion of the space shuttle Challenger, and the Asiana 214 airplane crash. Hence, although everybody advocates the importance of being responsive to employees' ideas and opinions, in reality managers, or people with power and resources to act upon upward voice, often disregard employee voice or react defensively to it. In return, employees who may possess critical knowledge grow reluctant to speak up or remain unsure about how to speak up most effectively (i.e., that they are heard and not punished). Consequently, better understanding of employee voice and managers' reactions to employee voice is highly relevant for today's organizations. It is important to note that, although in this dissertation voice is primarily discussed in a business context, issues that I address are relevant for any organization with a hierarchical structure (e.g., governmental organizations, educational institutions, etc.). Insights form this dissertation have 
meaningful practical implications for managers, employees, and human resources specialists.

For managers, this dissertation highlights the important role of the context in how they respond to upward voice. In particular, when reacting defensively to employee voice in public, a manager not only may lose the benefit of this specific piece of input, but also discourage other employees present from speaking up. This may have negative implications for team functioning. This is because when voicing publically employees likely expose other team members to new perspectives that they might not have previously considered, thus stimulating more in-depth discussions (De Dreu \& West, 2001; Nemeth et al., 2001). In contrast, voice that is privately expressed in the confines of closed-door oneon-one meetings with the manager can fail to similarly mobilize collective contemplation of issues (Detert \& Edmondson, 2011). In addition, employees waiting for a private opportunity to express their ideas or concerns may speak up too late when their input is no longer useful or can no longer be implemented (Detert \& Edmondson, 2011). Thus, managers should be wary of the fact that by disregarding or discouraging public voice, they let their concerns about social image come in the way of more effective team functioning.

Furthermore, the finding that managers react particularly negatively to public voice from employees who are outside the loyal circle of confidants illustrates to managers that they are likely to miss out on potentially contrary viewpoints to which they might not otherwise have access. This is because such employees are more likely to have non-overlapping perspectives vis-à-vis the manager (e.g., Granovetter, 1983).

For employees, this dissertation also provides insights into the tactics that they may use when wishing to effectively raise suggestions, ideas, or concerns. If employees aim for bringing about change, they will be more likely to succeed if they speak up in public rather than in private. Yet, employees should be aware that public voice might trigger image-related concerns in managers, as a results of which the manager may initially react defensively by showing low willingness to endorse such voice. Hence, we recommend that when speaking up in public, employees be especially careful in order to assure that their voice does not come across to managers as criticism of their prior actions or decisions. One way to do so is to invest more time in developing closer and trusting relationship with one's manager. Furthermore, employees who are in the loyal circle of confidants to the manager may find it useful to know that their public voice is less threatening for managers; thus, they, more than other employees, should feel confident in expressing their voice in the presence of other people. This is a particularly important insight because, as we have seen in Chapter 4, regardless of whether managers come across as open and supportive of voice or not, high LMX employees typically prefer to voice in private settings, thereby failing to utilize the benefits of public discussions. 
For human resource specialists, these findings highlight the need to foster an organizational culture in which both managers and employees perceive public voice to be normative. In this regard, we suggest that human resource specialists use the findings from this dissertation to develop specific training programs for both managers and employees which would foster such a culture. An important element in these programs should be the clear communication and explanation of the benefits and drawbacks associated with public voice. This may help reduce the possible negative effect of individuals' implicit theories about public voice. Furthermore, in such programs, managers should actively practice various techniques of how to actively solicit voice (e.g., organizing regular feedback meetings), while employees should discuss and practice the do's and don'ts of speaking up in public settings. Next to that, such training programs may include intervention programs directed at reducing managers' concerns about their social standing in the group. Finally, we believe that both managers and employees would greatly benefit from having regular coaching sessions in which they can analyse and discuss their experiences of public and private voice events. Development of such training programs seems especially relevant because too many managers often assume that having "open-door policies" is sufficient to motivate employees to share their ideas or concerns (Detert \& Burris, 2016). In fact, such passive initiatives typically fall short, and organizations need to learn to create an environment where employees are comfortable in sharing their input and opinions in public and private settings.

Finally, insights from this dissertation are also relevant for educational purposes. Lecturers in business and management schools and universities can incorporate findings from this dissertation in courses focused on organizational behaviour, leadership, effective communication, and human resources management. Today's business and management students are tomorrow's employees and managers and discussing with them that the setting in which voice occurs matters will prepare them to be more effective in managing and utilizing upward input.

To conclude, findings from this dissertation provide insights to employees, managers, and human resources specialists on the relevance of the social setting in which voice occurs. The recognition of differences in perception and consequences of public versus private voice is a small but an important step in building an environment in which the potential of upward voice is used to its best effects. 



\section{References}

Aguinis, H., \& Bradley, K. J. (2014). Best practice recommendations for designing and implementing experimental vignette methodology studies. Organizational Research Methods, 17(4), 351-371. https://doi.org/10.1177/1094428114547952

Aiken, L. S., \& West, S. G. (1991). Multiple regression: Testing and interpreting interactions. New York, NY: Sage.

Ajzen, I. (1991). The theory of planned behavior. Organizational Behavior and Human Decision Processes, 50(2), 179-211. https://doi.org/10.1016/0749-5978(91)90020-T

Ashford, S. J. (1989). Self-assessments in organizations: A literature review and integrative model. In L. L. Cummings \& B. M. Staw (Eds.), Research in organizational behavior (Vol. 11, pp. 133-174). Greenwich, CT: JAI Press.

Ashford, S. J., Blatt, R., \& VandeWalle, D. (2003). Reflections on the looking glass: A review of research on feedback-seeking behavior in organizations. Journal of Management, 29(6), 773-799. https://doi.org/10.1016/S0149-2063

Ashford, S. J., \& Northcraft, G. B. (1992). Conveying more (or less) than we realize: The role of impressionmanagement in feedback-seeking. Organizational Behavior and Human Decision Processes, 53(3), 310-334. https://doi.org/10.1016/0749-5978(92)90068-I

Ashford, S. J., Sutcliffe, K. M., \& Christianson, M. K. (2009). Speaking up and speaking out: The leadership dynamics of voice in organizations. In J. Greenberg \& M. Edwards (Eds.), Voice and silence in organizations (pp. 175-202). Bingley, UK: Emerald.

Avey, J. B., Wernsing, T. S., \& Palanski, M. E. (2012). Exploring the process of ethical leadership: The mediating role of employee voice and psychological ownership. Journal of Business Ethics, 107(1), 21-34. https://doi.org/10.1007/s10551-012-1298-2

Bandura, A. (1977). Self-efficacy: Toward a unifying theory of behavioral change. Psychological Review, 84(2), 191-215. https://doi.org/10.1037/0033-295X.84.2.191

Baumeister, R. F. (1982). A self-presentational view of social phenomena. Psychological Bulletin, 91(1), 3-26. https://doi.org/10.1037/0033-2909.91.1.3

Baumeister, R. F., \& Leary, M. R. (1995). The need to belong: Desire for interpersonal attachments as a fundamental human motivation. Psychological Bulletin, 117(3), 497-527. https://doi.org/10.1037/0033-2909.117.3.497

Blader, S. L., \& Chen, Y.-R. (2012). Differentiating the effects of status and power: A justice perspective. Journal of Personality and Social Psychology, 102(5), 994-1014. https://doi.org/10.1037/a0026651

Bolino, M. C. (1999). Citizenship and impression management: Good soldiers or good actors? Academy of Management Review, 24(1), 82-98. https://doi.org/10.5465/AMR.1999.1580442

Bolino, M. C., \& Turnley, W. H. (1999). Measuring impression management in organizations: A scale development based on the Jones and Pittman taxonomy. Organizational Research Methods, 2(2), 187206. https://doi.org/10.1177/109442819922005

Bolino, M. C., Turnley, W. H., \& Niehoff, B. P. (2004). The other side of the story: Reexamining prevailing assumptions about organizational citizenship behavior. Human Resource Management Review, 14(2), 229-246. https://doi.org/10.1016/j.hrmr.2004.05.004

Boroff, K. E., \& Lewin, D. (1997). Loyalty, voice, and intent to exit a union firm: A conceptual and empirical analysis. ILR Review, 51(1), 50-63. https://doi.org/10.1177/001979399705100104

Botero, I. C., \& Van Dyne, L. (2009). Employee voice behavior: Interactive effects of LMX and power distance 
in the United States and Colombia. Management Communication Quarterly, 23(1), 84-104. https://doi.org/10.1177/0893318909335415

Bowler, W. M., Halbesleben, J. R. B., \& Paul, J. R. B. (2010). If you're close with the leader, you must be a brownnose: The role of leader-member relationships in follower, leader, and coworker attributions of organizational citizenship behavior motives. Human Resource Management Review, 20(4), 309-316. https://doi.org/10.1016/j.hrmr.2010.04.001

Breckler, S. J., \& Greenwald, A. G. (1986). Motivational facets of the self. In E. T. Higgins \& R. Sorrentino (Eds.), Handbook of motivation and cognition (pp. 145-164). New York, NY: Guilford Press.

Brislin, R. W. (1980). Cross-cultural research methods. In I. Altman, A. Rapoport, \& J. F. Wohlwill (Eds.), Environment and culture. Human behavior and environment (Advances in theory and research) (Vol. 4, pp. 47-82). Boston, MA: Springer. https://doi.org/10.1007/978-1-4899-0451-5_3

Brown, P., \& Levinson, S. C. (1987). Politeness: Some universals in language usage. New York, NY: Cambridge University Press.

Brown, V. R., \& Paulus, P. B. (2002). Making group brainstorming more effective: Recommendations from an associative memory perspective. Current Directions in Psychological Science, 11(6), 208-212. https://doi.org/10.1111/1467-8721.00202

Burgoon, J. K. (2009). Expectancy violations theory. In E. Griffin (Ed.), A first look at communication theory (pp. 84-97). New York, NY: McGraw-Hill.

Burris, E. R. (2012). The risks and rewards of speaking up: Managerial responses to employee voice. Academy of Management Journal, 55(4), 851-875. https://doi.org/10.5465/amj.2010.0562

Burris, E. R., Detert, J. R., \& Chiaburu, D. S. (2008). Quitting before leaving: The mediating effects of psychological attachment and detachment on voice. Journal of Applied Psychology, 93(4), 912-922. https://doi.org/10.1037/0021-9010.93.4.912

Burris, E. R., Detert, J. R., \& Romney, A. C. (2013). Speaking up vs. being heard: The disagreement around and outcomes of employee voice. Organization Science, 24(1), 22-38. https://doi.org/10.1287/orsc.1110.0732

Burris, E. R., Rockmann, K., \& Kimmons, Y. S. (2017). (in press). The value of voice (to managers): Employee identification and the content of voice. Academy of Management Journal. https://doi.org/10.5465/amj.2014.0320

Burris, E. R., Rodgers, M. S., Mannix, E. A., Hendron, M. G., \& Oldroyd, J. B. (2009). Playing favorites: The influence of leaders' inner circle on group processes and performance. Personality and Social Psychology Bulletin, 35(9), 1244-1257. https://doi.org/10.1177/0146167209338747

Caldwell, S. D., Herold, D. M., \& Fedor, D. B. (2004). Toward an understanding of the relationships among organizational change, individual differences, and changes in person-environment fit: A cross-level study. Journal of Applied Psychology, 89(5), 868-882. https://doi.org/10.1037/0021-9010.89.5.868

Carver, C. S., Lawrence, J. W., \& Scheier, M. F. (1999). Self-discrepancies and affect: Incorporating the role of feared selves. Personality and Social Psychology Bulletin, 25(7), 783-792. https://doi.org/10.1177/0146167299025007002

Chan, D. (2009). So why ask me? Are self-report data really that bad? In C. E. Lance \& R. J. Vandenberg (Eds.), Statistical and methodological myths and urban legends: Doctrine, verity and fable in the organizational and social sciences (pp. 309-336). New York, NY: Routledge.

Chen, G., Gully, S. M., \& Eden, D. (2001). Validation of a new general self-efficacy scale. Organizational Research Methods, 4(1), 62-83. https://doi.org/10.1177/109442810141004

Chen, Z., Lam, W., \& Zhong, J. A. (2007). Leader-member exchange and member performance: A new look at individual-level negative feedback-seeking behavior and team-level empowerment climate. Journal of Applied Psychology, 92(1), 202-212. https://doi.org/10.1037/0021-9010.92.1.202

Chiu, C., Hong, Y., \& Dweck, C. S. (1997). Lay dispositionism and implicit theories of personality. Journal of Personality and Social Psychology, 73(1), 19-30. https://doi.org/10.1037/0022-3514.73.1.19

Cho, Y., \& Fast, N. J. (2012). Power, defensive denigration, and the assuaging effect of gratitude expression. Journal of Experimental Social Psychology, 48(3), 778-782. https://doi.org/10.1016/j.jesp.2011.12.016

Cupach, W. R., \& Carson, C. L. (2002). Characteristics and consequences of interpersonal complaints associated with perceived face threat. Journal of Social and Personal Relationships, 19(4), 443-462. https://doi.org/10.1177/0265407502019004047

De Dreu, C. K. W., \& West, M. A. (2001). Minority dissent and team innovation: The importance of 
participation in decision making. Journal of Applied Psychology, 86(6), 1191-1201. https://doi.org/10.1037//0021-9010.86.6.1191

DeNisi, A. S., \& Kluger, A. N. (2000). Feedback effectiveness: Can 360-degree appraisals be improved? The Academy of Management Executive, 14(1), 129-139. https://doi.org/10.5465/AME.2000.2909845

Detert, J. R., \& Burris, E. R. (2007). Leadership behavior and employee voice: Is the door really open? Academy of Management Journal, 50(4), 869-884. https://doi.org/10.5465/AMJ.2007.26279183

Detert, J. R., \& Burris, E. R. (2016). Can your employees really speak freely? Harvard Business Review, 94(1-2), 80-87.

Detert, J. R., Burris, E. R., Harrison, D. A., \& Martin, S. R. (2013). Voice flows to and around leaders: Understanding when units are helped or hurt by employee voice. Administrative Science Quarterly, 58(4), 624-668. https://doi.org/doi/abs/10.1177/0001839213510151

Detert, J. R., \& Edmondson, A. C. (2006). Everyday failures in organizational learning: Explaining the high threshold for speaking up at work. Working paper 06-024, Boston, MA: Harvard Business School.

Detert, J. R., \& Edmondson, A. C. (2011). Implicit voice theories: Taken-for-granted rules of self-censorship at work. Academy of Management Journal, 54(3), 461-488. https://doi.org/10.5465/AMJ.2011.61967925

Detert, J. R., \& Treviño, L. K. (2010). Speaking up to higher-ups: How supervisors and skip-level leaders influence employee voice. Organization Science, 21(1), 249-270. https://doi.org/10.1287/orsc.1080.0405

Dienesch, R. M., \& Liden, R. C. (1986). Leader-member exchange model of leadership: A critique and further development. Academy of Management Review, 11(3), 618-634. https://doi.org/10.5465/AMR.1986.4306242

Dinh, J. E., \& Lord, R. G. (2012). Implications of dispositional and process views of traits for individual difference research in leadership. Leadership Quarterly, 23(4), 651-669. https://doi.org/10.1016/j.leaqua.2012.03.003

Duchon, D., Green, S. G., \& Taber, T. D. (1986). Vertical dyad linkage: A longitudinal assessment of antecedents, measures, and consequences. Journal of Applied Psychology, 71(1), 56-60. https://doi.org/10.1016/0030-5073(75)90005-7

Dulebohn, J. H., Bommer, W. H., Liden, R. C., Brouer, R. L., \& Ferris, G. R. (2012). A meta-analysis of antecedents and consequences of leader-member exchange: Integrating the past with an eye toward the future. Journal of Management, 38(6), 1715-1759. https://doi.org/10.1177/0149206311415280

Dutton, J. E., \& Ashford, S. J. (1993). Selling issues to top management. Academy of Management Review, 18(3), 397-428. https://doi.org/10.5465/AMR.1993.9309035145

Dutton, J. E., Ashford, S. J., O’Neill, R. M., \& Lawrence, K. A. (2001). Moves that matter: Issue selling and organizational change. Academy of Management Journal, 44(4), 716-736. https://doi.org/10.2307/3069412

Dyne, L. Van, Ang, S., \& Botero, I. C. (2003). Conceptualizing employee silence and employee voice as multidimensional constructs. Journal of Management Studies, 40(6), 1359-1392. https://doi.org/10.1111/1467-6486.00384

Eagly, A. H., \& Karau, S. J. (2002). Role congruity theory of prejudice toward female leaders. Psychological Review, 109(3), 573-598. https://doi.org/10.1037/0033-295X.109.3.573

Eden, J., \& Long, T. (2014). The obligation to dissent. Retrieved from http://www.greatleadershipbydan.com/2014/04/the-obligation-to-dissent.html

Edmondson, A. C. (1996). Learning from mistakes is easier said than done: Group and organizational influences on the detection and correction of human error. Journal of Applied Behavioral Science, 32(1), 5-28. https://doi.org/10.1177/0021886396321001

Edmondson, A. C. (2003). Speaking up in the operating room: How team leaders promote learning in interdisciplinary action teams. Journal of Management Studies, 40(6), 1419-1452. https://doi.org/10.1111/1467-6486.00386

Enders, C. K., \& Tofighi, D. (2007). Centering predictor variables in cross-sectional multilevel models: A new look at an old issue. Psychological Methods, 12(2), 121-138. https://doi.org/10.1037/1082989X.12.2.121

Epitropaki, O., \& Martin, R. (2004). Implicit leadership theories in applied settings: Factor structure, generalizability, and stability over time. Journal of Applied Psychology, 89(2), 293-310. https://doi.org/10.1037/0021-9010.89.2.293 
Fast, N. J., Burris, E. R., \& Bartel, C. A. (2014). Managing to stay in the dark: Managerial self-efficacy, ego defensiveness, and the aversion to employee voice. Academy of Management Journal, 57(4), 10131034. https://doi.org/10.5465/amj.2012.0393

Fast, N. J., \& Chen, S. (2009). When the boss feels inadequate: Power, incompetence, and aggression. Psychological Science, 20(11), 1406-1413. https://doi.org/10.1111/j.1467-9280.2009.02452.x

Ferris, G. R., Judge, T. A., Rowland, K. M., \& Fitzgibbons, D. E. (1994). Subordinate influence and the performance evaluation process: Test of a model. Organizational Behavior and Human Decision Processes, 58(1), 101-135. https://doi.org/10.1006/obhd.1994.1030

Fiske, S., \& Taylor, S. (2008). Social cognition: From brains to culture. New York, NY: McGraw-Hill.

Folger, R., \& Skarlicki, D. P. (1998). When tough times make tough bosses: Managerial distancing as a function of layoff blame. Academy of Management Journal, 41(1), 79-87. https://doi.org/10.2307/256899

Frazier, M. L., \& Bowler, W. M. (2015). Voice climate, supervisor undermining, and work outcomes: A grouplevel examination. Journal of Management, 41(3), 841-863. https://doi.org/10.1177/0149206311434533

Frazier, M. L., \& Fainshmidt, S. (2012). Voice climate, work outcomes, and the mediating role of psychological empowerment: A multilevel examination. Group \& Organization Management, 37(6), 691-715. https://doi.org/10.1177/1059601112463960

Furst, S. A., \& Cable, D. M. (2008). Employee resistance to organizational change: Managerial influence tactics and leader-member exchange. Journal of Applied Psychology, 93(2), 453-462. https://doi.org/10.1037/0021-9010.93.2.453

Galilei, G. (1967). Dialogue concerning the two chief world systems, Ptolemaic \& Copernican. Berkeley, CA: University of California Press.

Gao, L., Janssen, O., \& Shi, K. (2011). Leader trust and employee voice: The moderating role of empowering leader behaviors. Leadership Quarterly, 22(4), 787-798. https://doi.org/10.1016/j.leaqua.2011.05.015

Georgesen, J., \& Harris, M. J. (2006). Holding onto power: Effects of powerholders' positional instability and expectancies on interactions with subordinates. European Journal of Social Psychology, 36(4), 451468. https://doi.org/10.1002/ejsp.352

Giacalone, R. A., \& Rosenfeld, P. (1986). Self-presentation and self-promotion in an organizational setting. The Journal of Social Psychology, 126(3), 321-326. https://doi.org/10.1080/00224545.1986.9713592

Godfrey, D. K., Jones, E. E., \& Lord, C. G. (1986). Self-promotion is not ingratiating. Journal of Personality and Social Psychology, 50(1), 106-115. https://doi.org/10.1037/0022-3514.50.1.106

Goffman, E. (1959). The presentation of self in everyday life. New York, NY: Doubleday Anchor.

Goffman, E. (1967). Interaction ritual: Essays on face-to-face behavior. Garden City, NY: Anchor Books.

Graen, G. B., \& Scandura, T. A. (1987). Toward a psychology of dyadic organizing. Research in Organizational Behavior, 9, 175-208.

Graen, G. B., \& Uhl-Bien, M. (1995). Relationship-based approach to leadership: Development of leadermember exchange (LMX) theory of leadership over 25 years: Applying a multi-level multi-domain perspective. Leadership Quarterly, 6(2), 219-247. https://doi.org/10.1016/1048-9843(95)90036-5

Graen, G. B., \& Cashman, J. F. (1975). A role-making model of leadership in formal organizations: A developmental approach. In J. G. Hunt \& L. L. Larson (Eds.), Leadership Frontiers (pp. 143-166). Kent, $\mathrm{OH}$ : Kent State University Press.

Granovetter, M. (1983). The strength of weak ties: A network theory revisited. Sociological Theory, 201-233.

Grant, A. M. (2013). Rocking the boat but keeping it steady: The role of emotion regulation in employee voice. Academy of Management Journal, 56(6), 1703-1723. https://doi.org/10.5465/amj.2011.0035

Grant, A. M., \& Mayer, D. M. (2009). Good soldiers and good actors: Prosocial and impression management motives as interactive predictors of affiliative citizenship behaviors. Journal of Applied Psychology, 94(4), 900-912. https://doi.org/10.1037/a0013770

Grant, A. M., Parker, S., \& Collins, C. (2009). Getting credit for proactive behavior: Supervisor reactions depend on what you value and how you feel. Personnel Psychology, 62(1), 31-55. https://doi.org/10.1111/j.1744-6570.2008.01128.x

Greenberg, J. (1990). Organizational justice: Yesterday, today, and tomorrow. Journal of Management, 16(2), 399-432. https://doi.org/10.1177/014920639001600208

Greenberg, J., \& Eskew, D. E. (1993). The role of role playing in organizational research. Journal of Management, 19(2), 221-241. https://doi.org/10.1016/0149-2063(93)90053-P 
Griffin, M. A., Neal, A., \& Parker, S. K. (2007). A new model of work role performance: Positive behavior in uncertain and interdependent contexts. Academy of Management Journal, 50(2), 327-347. https://doi.org/10.5465/AMJ.2007.24634438

Grube, A., Schroer, J., Hentzschel, C., \& Hertel, G. (2008). The event reconstruction method: An efficient measure of experience-based job satisfaction. Journal of Occupational and Organizational Psychology, 81(4), 669-689. https://doi.org/10.1348/096317907X251578

Gurmankin, A. D., Baron, J., \& Armstrong, K. (2004a). Intended message versus message received in hypothetical physician risk communications: Exploring the gap. Risk Analysis, 24(5), 1337-1347. https://doi.org/10.1111/j.0272-4332.2004.00530.x

Gurmankin, A. D., Baron, J., \& Armstrong, K. (2004b). The effect of numerical statements of risk on trust and comfort with hypothetical physician risk communication. Medical Decision Making, 24(3), 265-271. https://doi.org/10.1177/0272989X04265482

Hayes, A. F. (2013). Introduction to mediation, moderation, and conditional process analysis: A regressionbased approach. New York, NY: Guilford Press.

Heilman, M. E. (2001). Description and prescription: How gender stereotypes prevent women's ascent up the organizational ladder. Journal of Social Issues, 57(4), 657-674. https://doi.org/10.1111/00224537.00234

Henderson, D. J., Liden, R. C., Glibkowski, B. C., \& Chaudhry, A. (2009). LMX differentiation: A multilevel review and examination of its antecedents and outcomes. Leadership Quarterly, 20(4), 517-534. https://doi.org/10.1016/j.leaqua.2009.04.003

Henderson, D. J., Wayne, S. J., Shore, L. M., Bommer, W. H., \& Tetrick, L. E. (2008). Leader-member exchange, differentiation, and psychological contract fulfillment: A multilevel examination. Journal of Applied Psychology, 93(6), 1208-1219. https://doi.org/10.1037/a0012678

Herman, H. M., Ashkanasy, N. M., \& Dasborough, M. T. (2012). Relative leader-member exchange, negative affectivity and social identification: A moderated-mediation examination. Leadership Quarterly, 23(3), 354-366. https://doi.org/10.1016/j.leaqua.2011.08.009

Hernez-Broome, G., \& McLaughlin, C. (2006). Selling yourself without selling out: A leader's guide to ethical self-promotion. Greensboro, NC: Center for Creative Leadership.

Hirschman, A. O. (1970). Exit, voice, and loyalty: Responses to decline in firms, organizations, and states. Cambridge, MA: Harvard University Press.

Hofmann, D. A., \& Gavin, M. B. (1998). Centering decisions in hierarchical linear models: Implications for research in organizations. Journal of Management, 24(5), 623-641. https://doi.org/10.1016/S01492063(99)80077-4

Hornsey, M. J., Frederiks, E., Smith, J. R., \& Ford, L. (2007). Strategic defensiveness: Public and private responses to group criticism. British Journal of Social Psychology, 46(4), 697-716. https://doi.org/10.1348/014466606X170315

Howell, T. M., Harrison, D. A., Burris, E. R., \& Detert, J. R. (2015). Who gets credit for input? Demographic and structural status cues in voice recognition. Journal of Applied Psychology, 100(6), 1765-1784. https://doi.org/10.1037/apl0000025

Hu, J., \& Liden, R. C. (2013). Relative leader-member exchange within team contexts: How and when social comparison impacts individual effectiveness. Personnel Psychology, 66(1), 127-172. https://doi.org/10.1111/peps.12008

Huang, J. L., Bowling, N. A., Liu, M., \& Li, Y. (2015). Detecting insufficient effort responding with an infrequency scale: Evaluating validity and participant reactions. Journal of Business and Psychology, 30(2), 299-311. https://doi.org/10.1007/s10869-014-9357-6

lida, M., Shrout, P. E., Laurenceau, J.-P., \& Bolger, N. (2012). Using diary methods in psychological research. In H. Cooper, P. M. Camic, D. L. Long, A. T. Panter, D. Rindskopf, \& K. J. Sher (Eds.), APA handbook of research methods in psychology (pp. 277-305). Washington, DC: American Psychological Association.

Ilgen, D. R., Fisher, C. D., \& Taylor, M. S. (1979). Consequences of individual feedback on behavior in organizations. Journal of Applied Psychology, 64(4), 349-371. https://doi.org/10.1037//00219010.64.4.349

Ilgen, D. R., \& Pulakos, E. D. (1999). The changing nature of performance: Implications for staffing, motivation, and development. Frontiers of industrial and organizational psychology. San Francisco, CA: Jossey-Bass.

Johns, G. (2006). The essential impact of context on organizational behavior. Academy of Management 
Review, 31(2), 386-408. https://doi.org/10.5465/AMR.2006.20208687

Judge, T. A., Piccolo, R. F., \& Ilies, R. (2004). The forgotten ones? The validity of consideration and initiating structure in leadership research. Journal of Applied Psychology, 89(1), 36-51. https://doi.org/10.1037/0021-9010.89.1.36

Jussim, L., Coleman, L. M., \& Lerch, L. (1987). The nature of stereotypes: A comparison and integration of three theories. Journal of Personality and Social Psychology, 52(3), 536-546.

Kahneman, D., Krueger, A. B., Schkade, D. A., Schwarz, N., \& Stone, A. A. (2004). A survey method for characterizing daily life experience: The day reconstruction method. Science, 306(5702), 1776-1780. https://doi.org/10.1126/science.1103572

Kahneman, D., \& Miller, D. T. (1986). Norm theory: Comparing reality to its alternatives. Psychological Review, 93(2), 136-153. https://doi.org/10.1037//0033-295X.93.2.136

Kim, M. G., \& Mattila, A. S. (2010). The impact of mood states and surprise cues on satisfaction. International Journal of Hospitality Management, 29(3), 432-436. https://doi.org/10.1016/j.ijhm.2009.10.022

Kim, T., Rosen, B., \& Lee, D. (2009). South Korean managerial reactions to voicing discontent: The effects of employee attitude and employee communication styles. Journal of Organizational Behavior, 30(7), 1001-1018. https://doi.org/10.1002/job.612

Klein, H. J., Cooper, J. T., Molloy, J. C., \& Swanson, J. A. (2014). The assessment of commitment: Advantages of a unidimensional, target-free approach. Journal of Applied Psychology, 99(2), 222-238. https://doi.org/10.1037/a0034751

Kluger, A. N., \& DeNisi, A. (1996). The effects of feedback interventions on performance: A historical review, a meta-analysis, and a preliminary feedback intervention theory. Psychological Bulletin, 119(2), 254284. https://doi.org/10.1037/0033-2909.119.2.254

Kozlowski, S. W. J., Mak, S., \& Chao, G. T. (2016). Team-centric leadership: An integrative review. Annual Review of Organizational Psychology and Organizational Behavior, 3, 21-54. https://doi.org/10.1146/annurev-orgpsych-041015-062429

Lam, C. F., \& Mayer, D. M. (2014). When do employees speak up for their customers? A model of voice in a customer service context. Personnel Psychology, 67(3), 637-666. https://doi.org/10.1111/peps.12050

Landis, R. S., Beal, D. J., \& Tesluk, P. E. (2000). A comparison of approaches to forming composite measures in structural equation models. Organizational Research Methods, 3(2), 186-207. https://doi.org/10.1177/109442810032003

Leary, M. R., Barnes, B. D., Griebel, C., Mason, E., \& McCormack, D. (1987). The impact of conjoint threats to social- and self-esteem on evaluation apprehension. Social Psychology Quarterly, 50(4), 304-311. https://doi.org/10.2307/2786815

Leary, M. R., Terry, M. L., Allen, A. B., \& Tate, E. B. (2009). The concept of ego threat in social and personality psychology: Is ego threat a viable scientific construct? Personality and Social Psychology Review, 13(3), 151-164. https://doi.org/10.1177/1088868309342595

LePine, J. A., \& Van Dyne, L. (1998). Predicting voice behavior in work groups. Journal of Applied Psychology, 83(6), 853-868. https://doi.org/10.1037/0021-9010.83.6.853

Lerner, J. S., \& Tetlock, P. E. (1999). Accounting for the effects of accountability. Psychological Bulletin, 125(2), 255-275. https://doi.org/10.1037/0033-2909.125.2.255

Levy, S. R., Chiu, C., \& Hong, Y. (2006). Lay theories and intergroup relations. Group Processes \& Intergroup Relations, 9(1), 5-24. https://doi.org/10.1177/1368430206059855

Levy, S. R., Stroessner, S. J., \& Dweck, C. S. (1998). Stereotype formation and endorsement: The role of implicit theories. Journal of Personality and Social Psychology, 74(6), 1421-1436. https://doi.org/10.1037/0022-3514.74.6.1421

Liden, R. C., \& Graen, G. (1980). Generalizability of the vertical dyad linkage model of leadership. Academy of Management Journal, 23(3), 451-465.

Liden, R. C., \& Maslyn, J. M. (1998). Multidimensionality of leader-member exchange: An empirical assessment through scale development. Journal of Management, 24(1), 43-72. https://doi.org/10.1177/014920639802400105

Lievens, F., Van Hoye, G., \& Anseel, F. (2007). Organizational identity and employer image: Towards a unifying framework. British Journal of Management, 18(s1), S45-S59. https://doi.org/10.1111/j.14678551.2007.00525.x

Liu, W., Song, Z., Li, X., \& Liao, Z. (2017). Why and when leaders' affective states influence employee upward 
voice. Academy of Management Journal, 60(1), 238-263. https://doi.org/10.5465/amj.2013.1082

Liu, W., Tangirala, S., Lam, W., Chen, Z., Jia, R. T., \& Huang, X. (2015). How and when peers' positive mood influences employees' voice. Journal of Applied Psychology, 100(3), 976-989. https://doi.org/10.1037/a0038066

Liu, W., Tangirala, S., \& Ramanujam, R. (2013). The relational antecedents of voice targeted at different leaders. Journal of Applied Psychology, 98(5), 841-851. https://doi.org/10.1037/a0032913

Liu, W., Zhu, R., \& Yang, Y. (2010). I warn you because I like you: Voice behavior, employee identifications, and transformational leadership. Leadership Quarterly, 21(1), 189-202. https://doi.org/10.1016/j.leaqua.2009.10.014

Loi, R., Mao, Y., \& Ngo, H. (2009). Linking leader-member exchange and employee work outcomes: The mediating role of organizational social and economic exchange. Management and Organization Review, 5(3), 401-422. https://doi.org/10.1111/j.1740-8784.2009.00149.x

Lucas, J. W., \& Baxter, A. R. (2012). Power, influence, and diversity in organizations. The Annals of the American Academy of Political and Social Science, 639(1), 49-70. https://doi.org/10.1177/0002716211420231

MacKenzie, S. B., Podsakoff, P. M., \& Podsakoff, N. P. (2011). Construct measurement and validation procedures in MIS and behavioral research: Integrating new and existing techniques. MIS Quarterly, 35(2), 293-334.

Markus, H. (1978). The effect of mere presence on social facilitation: An unobtrusive test. Journal of Experimental Social Psychology, 14(4), 389-397. https://doi.org/10.1016/0022-1031(78)90034-3

Mayer, R. C., Davis, J. H., \& Schoorman, F. D. (1995). An integrative model of organizational trust. Academy of Management Review, 20(3), 709-734. https://doi.org/10.5465/AMR.1995.9508080335

Mayes, B. T., \& Ganster, D. C. (1988). Exit and voice: A test of hypotheses based on fight/flight responses to job stress. Journal of Organizational Behavior, 9(3), 199-216. https://doi.org/10.1002/job.4030090302

Maynes, T. D., \& Podsakoff, P. M. (2014). Speaking more broadly: An examination of the nature, antecedents, and consequences of an expanded set of employee voice behaviors. Journal of Applied Psychology, 99(1), 87-112. https://doi.org/10.1037/a0034284

McClean, E., Burris, E. R., \& Detert, J. (2012). When does voice lead to exit? It depends on leadership. Academy of Management Journal, 56(2), 525-548. https://doi.org/10.5465/amj.2011.0041

Meindl, J. R., Ehrlich, S. B., \& Dukerich, J. M. (1985). The romance of leadership. Administrative Science Quarterly, 30(1), 78-102. https://doi.org/10.2307/2392813

Menon, T., \& Blount, S. (2003). The messenger bias: A relational model of knowledge valuation. Research in Organizational Behavior, 25, 137-186. https://doi.org/0.1016/S0191-3085(03)25004-8

Mesmer-Magnus, J. R., \& DeChurch, L. A. (2009). Information sharing and team performance: A meta-analysis. Journal of Applied Psychology, 94(2), 535-546. https://doi.org/10.1037/a0013773

Milliken, F. J., \& Morrison, E. W. (2003). Shades of silence: Emerging themes and future directions for research on silence in organizations. Journal of Management Studies, 40(6), 1563-1568. https://doi.org/10.1111/1467-6486.00391

Milliken, F. J., Morrison, E. W., \& Hewlin, P. F. (2003). An exploratory study of employee silence: Issues that employees don't communicate upward and why. Journal of Management Studies, 40(6), 1453-1476. https://doi.org/10.1111/1467-6486.00387

Mitchell, M. S., Vogel, R. M., \& Folger, R. (2015). Third parties' reactions to the abusive supervision of coworkers. Journal of Applied Psychology, 100(4), 1040-1055. https://doi.org/10.1037/apl0000002

Mollick, E. (2012). People and process, suits and innovators: The role of individuals in firm performance. Strategic Management Journal, 33(9), 1001-1015. https://doi.org/10.1002/smj.1958

Morrison, E. W. (2011). Employee voice behavior: Integration and directions for future research. Academy of Management Annals, 5(1), 373-412. https://doi.org/10.1080/19416520.2011.574506

Morrison, E. W. (2014). Employee voice and silence. Annual Review of Organizational Psychology and Organizational Behavior, 1(1), 173-197. https://doi.org/10.1146/annurev-orgpsych-031413-091328

Morrison, E. W., \& Milliken, F. J. (2000). Organizational silence: A barrier to change and development in a pluralistic world. Academy of Management Review, 25(4), 706-725. https://doi.org/10.5465/AMR.2000.3707697

Morrison, E. W., Wheeler-Smith, S. L., \& Kamdar, D. (2011). Speaking up in groups: A cross-level study of group voice climate and voice. Journal of Applied Psychology, 96(1), 183-191. 
https://doi.org/10.1037/a0020744

Nemeth, C. J. (1997). Managing innovation: When less is more. California Management Review, 40(1), 59-74. https://doi.org/10.2307/41165922

Nemeth, C. J., Connell, J. B., Rogers, J. D., \& Brown, K. S. (2001). Improving decision making by means of dissent. Journal of Applied Social Psychology, 31(1), 48-58. https://doi.org/10.1111/j.15591816.2001.tb02481.x

Newman, D. A. (2014). Missing data: Five practical guidelines. Organizational Research Methods, 17(4), 372411. https://doi.org/10.1177/1094428114548590

Nickerson, R. S. (1998). Confirmation bias: A ubiquitous phenomenon in many guises. Review of General Psychology, 2(2), 175-220. https://doi.org/10.1037//1089-2680.2.2.175

O'Reilly, C. A., \& Chatman, J. (1986). Organizational commitment and psychological attachment: The effects of compliance, identification, and internalization on prosocial behavior. Journal of Applied Psychology, 71(3), 492-499. https://doi.org/10.1037/0021-9010.71.3.492

Olson, J. M., Roese, N. J., \& Zanna, M. P. (1996). Expectancies. In E. T. Higgins \& A. W. Kruglanski (Eds.), Social psychology: Handbook of basic principles (pp. 211-238). New York, NY: Guilford Press.

Ortony, A., Clore, G. L., \& Collins, A. (1988). The cognitive structure of emotions. New York, NY: Cambridge University Press.

Paglis, L. L., \& Green, S. G. (2002). Leadership self-efficacy and managers' motivation for leading change. Journal of Organizational Behavior, 23(2), 215-235. https://doi.org/10.1002/job.137

Parker, S. K., \& Collins, C. G. (2010). Taking stock: Integrating and differentiating multiple proactive behaviors. Journal of Management, 36(3), 633-662. https://doi.org/10.1177/0149206308321554

Paulus, P. B., Levine, D. S., Brown, V. R., Minai, A. A., \& Doboli, S. (2010). Modeling ideational creativity in groups: Connecting cognitive, neural, and computational approaches. Small Group Research, 41(6), 688-724. https://doi.org/10.1177/1046496410369561

Peer, E., Brandimarte, L., Samat, S., \& Acquisti, A. (2017). Beyond the Turk: Alternative platforms for crowdsourcing behavioral research. Journal of Experimental Social Psychology, 70, 153-163. https://doi.org/10.1016/j.jesp.2017.01.006

Pfeffer, J. (1977). The ambiguity of leadership. Academy of Management Review, 2(1), 104-112. https://doi.org/10.5465/AMR.1977.4409175

Pfeffer, J. (1992). Managing with power: Politics and influence in organizations. Boston, MA: Harvard Business Press.

Phillips, K. W., \& Loyd, D. L. (2006). When surface and deep-level diversity collide: The effects on dissenting group members. Organizational Behavior and Human Decision Processes, 99(2), 143-160. https://doi.org/10.1016/j.obhdp.2005.12.001

Piderit, S. K., \& Ashford, S. J. (2003). Breaking silence: Tactical choices women managers make in speaking up about gender-equity issues. Journal of Management Studies, 4O(6), 1477-1502. https://doi.org/10.1111/1467-6486.00388

Platania, J., \& Moran, G. P. (2001). Social facilitation as a function of the mere presence of others. Journal of Social Psychology, 141(2), 190-197. https://doi.org/10.1080/00224540109600546

Podsakoff, P. M., MacKenzie, S. B., Lee, J.-Y., \& Podsakoff, N. P. (2003). Common method biases in behavioral research: A critical review of the literature and recommended remedies. Journal of Applied Psychology, 88(5), 879-903. https://doi.org/10.1037/0021-9010.88.5.879

Raudenbush, S. W., \& Bryk, A. S. (2002). Hierarchical linear models: Applications and data analysis methods (Vol. 1). Newbury Park, CA: Sage.

Reis, H. T., \& Judd, C. M. (2000). Handbook of research methods in social and personality psychology. Cambridge: Cambridge University Press.

Ross, L., Greene, D., \& House, P. (1977). The "false consensus effect": An egocentric bias in social perception and attribution processes. Journal of Experimental Social Psychology, 13(3), 279-301. https://doi.org/10.1016/0022-1031(77)90049-X

Ross, M. (1989). Relation of implicit theories to the construction of personal histories. Psychological Review, 96(2), 341-357. https://doi.org/10.1037/0033-295X.96.2.341

Rudman, L. A. (1998). Self-promotion as a risk factor for women: The costs and benefits of counterstereotypical impression management. Journal of Personality and Social Psychology, 74(3), 629-645. https://doi.org/10.1037/0022-3514.74.3.629 
Rusbult, C. E., Farrell, D., Rogers, G., \& Mainous, A. G. (1988). Impact of exchange variables on exit, voice, loyalty, and neglect: An integrative model of responses to declining job satisfaction. Academy of Management Journal, 31(3), 599-627. https://doi.org/10.2307/256461

Saunders, D. M., Sheppard, B. H., Knight, V., \& Roth, J. (1992). Employee voice to supervisors. Employee Responsibilities and Rights Journal, 5(3), 241-259. https://doi.org/10.1007/BF01385051

Schlenker, B. R., \& Leary, M. R. (1982). Social anxiety and self-presentation: A conceptualization model. Psychological Bulletin, 92(3), 641-669. https://doi.org/10.1037/0033-2909.92.3.641

Schyns, B. (2002). Überprüfung einer deutschsprachigen Skala zum Leader-Member-Exchange-Ansatz= Evaluation of a German scale for the assessment of Leader-Member-Exchange. Zeitschrift Für Differentielle Und Diagnostische Psychologie, 23(2), 235-245. https://doi.org/10.1024//01701789.23.2.235

Scott, M. A., Simonoff, J. S., \& Marx, B. D. (2013). The SAGE handbook of multilevel modeling. Thousand Oaks, CA: Sage.

Sedikides, C., \& Green, J. D. (2004). What I don't recall can't hurt me: Information negativity versus information inconsistency as determinants of memorial self-defense. Social Cognition, 22(1), 4-29. https://doi.org/10.1521/soco.22.1.4.30987

Seibert, S. E., Kraimer, M. L., \& Crant, J. M. (2001). What do proactive people do? A longitudinal model linking proactive personality and career success. Personnel Psychology, 54(4), 845-874. https://doi.org/10.1111/j.1744-6570.2001.tb00234.x

Sherf, E. N., \& Venkataramani, V. (2015). Friend or foe? The impact of relational ties with comparison others on outcome fairness and satisfaction judgments. Organizational Behavior and Human Decision Processes, 128(1), 1-14. https://doi.org/10.1016/j.obhdp.2015.02.002

Shore, L. M., Barksdale, K., \& Shore, T. H. (1995). Managerial perceptions of employee commitment to the organization. Academy of Management Journal, 38(6), 1593-1615. https://doi.org/10.2307/256845

Siemsen, E., Roth, A., \& Oliveira, P. (2010). Common method bias in regression models with linear, quadratic, and interaction effects. Organizational Research Methods, 13(3), 456-476. https://doi.org/10.1177/1094428109351241

Sijbom, R. B. L., Janssen, O., \& Van Yperen, N. W. (2015a). How to get radical creative ideas into a leader's mind? Leader's achievement goals and subordinates' voice of creative ideas. European Journal of Work and Organizational Psychology, 24(2), 279-296. https://doi.org/10.1080/1359432X.2014.892480

Sijbom, R. B. L., Janssen, O., \& Van Yperen, N. W. (2015b). Leaders' receptivity to subordinates' creative input: The role of achievement goals and composition of creative input. European Journal of Work and Organizational Psychology, 24(3), 462-478. https://doi.org/10.1080/1359432X.2014.964215

Sin, H.-P., Nahrgang, J. D., \& Morgeson, F. P. (2009). Understanding why they don't see eye to eye: An examination of leader-member exchange (LMX) agreement. Journal of Applied Psychology, 94(4), 1048-1057. https://doi.org/10.1037/a0014827

Smith, A. (1776). The wealth of nations. New York, NY: The Modern Library.

Snyder, M., \& Swann, W. B. (1978). Behavioral confirmation in social interaction: From social perception to social reality. Journal of Experimental Social Psychology, 14(2), 148-162. https://doi.org/10.1016/0022-1031(78)90021-5

Sparrowe, R. T., \& Liden, R. C. (2005). Two routes to influence: Integrating leader-member exchange and social network perspectives. Administrative Science Quarterly, 50(4), 505-535. https://doi.org/10.2189/asqu.50.4.505

Spector, P. E., \& Brannick, M. T. (2011). Methodological urban legends: The misuse of statistical control variables. Organizational Research Methods, 14(2), 287-305. https://doi.org/10.1177/1094428110369842

Sproull, L., Subramani, M., Kiesler, S., Walker, J. H., \& Waters, K. (1996). When the interface is a face. HumanComputer Interaction, 11(2), 97-124. https://doi.org/10.1207/s15327051hci1102_1

Stamper, C. L., \& Dyne, L. Van. (2001). Work status and organizational citizenship behavior: A field study of restaurant employees. Journal of Organizational Behavior, 22(5), 517-536. https://doi.org/10.1002/job.100

Takeuchi, R., Chen, Z., \& Cheung, S. Y. (2012). Applying uncertainty management theory to employee voice behavior: An integrative investigation. Personnel Psychology, 65(2), 283-323. https://doi.org/10.1111/j.1744-6570.2012.01247.x 
Tangirala, S., Kamdar, D., Venkataramani, V., \& Parke, M. R. (2013). Doing right versus getting ahead: The effects of duty and achievement orientations on employees' voice. Journal of Applied Psychology, 98(6), 1040-1050. https://doi.org/10.1037/a0033855

Tangirala, S., \& Ramanujam, R. (2008). Employee silence on critical work issues: The cross level effects of procedural justice climate. Personnel Psychology, 61(1), 37-68. https://doi.org/10.1111/j.17446570.2008.00105.x

Tangirala, S., \& Ramanujam, R. (2012). Ask and you shall hear (but not always): Examining the relationship between manager consultation and employee voice. Personnel Psychology, 65(2), 251-282. https://doi.org/10.1111/j.1744-6570.2012.01248.x

Tetlock, P. E. (1983). Accountability and complexity of thought. Journal of Personality and Social Psychology, 45(1), 74-83. https://doi.org/10.1037/0022-3514.45.1.74

Tost, L. P. (2015). When, why, and how do powerholders "feel the power"? Examining the links between structural and psychological power and reviving the connection between power and responsibility. Research in Organizational Behavior, 35, 29-56. https://doi.org/10.1016/j.riob.2015.10.004

Triplett, N. (1898). The dynamogenic factors in pacemaking and competition. American Journal of Psychology, 9(4), 507-533. https://doi.org/10.2307/1412188

Tuckey, M., Brewer, N., \& Williamson, P. (2002). The influence of motives and goal orientation on feedback seeking. Journal of Occupational and Organizational Psychology, 75(2), 195-216. https://doi.org/10.1348/09631790260098677

Turnley, W. H., \& Bolino, M. C. (2001). Achieving desired images while avoiding undesired images: Exploring the role of self-monitoring in impression management. Journal of Applied Psychology, 86(2), 351-360. https://doi.org/10.1037/0021-9010.86.2.351

Urbig, D. (2008). A short measure of four types of personal optimism: Ability, rivalry, chance, and social support (ARCS). Jena economic research papers.

Uziel, L. (2007). Individual differences in the social facilitation effect: A review and meta-analysis. Journal of Research in Personality, 41(3), 579-601. https://doi.org/10.1016/j.jrp.2006.06.008

Van Dyne, L., Cummings, L. L., \& Parks, J. M. (1995). Extra-role behaviors: In pursuit of construct and definitional clarity (a bridge over muddied waters). In B. M. Staw \& L. L. Cummings (Eds.), Research in Organizational Behavior (Vol. 17, pp. 215-285). Greenwich, CT: JAI Press.

Van Dyne, L., Kamdar, D., \& Joireman, J. (2008). In-role perceptions buffer the negative impact of low LMX on helping and enhance the positive impact of high LMX on voice. Journal of Applied Psychology, 93(6), 1195-1207. https://doi.org/10.1037/0021-9010.93.6.1195

Van Dyne, L., \& LePine, J. A. (1998). Helping and voice extra-role behaviors: Evidence of construct and predictive validity. Academy of Management Journal, 41(1), 108-119. https://doi.org/10.2307/256902

Vidyarthi, P. R., Liden, R. C., Anand, S., Erdogan, B., \& Ghosh, S. (2010). Where do I stand? Examining the effects of leader-member exchange social comparison on employee work behaviors. Journal of Applied Psychology, 95(5), 849-861. https://doi.org/10.1037/a0020033

Vohs, K. D., Baumeister, R. F., \& Ciarocco, N. J. (2005). Self-regulation and self-presentation: Regulatory resource depletion impairs impression management and effortful self-presentation depletes regulatory resources. Journal of Personality and Social Psychology, 88(4), 632-657. https://doi.org/10.1037/0022-3514.88.4.632

Walumbwa, F. O., \& Schaubroeck, J. (2009). Leader personality traits and employee voice behavior: Mediating roles of ethical leadership and work group psychological safety. Journal of Applied Psychology, 94(5), 1275-1286. https://doi.org/10.1037/a0015848

Wang, Y.-D., \& Hsieh, H.-H. (2013). Organizational ethical climate, perceived organizational support, and employee silence: A cross-level investigation. Human Relations, 66(6), 783-802. https://doi.org/10.1177/0018726712460706

Wayne, S. J., \& Ferris, G. R. (1990). Influence tactics, affect, and exchange quality in supervisor-subordinate interactions: A laboratory experiment and field study. Journal of Applied Psychology, 75(5), 487-499. https://doi.org/10.1037/0021-9010.75.5.487

Weick, K., \& Sutcliffe, K. (2001). Managing the unexpected: Assuring high performance in an age of uncertainty. San Francisco, CA: Jossey-Bass.

Welbourne, T. M., Johnson, D. E., \& Erez, A. (1998). The role-based performance scale: Validity analysis of a theory-based measure. Academy of Management Journal, 41(5), 540-555. 
https://doi.org/10.2307/256941

Wheeler, A. R., Shanine, K. K., Leon, M. R., \& Whitman, M. V. (2014). Student-recruited samples in organizational research: A review, analysis, and guidelines for future research. Journal of Occupational and Organizational Psychology, 87(1), 1-26. https://doi.org/10.1111/joop.12042

Whiting, S. W., Maynes, T. D., Podsakoff, N. P., \& Podsakoff, P. M. (2012). Effects of message, source, and context on evaluations of employee voice behavior. Journal of Applied Psychology, 97(1), 159-182. https://doi.org/10.1037/a0024871

Whiting, S. W., Podsakoff, P. M., \& Pierce, J. R. (2008). Effects of task performance, helping, voice, and organizational loyalty on performance appraisal ratings. Journal of Applied Psychology, 93(1), 125-139. https://doi.org/10.1037/0021-9010.93.1.125

Wiggins, J. S., Trapnell, P., \& Phillips, N. (1988). Psychometric and geometric characteristics of the Revised Interpersonal Adjective Scales (IAS-R). Multivariate Behavioral Research, 23(4), 517-530. https://doi.org/10.1207/s15327906mbr2304_8

Withey, M. J., \& Cooper, W. H. (1989). Predicting exit, voice, loyalty, and neglect. Administrative Science Quarterly, 34(4), 521-539. https://doi.org/10.2307/2393565

Wolfe, R., Wright, P. M., \& Smart, D. L. (2006). Radical HRM innovation and competitive advantage: The Moneyball story. Human Resource Management, 45(1), 111-145. https://doi.org/10.1002/hrm.20100

Yukl, G., \& Tracey, J. B. (1992). Consequences of influence tactics used with subordinates, peers, and the boss. Journal of Applied Psychology, 77(4), 525-535. https://doi.org/10.1037/0021-9010.77.4.525

Zajonc, R. B. (1965). Social facilitation. Science, 149, 269-274. 



\section{About the Author}

Sofya Isaakyan was born on January 4, 1990 in Yerevan, Armenia. In 1995, Sofya together with her family moved to Moscow, Russia where she obtained her high school certificate. In 2006, she started her bachelor's studies in Psychology at the National Research University - Higher School of Economics (NRE-HSE), Moscow, which she completed in 2010. During the last year of her bachelor's studies, she started working as a trainee-researcher in the International Laboratory for Socio-Cultural Research at the NRU-HSE. Sofya then proceeded to obtain a research master's degree in Psychology in Business, also at NREHSE, graduating Cum Laude. Her desire for international experience led her to study abroad. Sofya was awarded the prestigious Huygens Scholarship to fund her master's degree in Work and Organizational Psychology from Maastricht University, which she graduated Cum Laude. While pursuing these studies at Maastricht University she did an internship at the Centre for Creative Leadership (CCL), Brussels, Belgium.

In September 2013, Sofya started her PhD in the Department of Organization and Strategy at the School of Business and Economics, Maastricht University. Between November 2015 and March 2016, she made a research visit in the Robert H. Smith Business School at the University of Maryland. During her PhD, she presented her dissertation research at different international conferences. Her research focuses mostly on understanding employees' upward expression of ideas and concerns about work-related issues (i.e., voice behaviour) and the corresponding reactions by managers and team members. Sofya's teaching activities include such themes as organizational behaviour, leadership, and decision-making. As of September 2017, Sofya is working as an Assistant Professor in the department of Organization and Personnel Management at Rotterdam School of Management, Erasmus University, The Netherlands. 